\title{
A Review of Organic and Inorganic Biomaterials for Neural Interfaces
}

\author{
Pouria Fattahi, \\ Biomedical Engineering Department and Chemical Engineering Departments, Pennsylvania State \\ University, University Park, PA, 16802, USA \\ Guang Yang, \\ Biomedical Engineering Department, Pennsylvania State University, University Park, PA, 16802, \\ USA \\ Gloria Kim, and \\ Biomedical Engineering Department, Pennsylvania State University, University Park, PA, 16802, \\ USA
}

\section{Prof. Mohammad Reza Abidian \\ Biomedical Engineering Department, Materials Science \& Engineering Department, Chemical Engineering Department, Materials Research Institute, Huck Institutes of the Life Sciences, Pennsylvania State University, University Park, PA, 16802, USA}

Mohammad Reza Abidian: mabidian@psu.edu

\begin{abstract}
Recent advances in nanotechnology have generated wide interest in applying nanomaterials for neural prostheses. An ideal neural interface should create seamless integration into the nervous system and performs reliably for long periods of time. As a result, many nanoscale materials not originally developed for neural interfaces become attractive candidates to detect neural signals and stimulate neurons. In this comprehensive review, an overview of state-of-the-art microelectrode technologies provided first, with focus on the material properties of these microdevices. The advancements in electro active nanomaterials are then reviewed, including conducting polymers, carbon nanotubes, graphene, silicon nanowires, and hybrid organic-inorganic nanomaterials, for neural recording, stimulation, and growth. Finally, technical and scientific challenges are discussed regarding biocompatibility, mechanical mismatch, and electrical properties faced by these nanomaterials for the development of long-lasting functional neural interfaces.
\end{abstract}

\section{Introduction}

Recent advances have generated wide interest in the creation of interfaces between neurons and external devices to restore or supplement the function of the nervous system lost during injury or disease. The objective of neural interface technology is to create a link between the outside world and the nervous system by stimulating or recording from neural tissue in order

(C) 2014 WILEY-VCH Verlag GmbH \& Co. KGaA, Weinheim

Correspondence to: Mohammad Reza Abidian, mabidian@psu . edu. 
to assist people with neurological disabilities ${ }^{[1-4]}$ These devices can improve our understanding of the organization and operation of the nervous system and may lead to improving the current state-of-art neural technologies for tackling of some mankind's most debilitating disorders, including deafness, paralysis, blindness, epilepsy, and Parkinson's disease. Since the 1960s, brain-machine interfaces have been used to record neural activity or stimulate neural tissue in humans and animals. ${ }^{[5,6]}$ Today, implantation of macro and microdevices into the brain is increasingly used for treatment of neurological disorders. ${ }^{[7-9]}$ Electrical stimulation of the brain can alter the brain function by injecting electrical signals into neurons. A deep brain stimulator implant is a remarkable treatment that manipulates basal ganglia to relieve the rigidity of Parkinson's disease; ${ }^{[10]}$ however, this device does not establish a communication link with the patient. Advances have been made in the development of intracortical recording systems to detect neural signals and translate them into command signals that can control external devices. ${ }^{[4,9,11,12]}$ Such systems are potentially valuable for restoring lost neuronal function associated with neurological diseases and injuries. ${ }^{[11,13]}$ Neural interfaces communicate with the nervous system via implantable electrodes that transduce electric signals to and from bioelectric signals (Figure 1). ${ }^{[14,15]}$ The primary requirements of these electrodes include communication with as many individual neurons as possible with a high degree of signal-to-noise ratio (SNR) for specific time periods that may extend from hours to years. ${ }^{[13,16,17]}$ This translates toward new electrode materials for development of high-density neural probes that are biologically transparent and biocompatible, ${ }^{[18,19]}$ support seamless integration with neurons, ${ }^{[16,20]}$ and remain functional for long period of time. ${ }^{[21,22]}$ As a result, many materials that were not originally developed for neural interfaces have been recently applied for neural recording and stimulation.

Existing neural electrodes use conventional electronic materials that are often not intrinsically compatible with biological systems and do not conduct integration with neural tissue. ${ }^{[14,15,22]}$ Although biocompatible metallic materials do exist, the hard, electronic, dry, and static nature of metals and metal oxides are quite foreign to biological tissue, which is soft, ionic, wet, and dynamic. ${ }^{[18,23]}$ The performance of electrode-tissue interface ultimately rests on the quality of the martial substrate, which enables a long-lasting functional neural device. The challenge for materials science is to apply nanotechnology strategies and develop innovative biocompatible nanomaterials that mimic neural tissue characteristics, cause minimal inflammation and neuronal cell loss, and are functional for a long period of time. ${ }^{[24,25]}$ The complex nanoscale structural features of neural tissue require a neural interface with nanoscale components. Many elements of neurons, glial cells, and extracellular matrix (ECM) have nanoscale dimensions; thus, the unique intrinsic properties of nanomaterials offer a great promise to seamlessly integrate with neural tissue and simulate features and functions of cells and ECM. ${ }^{[26]}$ Electrically active nanomaterials $(\mathrm{EANs})^{[27]}$ such as carbon nanotubes, ${ }^{[28,29]}$ silicon nanowires, ${ }^{[30]}$ gallium phosphide nanowires, ${ }^{[31]}$ and conducting polymer nanotubes ${ }^{[32]}$ have been already interfaced with central and peripheral nervous systems. These conductive nanomaterials are able to provide a more-effective surface area than regular metals for signal transduction at the electrodetissue interface, thus enhancing the electrical characteristics of neural recordings and stimulations, such as SNR and safe charge injection density. ${ }^{[24,33]}$ Incorporation of drugs 
and bioactive molecules into EANs can improve the biocompatibility of neural electrodes, reduce reactive tissue response, and promote neural process outgrowth. ${ }^{[18,34-37]}$ Recently EANs have been hybridized with hydrogels and were used as soft and conductive coatings for neural electrodes to decrease the mechanical mismatch between stiff electrodes and soft tissue. ${ }^{[38,39]}$ While there are a number of excellent review articles focused on technologies and materials applied to neural interfaces, ${ }^{[14,24,40,41]}$ this report will attempt to review the application of biomaterials, in particular, conducting polymers, carbon nanotubes, graphene, silicon nanowires, and hybrid organic-inorganic nanomaterials for neural interfaces.

\section{Reactive Tissue Responses to Neural Implants}

It has been shown that the distance between the electrode and the neurons significantly influences the strength and quality of the recording signals. ${ }^{[16,18]}$ The extracellular spike amplitude decreases rapidly as a function of distance from the neuron. Based on theoretical models and direct measurements, the maximum distance required for maintaining a stable recording between an electrode and a neuron cell body is between 50 and $100 \mu \mathrm{m} \cdot{ }^{[16,42-45]}$ In addition to the strength of the spike amplitude sent from nearby neurons, the degree of foreign body response occurring at the interface between the electrode and the surrounding neural tissue plays an important role in determining the success of neuroprosthetic devices. ${ }^{[19,34,46,47]}$ An ideal recording electrode should be very small to minimize brain injury and have a large number of recording sites to monitor many neurons. ${ }^{[16,48,49]}$ In order to design neural electrodes with minimized tissue response and stable recording capability, it is necessary to understand the biological mechanisms involved in the response of the brain to implanted electrodes.

\subsection{Acute Response}

Acute inflammation in the central nervous system (CNS) is initiated by the mechanical trauma of electrode insertion. ${ }^{[18,50]}$ It occurs mainly due to a difference between the mechanical properties of the implanted electrode (e.g., elastic modulus of ca. $150 \mathrm{GPa}$ for silicon) and the neighboring tissues (elastic modulus of ca. $100 \mathrm{kPa}$ for brain tissue). As the electrode is inserted (Figure 2a), neurons will be either ripped or sliced, ${ }^{[48]}$ and the tissue may swell and push the neighboring neurons away from the electrode surface. ${ }^{[51-53]}$ Moreover, the formation of necrotic tissue following the insertion and fluid movement across the blood vessels will cause edema, exerting hydrostatic pressure around the implanted electrodes. ${ }^{[51,54]}$ Acute inflammation can be characterized by the presence of erythrocytes, activated platelets, clotting, and factors released from disrupted blood vessels. ${ }^{[18,51,55]}$ Activated microglia will then approach the site of the injury from a blood vessel as early as one day post-implantation (Figure $2 \mathrm{a}$ and $2 \mathrm{~b}$ ), These inflammatory cells release numerous neurotoxic factors, including cytokines, chemokines, neurotransmitters, and reactive oxygen species. After about 6-8 days of implantation, microglia have degraded most cellular debris and damaged matrix by phagocytosis. ${ }^{[51,56]}$ The physiological changes occurring near an implanted electrode during acute response can appear as a spike in the impedance values during in vivo impedance spectroscopy measurements. ${ }^{[51,52,57]}$ Initially, few neurons can be found within $100 \mu \mathrm{m}$ of the electrode, but the neuron density is almost normal outside this zone. Since the acute response normally causes neuronal death, it takes 
roughly 4 to 6 months for healthy-appearing neurons to grow closer to the electrode. Among the viable neurons that have survived the acute reaction, remaining electrically active in proximity of the chronically implanted electrode is an important factor determining the strength of the neuronal signals to be recorded by implants. ${ }^{[18,48,58-60]}$

\subsection{Chronic Response}

Once acute inflammation declines, chronic response will initiate (Figure 2c). Chronic inflammation is characterized by the presence of both reactive astrocytes and activated microglia (Figure $2 \mathrm{c}$ and $2 \mathrm{~d}$ ) that form a glial scar (Figure 2e-h). ${ }^{[19,53]}$ After the initial wound healing is complete, activated microglia remain at the surface of the implanted microelectrode. Microglia colonies can be mediated by the adsorption of serum factors such as monocyte/macrophage chemotactic proteins on the surface of an implanted electrode. ${ }^{[61,62]}$ During the colonization of microglia, it will lead further events such as releasing lytic enzymes and reactive oxygen agents to degrade and finally remove the foreign material. ${ }^{[63]}$ Furthermore, microglia regulate the production of a thin layer of ECM proteins, basal lamina that can aid in organizing the glial scar. ${ }^{[51]}$ Microglia attempt to phagocytose the foreign objects and complete the elimination process. ${ }^{[64-66]}$ On the contrary, if the individual macrophages fail to degrade the foreign object, they will fuse into multinucleated foreign-body giant cells and continue the secretion of degradative agents. ${ }^{[19,34,67]}$ Glial scars (i.e., gliosis) are the most common observation of the CNS response to chronically implanted neural electrodes. ${ }^{[34,68-70]}$ Gliosis will lead to astrocyte proliferation, a protection against further injury or infection, which creates glial scars. Studies have shown that glial scars isolate neural electrodes from the surrounding tissue in a process similar to the fibrotic encapsulation process. in which non-degradable implants are encapsulated in soft tissues. ${ }^{[51,71-74]}$ The glial scar insulates the electrode from nearby neurons and increases the impedance of the tissue-electrode interface. Gliosis pushes away the surrounding tissues, and this extends the distance between the electrode and its nearest target neurons, thus dramatically degrading the amplitude of the recording signals from neurons. ${ }^{[34,48,75-80]}$

\section{Classification of Neural Signals and Sensors for Neural Interface Systems}

Field potentials and action potentials (spikes) are two classes of recording signals for neural prosthetic devices (Figure 3). Field potentials, including electroencephalogram (EEG) signals, electrocortiogram (ECoG) signals, and local field potentials have been largely used in humans,${ }^{[7,81,82]}$ while action potentials-based electrodes have been adopted to animal models, ${ }^{[11,83]}$ and more recently in humans. ${ }^{[13,84]}$ EEG signals are slow rhythms $(5-300 \mu \mathrm{V}$, $<100 \mathrm{~Hz}$ ) and can be recorded non-invasively from single or multiple sites on the scalp. ECoG signals are medium rhythms $(0.01-5 \mathrm{mV},<200 \mathrm{~Hz})$ and can be monitored using epicortical electrodes by placing them on the surface of the brain (invasive method). Penetrating electrodes are used to record local field potentials $(<1 \mathrm{mV},<200 \mathrm{~Hz})$ and action potentials (ca. $500 \mu \mathrm{V}, 0.1-7 \mathrm{kHz}$ ) (Figure 3a-c). 
EEG recordings could be used in human with severe paralysis for applications ranging from letter-by-letter spelling ${ }^{[9,81]}$ to $2 \mathrm{D}$ cursor control. ${ }^{[82]}$ EEG signals have several drawbacks as field potential signal sources for neural interfaces, including limited bandwidth (loss of higher frequency due to scalp filtering), variability in sensor contact over time, multiple wirings and tethering to instrumentation, significant noise, and environmental artifacts. In comparison with EEG signals, ECoG can provide a lower noise signal and higher bandwidth and power, because filtering by the scalp is reduced. ${ }^{[85]}$ Wireless ECoG electrodes can eliminate some of the drawbacks associated with EEG electrodes, but US Food and Drug Administration (FDA)-approved ECoG electrodes for longterm neural interfaces are currently unavailable. ECoG electrodes are used for short-term subdural placement in patients with epilepsy. These electrodes are ca. $4 \mathrm{~mm}$ in size, arranged in a silastic sheet that covers a large area of cortical surface in order to map surgical resections. It is widely accepted that spikes hold the richest neural movement information and the amount of data available from action potential is impressive. For example, neurons in the motor cortex carry hand velocity, position, and forces. ${ }^{[86]}$ The number of neurons in the motor cortex required for reliable reconstruction of hand movement in a $2 \mathrm{D}$ or $3 \mathrm{D}$ space is around 50 cells. ${ }^{[12,20]}$ Penetrating microwires and micromachined electrodes are used to record spikes and local field potentials in animals and humans. Although spikes can be separated to the level of single unit activity using signal-sorting algorithms, gathering information from a population of a few dozen neurons (multiunit activity recording) has shown to be of great interest for neural interface technologies. ${ }^{[87]}$ There is an ongoing debate in the field of neural interface technology regarding the concerns of whether the invasiveness of neural electrodes that are used to obtain action potentials or field potentials from ECoGs or local field potentials can provide sufficiently stable and reliable signals to justify the risk of implantation and the longterm presence of an object inside the brain. ${ }^{[1,88]}$ Safety and long-term, reliable signal recording are the major concerns in the neural interface community. Deep brain stimulators are FDA-approved neurological devices implanted centimeters deep in the brain to help more than 30000 people with Parkinson's disease.

\subsection{Past and Current Neural Interface Technologies}

In 1870, Fritz and co-workers demonstrated the controllability over animal muscle movements by applying electrical stimulation to the brain motor cortex regions. ${ }^{[60,89]} \mathrm{In}$ 1963, Gray Walter, a pioneer in the use of electroencephalography, demonstrated the use of recorded brain signals from human motor cortex to operate a slide projector. This was the first attempt to show the feasibility of cortical neural prosthetics. ${ }^{[90]}$ Since then, extensive scientific research has been done to design and develop neural devices that can be implanted into the nervous system for both recording and stimulation. ${ }^{[15,33,48,91-93]}$ In 1996, cortical microwire electrodes were implanted in the right and left hemispheres of a monkey's brain, generating population vectors for prosthetic arm control. ${ }^{[49]}$ Much later, Nicolelis et al. reported successful neural recording from implanted microwires (totaling 96-704 per subject) in a monkey's brain, up to 18 months after implantation. ${ }^{[22]}$ Donoghue and coworkers implanted an array of 96 microfabricated silicon electrodes in the primary motor cortex, for the control of prosthetic devices in a human with tetraplegia. ${ }^{[13,84]}$ They remarkably recorded neuronal activity of neurons 3 years after spinal cord injury. Their results suggested that recording neural signals could be used for the development of new 
technologies to restore independence for humans with paralysis. ${ }^{[13]}$ More recently, flexible surface microelectrodes have been designed for acute and chronic neural recoding. ${ }^{[94,95]}$ Flexible electrodes that are made of polyimide (PI) and parylene $\mathrm{C}$ have elastic modulus (ca. 3.2 GPa) significantly lower than that of silicon; therefore, these electrodes may generate less tissue damage and be functional longer than silicon-based electrodes. Rogers and coworkers developed ultrathin $(2.5 \mu \mathrm{m})$ polyimide-based neural electrode arrays to record signals form the visual cortex in cats. ${ }^{[94]}$ The ultrathin PI electrode array outperformed thick PI electrodes $(75 \mu \mathrm{m})$ with nearly all channels in good conformal contact and a still higher SNR.

\section{Materials for Neural Electrodes}

Neural electrodes have evolved in their unique material, chemistry, shape, size, and texture, to modify the electrical properties, mechanical properties, and biocompatibility of the electrode-tissue interface, and thus to improve the electrode longevity and performance. ${ }^{[96,97]}$ Several materials have been explored for the electrode substrate, including silicon, ceramic, glass, sapphire, and polymers. ${ }^{[98-101]}$ For targeting specific regions of the brain, microwires and glass micropipette electrodes have been used. Later, they advanced into silicon shafts and even more complex micromachined silicon and polyimide flexible recording systems capable of monitoring neuron networks with improved temporal and spatial resolution. ${ }^{[19,57,70]}$ Table 1 summarizes the materials that have been utilized for neural interface technologies.

\subsection{Microwires}

Microwire electrodes (Figure 1f) are mainly made of conducting metal wires, such as platinum, gold, iridium, stainless steel, and tungsten. Neural recording occurs through the non-insulating tip of the wire and the rest of the wire is coated with a non-cytotoxic insulator material (Figure 1g). Microwires can be easily made into an array of 4 to over 100 electrodes with spacing of 100-300 $\mu \mathrm{m}$ supported by polyethylene glycol and methacrylate. ${ }^{[15,22,48,102]}$ Numerous attempts have been made to obtain chronic singleneural recording from behaving animals using arrays of microwires. ${ }^{[15,69,103,104]}$ Nicolas et al. recorded 247 individual cortical neurons from 384 out of 704 chronically implanted microwires in monkey's brain up to 18 months after implantation. ${ }^{[22]}$ However, microwire electrodes suffer from: i) a risk of surgical complications due to the transcutaneous wire connection; ii) forces and movements associated with the tethered electrodes, stimulating tissue responses; and iii) bending of the microwires during implantation due to the curvilinear surface of the brain tissue. ${ }^{[68,105]}$

\subsection{Micromachined Electrodes}

The next generation of neural electrodes is micro-electromechanical system (MEMS) electrodes (Figure 1a-e and 1h), which can be fabricated into complicated structures using microfabrication techniques. ${ }^{[17,67,106]}$ MEMS-based single-shank silicon electrodes (e.g., Michigan electrodes (Figure 1a-c) can overcome the technical barriers associated with microwire electrodes because, with the same amount of tissue displacement, the number of recording sites can be substantially increased, and they are significantly smaller in 
size ${ }^{[3,107]}$ Furthermore, multiple sites can be formed over the shank of the electrode, thus enabling simultaneous recording of the neuronal activity in the various layers of the cortex. Multi-shank electrodes are able to record from as many as neurons. Two major types of silicon microelectrode array are the Utah array (Figure 1d,e,h) and the Michigan electrode (Figure 1a-c). The Utah array has been used for over 20 years; its basic structure is that of a needle-like electrode, which is made of a single shank of silicon. It is made of 25 to 100 shanks per electrode (each shank being $1.5 \mathrm{~mm}$ in length and $1-100 \mu \mathrm{m}$ in diameter). ${ }^{[108]}$ Unlike the Utah array, the Michigan probe is a single-shank electrode having several recording sites placed on the surface of the shank. In order to overcome the challenges associated with the mechanical mismatch between the hard, planar silicon electrodes and the soft curvature tissues of the brain, Kim et al. fabricated electrodes with a soft and curvilinear surface made with a bioresorbable film of silk covering an array of ultrathin $(<10 \mu \mathrm{m})$ polyimide (PI) electrodes (Figure 11, Figure 4a). ${ }^{[109]}$ Reducing the thickness of the electrode substrate decreases the bending rigidity of the electrode, thereby improving the conformal contact. Unfortunately, thick clinical electrode arrays $\left(700 \mu \mathrm{m}^{[110])}\right.$ and even the thinnest devices designed for research $\left(>10 \mu \mathrm{m}^{[111])}\right.$ have thicknesses that are larger than desired to ensure conformal contact. Kim et al. implanted three different arrays of surface electrodes (30 electrodes per array) in cats for neural recording from the visual cortex (Figure 4b) (i.e., (1) PI thick electrodes ( $75 \mu \mathrm{m})$; (2) PI thin electrodes $(2.5 \mu \mathrm{m})$ supported by a silk layer; and (3) silk mesh electrodes $(2.5 \mu \mathrm{m})$. The authors successfully demonstrated that the $2.5 \mu \mathrm{m}$ mesh electrode showed the best performance, with nearly all the channels in good contact, and a still higher SNR of 5.7. The lower standard deviation of the $2.5 \mu \mathrm{m}$ array illustrated that most of the electrodes recorded good neural activity. Placing such devices on soft brain tissue and then allowing the silk to dissolve and resorb generates a spontaneous, conformal wrapping process driven by capillary forces at the biotic-abiotic interface. Remarkably, the authors did not observe any evidence of immune response after 4 weeks of implantation. ${ }^{[109]}$

The bridge that connects implanted electrodes to the external connector cable is the source of electrode micromotion. This micromotion is closely related to the foreign body response around the implant. ${ }^{[18]}$ Kipke and co-workers made a hybrid system that used siliconsubstrate microelectrodes with a printed circuit board on flexible PI ribbon cables (Figure 5a). ${ }^{[17]}$ The 16-channel microelectrodes consisted of four penetrating shanks with four recording sites on each shank. The electrode assembly included an integrated silicon ribbon cable and a percutaneous connector. These neural electrodes were found to consistently and reliably provide high-quality neural recordings over extended periods of time up to 127 days (Figure 5b). Fourteen electrodes were implanted in the cortices of 10 rats and $93 \%$ of them remained functional throughout the assessment period. More than $90 \%$ of the electrode sites consistently recorded neural activity with high SNR. Histological analysis of the tissue surrounding the electrodes indicated the development of a stable interface sufficient for sustained electrical contact (Figure 5c). The results of this study demonstrate that these hybrid silicon/flexible PI ribbon cable probes are suitable for long-term recording in the cerebral cortex. ${ }^{[17]}$ The shape and size of the neural electrodes may have a significant effect on the quality of signal recording and electrode-tissue interactions. Szarowski et al. showed the effect of electrode shape, size, and tip geometry on the level of cellular encapsulation to silicon neural electrodes. ${ }^{[19]}$ The authors compared different sizes of three cross-sectional 
shapes of the shafts (i.e., trapezoid, square, and elliptical). For each of these electrodes, they also used two tip geometries (i.e., sharp and rounded) with different insertion techniques. These studies demonstrated no significant reduction in the response of the brain to the implanted electrodes. ${ }^{[19]}$ While Rousche et al. and Schimidt et al. suggested that specific material surface characteristics such as the texture of an implant can reduce the chronic response, ${ }^{[15,112]}$ Szarowski et al. claimed that the effect of the electrode shape, size, texture, and tip geometry is insignificant to the immune response. Recently, Kipke and co-workers designed subcellular-sized parylene branches connected to parylene-based neural electrodes and implanted them in rat cerebral cortex for 4 weeks (Figure 5d). ${ }^{[113]}$ The parylene-based neural electrodes were fabricated with a thick shank $(48 \mu \mathrm{m})$ and an integrated, thin lateral platform ( $5 \mu \mathrm{m}$, either solid or one of three lattice sizes). The authors hypothesized that a subcellular-sized lateral edge would have less tissue encapsulation relative to the larger electrode shank. Immunostaining revealed that there was significant differential tissue response within $25 \mu \mathrm{m}$ of the lateral edge, compared with the shank (Figure $5 \mathrm{e}-\mathrm{h}$ ). The density of astrocytes and microglia in this region of the lateral edge was less than one-third of that of the corresponding region of the shank ( $129 \%$ and $425 \%$ increase, respectively). Moreover, neuronal density around the platform's lateral edge was about one-third higher than at the shank. Microglia reactivity and extracellular protein deposition was reduced at the lateral edge. The authors concluded that the ideal electrode location for their designs was on the outermost position at the edge $50 \mu \mathrm{m}$ thick, extending far from the probe shank. ${ }^{[113]}$

\section{Electroactive Nanomaterials for Electrode-Tissue Interfaces}

An immense amount of effort has been made in the development of neural interfaces that relieve local inflammation, a major contributor in the failure of neural probes. Previous studies suggested that the chemical, physical, and mechanical properties of implanted electrodes are important factors for suppressing chronic tissue encapsulation. ${ }^{[18,22,101]}$ Electrode size, tip shape, cross-sectional area, and surface roughness have been modified to elicit the minimum tissue responses. ${ }^{[19,22,68,101]}$ These studies suggested that the physical characteristics of neural electrodes may affect the initial wound healing response; however, glial-scar formation is not affected. To improve electrode-tissue interactions and minimize the chronic response, multiple material-based strategies have been implemented to control the molecular and cellular aspects of the immune response and to prevent electrode failure. ${ }^{[18,60,97]}$ One strategy to modulate the inflammatory response and achieve better integration of the neural electrodes with brain tissue is the chemical modification of the neural probe surface with antiinflammatory compounds, adhesion proteins, and bioactive molecules. ${ }^{[41,71,93,113-118]}$ The surface modification of neural electrodes includes biological modification, such as coating with hyaluronic acid, peptides, and growth factors, ${ }^{\text {[93,119-121] }}$ and non-biological modification, such as hydrogels, ${ }^{[122-124]}$ conducting polymers, ${ }^{[52,96,125,126]}$ and carbon nanotubes. ${ }^{[127-130]}$ The design and development of new materials that generate seamless neural interfaces with a high degree of sensitivity is a great challenge in applying neural electrodes for recording neural activity both in vitro and in vivo. Maintaining a high degree of electrode sensitivity is essential, especially when measuring single unit action potentials with signals on the order of microvolts. Long-term stability is another challenge that has motivated the design of novel materials. Electroactive 
nanomaterials such as silicon nanowires, ${ }^{[30,131]}$ carbon nanotubes ${ }^{[28,127]}$ and conducting polymer nanostructures ${ }^{[32,132]}$ may be able to achieve stable and sensitive chronic neural interfaces by significantly increasing the SNR. Neural probes with dimensions that are several orders of magnitude smaller than the dimension of the cell may appear invisible to the immune cells. These devices may penetrate into the neurons and therefore are able to accurately measure intracellular action potentials. It has been suggested that these nanomaterials may integrate into the cell membrane and create electrical shortcuts, improving the responsiveness of the neurons by forming tight contacts with the cell membranes that might favor electrical shortcuts between the proximal and distal compartments of the neuron. ${ }^{[29]}$

\subsection{Conducting Polymers}

While metallic and inorganic semiconductor materials are routinely made for neural interfaces, the preparation of polymeric materials has been relatively unexploited. Polymers provide a variety of advantages over other materials because they have a wide range of chemical structures and tunable surface functionalities. Among synthetic polymers, electroactive conducting polymers (CPs) have received considerable attention since the initial discovery of polyacetylene in the late 1970s. ${ }^{[133]}$ In 2000, the Nobel Prize in chemistry was awarded jointly to three scientists for the discovery and development of CPs. ${ }^{[134-136]}$ CPs have alternate single and double bond conjugation (Figure 6a), which provides the electronic conductivity after doping with suitable dopants. ${ }^{[137]}$ Their response to electrochemical oxidation and reduction can produce a remarkable change in wettability, ${ }^{[138]}$ color, ${ }^{[139]}$ volume, ${ }^{[140,141]}$ and conductivity. ${ }^{[136]}$ CPs can be synthesized by chemical and electrochemical methods. Chemical polymerization is desirable for mass production, but the processing time is significantly longer than electrochemical polymerization and entails the use of non-biocompatible oxidants such as ferric chloride. In addition, the resulting film suffers from poor electrical properties and may require a post doping process to enhance the electrical conductivity. ${ }^{[134-136]}$ In contrast, electrochemical polymerization is useful particularly when well-defined thin films are deposited on a surface of metallic substrate and no further improvement process is required (Figure 6b). The main advantage of electrochemical deposition is that a CP film can be formed in a simple one-step process with a high degree of control over the film thickness, surface properties, and electrical conductivity. ${ }^{[135,136]}$

CPs have numerous advantages for biomedical applications, including the ability to: i) entrap and release drugs and biomolecules; $[36,125,142]$ ii) be functionalized with bioactive molecules and proteins; ${ }^{[35,143-145]}$ iii) transfer the electrical charge from ions in living tissue to electrons in an electrode; ${ }^{[146-148]}$ and iv) alter the electrical, chemical, and physical properties of the surface to mediate the cellular response. ${ }^{[149]}$ Among these polymers, poly(pyrrole) (Ppy), poly(aniline) (PANI), poly(thiophene) (PT), and poly (3,4ethylenedioxythiophene) (PEDOT) (Figure 6a), and some of their derivatives have received more attention for biomedical applications, ${ }^{[146,149-151]}$ especially neural interfaces $^{[25,32,35,37,38,52,57,132,140,146,147,152-178]}$ since these CPs exhibit good biocompatibility, ${ }^{[149,177,179]}$ excellent electrical conductivity, and ease of synthesis. ${ }^{[134,136]}$ Ppy is the most commonly utilized $\mathrm{CP}$ for neural applications because of the superior water 
solubility of the pyrrole monomer. Due to its good biocompatibility, Ppy has been electrodeposited with different dopants on neural electrodes. ${ }^{[25,35,57,145,157,160,179-183]}$ The application of PEDOT in this field has, however, remained relatively unexplored. In comparison with the widely used Ppy, PEDOT exhibits a very high conductivity (ca. 1200 $\mathrm{S} / \mathrm{cm}),{ }^{[139,174]}$ outstanding chemical stability in the oxidized state, ${ }^{[139,184]}$ and excellent biocompatibility. ${ }^{[126,172,185-187]}$

5.1.1. Biocompatibility and Tissue Interaction-The biocompatibility of CPs is highly sensitive to the ionic species that can be integrated into the polymer structures during the polymerization process. CPs can be used as a substrate for the attachment, proliferation, and differentiation of neural cells. ${ }^{[57,160,164,188]}$ These capabilities are directly dependent upon the molecular composition of the dopants and overall electrical charge of the electrodeposited CPs on the surface of the electrode. Lundin et al. cultured neural stem cells on Ppy films containing different dopants and demonstrated a distanced coloration between the dopants and cell viability. The authors showed that cell viability was high on Ppy doped with dodecylbenzenesulfonate (DBS) compared with that on Ppy films containing chloride, perchlorate, and tosylate. ${ }^{[164]}$ In general, neural stem cell proliferation and differentiation on Ppy/DBS were comparable to cells on standard tissue culture polystyrene. Reduction of Ppy films decreased neural stem cell viability, with widespread cell death upon polymer reduction with a bias voltage of $-0.9 \mathrm{~V}$ for $120 \mathrm{s.}{ }^{[164]}$ These results suggested that different conformations of an adsorbed protein layer of fibronectin (Fn) on the surface of Ppy films doped with different dopants and reduced by a bias voltage might contribute to different cellular responses. ${ }^{[164,189]}$ Protein conformation plays a significant role in cell signalling and biological functions. Malliaras and co-workers showed a precise electrical control of protein conformation on the surface of PEDOT doped with p-toluenesulfonate (TOS). The authors assessed the Fn conformation using Forster resonance energy transfer (FRET) imaging (Figure 6c). They created gradients in the Fn conformation consisting of a $2 \mathrm{~cm}$ long, $0.7 \mathrm{~cm}$ wide PEDOT:TOS film on top of an indium tin oxide (ITO) electrode. A gradient in the surface potential was established by applying $\pm 1.0 \mathrm{~V}$ across the electrode while the electrode was incubated for $1 \mathrm{~h}$ in cell culture medium containing Fn (Figure 6c and 6d). ${ }^{[190]}$

More recent research has focused on enhancing the biocompatibility and tissue interactions of CPs through the use of biomolecules and therapeutic agents. Drugs and biomolecules can be incorporated as charged dopants ${ }^{[142,155,168]}$ or non-doping inclusions ${ }^{[144,191,192]}$ during polymerization. Biological dopants include laminin peptide sequences, ${ }^{[155]}$ hyaluronic acid, ${ }^{[176]}$ or silk-like polymer having fibronectin fragments (SLPF). ${ }^{[168]}$ Neurotrophic factors, whole laminin, and human serum albumin have been entrapped during polymerization, post-fabrication adsorption, and pre-attachment to the monomer. ${ }^{[144,155,193,194]}$ The trapped biomolecules either can be immobilized in the polymer structure or can be released from the polymer. ${ }^{[195]}$ These biological components can potentially enhance the biocompatibility and the integration of tissue with the surface of a neural electrode. Incorporation of brain-derived nerve growth factor (BDNF) and nerve growth factor (NGF) into the Ppy film significantly enhanced neurite extension of spiral ganglion explants and PC12 cells. ${ }^{[145,193,196]}$ These biomolecules have a significant impact 
on the physical, chemical, and optical polymer properties of CPs. ${ }^{[36]}$ Pool-Warren and coworkers showed that the dopant size appears to play a significant role in the polymer mechanical performance, with larger dopants producing softer and less-adherent films. ${ }^{[155]}$ In addition, the inclusion of additional large non-doping molecules, such as the NGF molecule, increases this effect. The authors incorporated NGF within PEDOT films doped with DEDEDYFQRYLI and DCDPGYIGSR laminin peptides and, additionally, a conventional dopant, paratoluene sulfonate (pTS) (Figure 6e). The peptide dopants produced a softer polymer interface than the PEDOT doped with pTS. The authors found that entrapment of NGF into PEDOT doped with peptide resulted in polymers with diminished electrical and mechanical stability. Entrapped NGF was determined to be biologically active, with PEDOT/ pTS/NGF producing neurite outgrowth (Figure 6f). While these results indicated the possibility of inclusions of multiple biomolecules in the CP films, the synergy, the molecular interactions between these bioactive molecules, monomer and dopants, and the anionic charges of the dopants must be considered for the development of functional CPs. ${ }^{[155]}$ In another study, Martin and co-workers entrapped two ECM proteins (i.e., SLPF and CDPGYIGSR peptide) within Ppy doped with lithium perchlorate on the surface of neural electrodes. ${ }^{[168]}$ The morphologies of the resulting films were rough and fuzzy, providing a high surface area for interaction with neural cells (Figure $6 \mathrm{~g}$ ). This high interfacial area also helped to significantly decease the impedance of the electrode site and to improve the quality of neural recording from the cerebellum of a guinea pig. The in vitro cell-culture results showed that glial cells appeared to attach better to Ppy/SLPF-coated electrodes than to bare gold electrodes (Figure $6 \mathrm{~h}$ and 6i). Neuroblastoma cells grew preferentially on and around the Ppy/CDPGYIGSR coated electrode sites. The in vivo experiments confirmed that high-quality neural signals could be recorded from single neurons using Ppy/SLPF-coated electrode sites. ${ }^{[168]}$

\subsubsection{Controlled Release of Drugs and Biomolecules-CPs can undergo a} reversible redox reaction, which involves the charging and discharging of the polymer, and is accompanied by the movement of ions and solvent into or out of the polymer. This mass transfer is the primary mechanism for the volume change of a CP. When ions and solvent enter the polymer, it expands, and when they exit it contracts (Figure 7a). ${ }^{[195,197-200]}$ The volume change mechanism in CPs is complex because the electrical, mechanical, and chemical properties of the materials are closely related. ${ }^{[201]}$ Actuation strains are large, from a few percent to over $30 \%{ }^{[202]}$ and can be operated in bending geometries or expansions/ contractions. CP actuators are unique in that they not only can be switched between fully expanded and contracted situations, but also can be held at an intermediate state. ${ }^{[195,202,203]}$ This feature enables the actuator to carefully move and be held precisely in a desired position. Utilizing this feature, efforts have been made to develop CP-based biomedical actuators, ${ }^{[202]}$ in particular for artificial muscles, ${ }^{[204,205]}$ microsurgical instruments, ${ }^{[206]}$ implants, ${ }^{[207]}$ bioMEMS, ${ }^{[208]}$ and drug delivery systems. ${ }^{[166,209]}$

CPs can be utilized for the precise delivery of ions to cells in a controlled fashion. Cells are regulated by ion fluxes for intercellular communication, and the biological signals are often represented as gradients in their environments. Berggren and co-workers took advantage of the combined electronic and ionic conduction properties of PEDOT doped with poly(styrene 
sulphonate) (PEDOT:PSS) to develop an electrophoretic ion pump that translates electronic signals into ion fluxes that communicate with cells. ${ }^{[147]}$ This ion pump device is able to control the ion homeostasis of individual neuronal cells. The PEDOT:PSS ion pump device can be used as an actuator, and pumps cations from a reservoir electrolyte to a target electrolyte with spatial and temporal resolutions that match a range of signalling events at the individual-cell level. The authors showed that ions were delivered in high quantities at an associated on/off ratio exceeding 300 . This induces physiological signalling events that can be recorded at the single-cell level. Furthermore, by fabricating a $50 \mu \mathrm{m}$-wide microchannel, a size that corresponds to many eukaryotic cell types, stimulation of individual cells was achieved. ${ }^{[147]}$

Drugs and bioactive molecules can be incorporated into CPs during electrochemical polymerization as charge dopants or entrapped inclusions (Figure 7a), or stored as reservoirs in the micro- and nanocavities of the CP (Figure $7 \mathrm{f}$ and $7 \mathrm{~g}$ ). ${ }^{[144,173,202,210-212]}$ In this context, Ppy containing pTS and neurotrophin-3 (NT-3) (Ppy/pTS/NT-3) was developed by Thompson et al. for controlled release of NT-3. ${ }^{[213]}$ During electrochemical polymerization, the positively charged NT-3 was entrapped within the Ppy doped with pTS (Figure 7b). Electrochemical stimulation of the Ppy by a pulsed voltage $( \pm 0.6 \mathrm{~V})$, pulsed current $( \pm 20$ $\mathrm{mA}$ ), or cyclic voltammetry (from $-0.8 \mathrm{~V}$ to $+1.0 \mathrm{~V}$ at a scan rate of $50 \mathrm{mV} / \mathrm{s}$ ) promoted the release of NT-3 at a greater rate than natural diffusion of NT-3 from Ppy film without electrical stimulation (Figure 7c). NT-3 was released from the Ppy film because of a volume change of the polymer during the mass transfer process (Figure 7a). NT-3 was released from Ppy as an initial burst in the first $24 \mathrm{~h}$, followed by prolonged release over the subsequent 6 days. The authors demonstrated that the amount of NT-3 incorporated into the polymer could be controlled either by varying the polymerization time or by developing multiple polymer film layers. Later, Richardson et al. applied a Ppy/pTS/NT-3 coating to $1.7 \mathrm{~mm}^{2}$ cochlear electrodes and implanted them in guinea pigs. The Ppy/pTS/NT-3-coated electrode stored $2 \mathrm{ng}$ of NT-3 and released $0.1 \mathrm{ng} /$ day with electrical stimulation (i.e., $1 \mathrm{~mA} \mathrm{~cm}{ }^{-2}$ biphasic current pulses). ${ }^{[125]}$ Guinea pigs implanted with electrically stimulated Ppy/pTS/ NT3-coated electrodes had lower electrically evoked auditory brainstem response thresholds and greater spiral ganglion neurons densities in implanted cochleae compared with nonimplanted cochleae and compared with animals implanted with Ppy/pTS-coated electrodes. This work demonstrated the use of the cochlear implant to deliver neurotrophins to neurons in a safe and controlled manner, in addition to electrical stimulation for enhanced preservation of spiral ganglion neurons after hearing loss. ${ }^{[125]}$ Another study utilized electrophoretic transport for the delivery of neurotransmitters from a device with distinct structural components (Figure 7d and 7e). ${ }^{[166]}$ Using PEDOT doped with PSS (PEDOT:PSS), Daniel et al developed an organic electronic device capable of precisely delivering neurotransmitters, such as glutamate, aspartic acid, and $\gamma$-amino butyric acid, that could mimic nerve synapses. This device was composed of: i) an electrolyte source; ii) an electrolyte target; iii) an anode; and iv) a cathode (Figure 7d). These components were fabricated into a variety of shapes and sizes and packed using encapsulating biomaterials. The devices were able to produce zero-order release kinetics of neurotransmitters. They demonstrated that the rate of release depended upon the magnitude of the applied voltage along with the mass and net charge of the molecule. They verified the release of the 
neurotransmitter in vitro by intracellular calcium recordings (Figure 7e). Using the peripheral auditory system and measuring the auditory brain response in cochlea, the in vivo controlled delivery of glutamate was validated. The authors showed that the device could selectively stimulate nerve cells out of a diverse population of cells (Figure 7e).

While the previously mentioned methods are able to release drugs and biomolecules incorporated into the $\mathrm{CP}$ structure, development of techniques that enable precise loading and delivery of a desired amount of drug is essential for the longterm performance of neural devices. Martin and co-workers developed a templating approach for loading a large volume of therapeutic agents into the cavities of CP nanotubes and precisely deliver it over 60 days. ${ }^{[173]}$ Dexamethaosne, an anti-inflammatory drug, was loaded into biodegradable poly(lactide-co-glycolide) (PLGA) nanofibers that were electrospun on the surface of neural electrodes (Figure 7g). The amount of incorporated dexamethasone within the PLGA nanofibers on each electrode was approximately $2 \mathrm{mg}$. PEDOT was electropolymerized around the drug-loaded nanofibers. Dexamethaosne was controllably released by electrical actuation of nanotubes at $+1.0 \mathrm{~V}$ (Figure 7f). As shown in Figure 7f, a release burst of 75\% was detected after 7 days for PLGA nanofibers (black squares), which can be explained by fast hydrolytic degradation and backbone cleavage of the PLGA nanofibers. Addition of the PEDOT coating around the PLGA nanofibers dramatically slowed the release rate (blue triangles). Under this condition, less than 25\% dexamethasone was released after 54 days. This extremely slow release was attributed to the hindered diffusion of dexamethasone through the walls of the PEDOT nanotubes, requiring the dexamethasone to migrate to the tube ends in order to escape. In other words, in the absence of any actuation, more than $75 \%$ of dexamethasone remained trapped inside the PEDOT nanotubes. To release the entrapped dexamethasone in a controlled fashion, the PEDOT nanotubes were actuated by applying a bias voltage of $+1 \mathrm{~V}$ for 5 times at different time points. Figure $7 \mathrm{f}$ illustrates the effect of this actuation on the release profile of dexamethasone (the vertical jumps in the data correspond to the applied electrical stimulations, red curve). Expansion and contraction of the PEDOT nanotubes after electrochemical stimulation produced a mechanical force creating pressure within the nanotubes. The hydrodynamic force inside the PEDOT nanotubes resulted in expulsion of degraded PLGA and dexamethasone. They suggested that dexamethasone released either from cracks on the surface of nanotubes or through the nanotube ends. A control experiment was also carried out to show that dexamethasone did not exhibit significant diffusion though the PEDOT nanotube walls. In this experiment, dexamethasone was incorporated inside the PEDOT layers; no dexamethasone elution into the media was detected. An externally applied voltage bias provides a means of controlling the release of the drug, as has been seen for other CPs. These results show that expansion and contraction of the $\mathrm{CP}$ cavities can provide an additional means for controlling the kinetics of drug release.

5.1.3. Neural Recording and Stimulation-The ability to record action potentials from individual neurons or stimulate neurons is dependent upon a trade-off between the size and the electrical properties of the electrode site, often referred to as the trade-off between selectivity and sensitivity. ${ }^{[52,214,215]}$ Ideally, the site of a microelectrode should have a small geometric area to communicate with individual neurons (selectivity). A low-impedance 
recording and high injection charge density site is necessary during recording and stimulation (sensitivity). ${ }^{[214-217]}$ Unfortunately, decreasing the geometric area of a recording site causes an increase in the impedance and a decrease in the capacity of the injection charge density of neural microelectrodes. ${ }^{[218,219]}$ Current neural microelectrode technologies suffer from a poor electrical performance because of their small-feature geometry. ${ }^{[57,174]}$ Moreover, the encapsulation process of the chronic response progressively increases the impedance of the electrode-tissue interface. ${ }^{[18,19,34,220]}$ While a number of studies have explored methods such as deposition metals, ${ }^{[169]}$ metal oxides, ${ }^{[221]}$ and applying bias voltage pulses ${ }^{[222]}$ to improve the electrical properties of neural microelectrodes, these methods have some drawbacks, including unstable impedance and poor adherence to the electrode site. Recently, CPs have been employed to improve the electrical properties of neural microelectrodes. ${ }^{[25]}$ CPs can significantly decrease electrode impedance and increase charge injection density as compared with metal sites of similar geometric area. ${ }^{[57,170]}$ The improvement of the electrical performance can be explained by increasing the effective surface area for ionic-to-electronic charge transfer at the interface between the brain tissue and the recording site. ${ }^{[168,223]}$ In addition, a CP is able to act as a mediator between the brain and the electrode to buffer the mechanical mismatch and reduce the foreign body response of the brain to the electrode, thus allowing recording of the brain electrical activity for a longer period of time. ${ }^{[32,52]}$

Given the high demand for the development of flexible electrodes for in vivo applications, Malliaras and co-workers reported a novel method to fabricate highly conformable CP electrodes (Figure 8a). ${ }^{[95]}$ They developed a general procedure for integrating CPs with a flexible substrate. The process involved the direct patterning of a commercially available PEDOT:PSS layer on gold ( $\mathrm{Au}$ ) sites of $4 \mu \mathrm{m}$ thickness of parylene $\mathrm{C}$ substrates (Figure 8a). Given the combination of the biocompatibility of PEDOT:PSS and parylene $C,{ }^{[224]}$ the good chemical stability, ${ }^{[225]}$ the excellent electrical conductivity of PEDOT:PSS, and the flexibility of parylene $\mathrm{C}$, this highly conformable electrode has a great potential for chronic application of neural electrodes. Each PEDOT:PSS array consisted of two subsets of 16 electrodes each, placed on a hexagonal lattice, with individual electrodes having an area of $20 \mu \mathrm{m} \times 20 \mu \mathrm{m}$ and a center-to-center distance of $60 \mu \mathrm{m}$. The array had a hole in the middle to allow simultaneous insertion of a silicone electrode (Figure 8b). The silicon electrode had a single shank with 16 electrodes ( $177 \mu \mathrm{m}^{2}$ area each) arranged in a linear configuration with $100 \mu \mathrm{m}$ spacing. In order to validate the PEDOT:PSS array and demonstrate that it can record neural signals, the electrodes were placed on the surface of rat brains and, at the same time, the silicone probe was also inserted into the brain. As ECoG signals were recorded by surface array, the silicon electrode also recorded the strong activity at the deepest layer for $20 \mathrm{~min}$. The authors showed that, even if all the sites do record synchronously the sharpwave events, each ECoG signal is specific to the particular location of the electrode, meaning that the spatial resolution of the array is of the order of the interelectrode spacing (Figure $8 \mathrm{~b}$ ). Furthermore, the PEDOT:PSS electrode proved to outperform Au electrodes of similar geometry. This conformable electrode array with high mechanical flexibility and low invasiveness compared with traditional electrode arrays has the potential to be applied in other areas of neuroscience. ${ }^{[95]}$ 
Abidian et al. developed a templating technique to fabricate $\mathrm{CP}$ nanotubes on the surface of microfabricated neural electrodes. ${ }^{[57,173,174]}$ The fabrication process includes: i) electrospinning of biodegradable poly(L-lactide) (PLLA) nanofibers on the shank of neural microelectrodes; ii) electrochemical deposition of PEDOT on the individual electrode sites $\left(1250 \mathrm{~mm}^{2}\right)$ and around the PLLA nanofibers; and iii) removal of the PLLA templates (Figure 8c). The wall thickness of the PEDOT nanotubes varied from 20 to $35 \mathrm{~nm}$, and the inner nanotube diameter ranged from 50 to $140 \mathrm{~nm}$. By controlling the polymerization time, the authors could reproducibly prepare tubular structures with thin walls or thick walls. The overall thickness of the PEDOT nanotube scaffolds was between 2.4 and $3.1 \mu \mathrm{m}$, depending on the thickness of the electrospun fiber mesh on the neural microelectrodes (Figure 8d). Impedance spectroscopy results revealed that that the impedance of both bare gold and PEDOT nanotube-coated electrode sites decreased with increasing frequency, while the impedance of coated electrodes was significantly lower than that of uncoated gold electrodes over the whole range of frequencies. The magnitude of the impedance was decreased from $800 \pm 20 \mathrm{k} \Omega$ for uncoated sites to $4 \pm 2 \mathrm{k} \Omega$ (about two orders of magnitude) for PEDOT nanotubes (at $1 \mathrm{kHz}$ ). These extremely low values of electrode impedance have been shown to significantly enhance the performance of these probes in vivo. The cyclic voltammetry measurements showed that the charge injection density increased from $0.001 \pm 10^{-4} \mu \mathrm{C}$ for bare gold electrodes to $4.9 \pm 0.6 \mu \mathrm{C}$ for PEDOT nanotubes. ${ }^{[174]}$ To validate the signal recordings of the PEDOT nanotubes, 6 chronic neural microelectrodes were implanted in the barrel cortex of rats. The impedances of the implanted microelectrodes were monitored after the surgery for 7 weeks. ${ }^{[32]}$ Although the impedance of both uncoated and PEDOT nanotube sites increased, the PEDOT nanotube sites always had lower impedance than the control sites, which should help in the quality of the recording signal. The electrodes modified with PEDOT nanotubes registered high quality unit activity (SNR $>4$ ) on $35 \%$ more sites than the controls (uncoated), primarily as a result of a reduced noise floor (Figure 8e). The increase in the average number of quality units is likely a result of a decrease in the noise. As expected, the average noise floor for the PEDOT nanotube sites across days was $6.1 \pm$ $0.8 \mathrm{mV}$, significantly lower than the control site noise floor of $6.4 \pm 0.9 \mathrm{mV}$. Moreover, local field potential (LFP) recordings demonstrated that the sites modified with PEDOT nanotubes have significantly less low frequency artifacts in LFP recordings. Other groups showed that the implantation of CPs for several weeks has led to only minimal inflammation, again pointing to low toxicities and good tissue compatibility of CPs. The results of this study indicate that PEDOT nanotubes provide an incremental benefit for obtaining high quality neural recordings.

In another study, Pool-Warren and co-workers demonstrated the capability of CPs for electrical stimulation of neural tissue. ${ }^{[156]}$ In this study, PEDOT/pTS was coated on Pt sites of microfabricated PDMS electrode array (Figure $8 \mathrm{f}$ and $8 \mathrm{~g}$ ). The physical and electrical stability of PEDOT/pTS following ethylene oxide sterilization and electrical stimulation using a biphasic voltage waveform was evaluated in the feline model. The charge injection limit of PEDOT was found to be on average 30 times larger than that of Pt when tested in physiological saline, and 20 times larger than that of Pt when tested in protein supplemented media. PEDOT doped with PSS is stable for up to 10 days, ${ }^{[154]}$ but PEDOT doped with pTS demonstrated superior stability. In vivo acute stimulation with a biphasic voltage waveform 
confirms PEDOT-coated electrodes elicit neural responses at an average of $67.0 \mu \mathrm{C} \mathrm{cm}^{-2}$ of injected charge, which was not significantly different to that of the Pt controls (average of $74.5 \mu \mathrm{C} \mathrm{cm}^{-2}$ ) (Figure 8h). This could be explained by suprachoroidal placement; thus, no reduction in charge threshold was observed when $\mathrm{CP}$ was coated on Pt sites. This study demonstrates the potential application of CPs in neural stimulation implants, as CP coating provides a lower voltage drop, resulting in improvements of power consumption and the potential to miniaturize systems without compromising the injection limit or safety.

\subsection{Carbon Nanotubes}

Carbon nanotubes (CNTs) are made of rolled-up graphite sheet(s) composed of either single or multi-walled nanotubes (SWCNTs and MWCNTs). ${ }^{[226]}$ SWCNTs consist of a single graphite sheet seamlessly wrapped into a cylindrical tube (Figure 9a-d). MCWNTs comprise an array of such nanotubes that are concentrically nested like rings of a tree trunk. ${ }^{[227-229]}$ SWCNTs may have either metallic or semiconducting properties, depending on the sheet direction rolled to form a nanotube cylinder, while the electronic properties of perfect MWNTs are rather similar to those of perfect SWNTs, because the coupling between the cylinders is weak in MWNTs. They possess remarkable properties, including a high electrochemically accessible surface area $\left(700-1000 \mathrm{~m}^{2} \mathrm{~g}^{-1}\right),{ }^{[28]}$ high mechanical strength (elastic modulus ca. $0.64 \mathrm{TPa}$ for an individual nanotube ${ }^{[230]}$ ), excellent thermal conductivity (individual MWNT $>3000 \mathrm{~W} \mathrm{~m}^{-1} \mathrm{~K}^{-1}$ ) ${ }^{[231]}$ and high electronic current (up to $\left.10^{9} \mathrm{~A} \mathrm{~cm}^{-2}\right) .{ }^{[232]}$ Because of these properties, CNTs are attractive for the fabrication of devices that use electrochemical double-layer charge injection, such as supercapacitors and actuators. ${ }^{[233]}$ CNTs have been used in the field of biotechnology, such as for DNA and protein biosensors, ${ }^{[234,235]}$ in ion channel blockers, ${ }^{[236]}$ and as bioseparators and biocatalysts. ${ }^{[237]}$ Regarding the biomedical applications of CNTs, these materials are becoming relevant in neuroscience research, ${ }^{[26]}$ and neural tissue engineering ${ }^{[238]}$ CNTs have been developed as 3D scaffolds for the regeneration of CNS (e.g., brain and spinal cord $)^{[239-241]}$ and the recording of neural activity. ${ }^{[28,29,127]}$ While a major technical barrier of CNTs for biomedical applications is insolubility in solvents, their functionalization with some reagents and biomolecules enhance the solubility. ${ }^{[242]}$ In addition, recent improvements of CNT synthesis and purification methods have opened pathways for CNTs as components of biosensors and implant coatings. ${ }^{[243-245]}$ Additionally the functionalization of the CNT surface with different polymers or bioactive molecules can improve their biocompatibility and bioactivity. ${ }^{[227,246-248]}$ They can be used to modulate neuronal behavior either at the structural (i.e., synaptogenesis and neurite elongation) or functional (i.e., synaptic efficacy) level. ${ }^{[241,249]}$ CNTs notably increase the effective surface area of the electrode-tissue interface and charge transfer capacity, and decrease the interfacial impedance of a recording site. ${ }^{[28,29,250]}$ This section highlights experiments addressing the biocompatibility of CNTs, cell-CNTs interactions, and the effect of CNTs on the functional performance of neural interfaces.

5.2.1. Biocompatibility and Cell Interaction-CNTs have been interfaced with neural tissue with an appropriate host response. ${ }^{[251,252]}$ While the biocompatibility of CNTs has been reported by several groups, the utilization of CNTs for biomedical applications, especially in human healthcare needs to be more investigated due to the potential 
cytotoxicity of CNTs. Although numerous studies have been performed to investigate the toxicity of CNTs, only a few clear conclusions have been reported, and there are mixed results about the toxicity of CNTs. ${ }^{[127,240,253-256]}$ Toxicity has not been observed for CNTs as coating and hybrid materials, which do not produce freely floating nanotubes. However, the possible toxicity of CNTs must be considered due to potential decomposition of the CNT composites used to manufacture neural electrodes. This is because various factors are involved in determining the toxicity of CNTs, such as composition, surface functionalization, and size. Thus, a clear understanding of the biocompatibility of CNTs is required in order to use these nanomaterials for neural applications. CNTs have been studied as substrate materials for neuronal cell adhesion, proliferation, and differentiation, ${ }^{[240,241,249,257,258]}$ and these studies have supported CNTs for neural applications.

Aggregation of CNTs has been known to have a strong impact on toxicity. Some studies have shown that aggregated bundles of CNTs are more toxic than well-dispersed CNTs. ${ }^{[259-261]}$ Raja et al. showed that the removal of large SWCNT aggregates $(>0.22 \mathrm{~mm})$ from cell culture test medium using a filter could produce a slightly lower toxic response compared with an unfiltered medium. ${ }^{[261]}$ The degree of dispersion is a factor that can moderate CNT toxicity. ${ }^{[262]}$ Riviere and co-workers revealed that even micrometer-sized well-dispersed CNTs were less toxic than aggregated one. ${ }^{[260]}$ It has been hypothesized that aggregated CNTs may bind to cells through their extracellular proteins and alter the cell membrane's ability to pass nutrients and waste. ${ }^{[261,263]}$ Another study examined the biocompatibility of different degrees of agglomeration of CNTs on neurons and glial cells using non-covalently wrapped SWCNTs. ${ }^{[264]}$ It is hypothesized that the degree of toxicity partially depends on the agglomeration state of the CNTs; larger SWCNT aggregates resulted in a reduced cell number over time. Thus, if SWCNTs can enter the nervous system at sufficiently high concentrations, activation and proliferation of glial cells might occur. Charge also appears to play a role in the toxicity of CNTs. More neurite branching and growth cones were observed when dorsal root ganglion (DRG) cells were exposed to positively charged CNTs. ${ }^{[240]}$ The CNT dimension can be another factor determining the toxicity of CNTs. From studies performed in the lung, the toxicity level of CNTs follows a trend based on their size. ${ }^{[265]}$ It was shown that CNTs with the smallest surface area appeared to be the most toxic in which SWCNTs induced stronger toxicity than MWCNTs. ${ }^{[262]}$ The exact mechanism behind this effect is unclear, but it may be explained by a theory that the dimension of the CNTs is similar to the dimension of a virus; thus, CNTs may resemble viruses and induce an immune response. ${ }^{[266]}$

Functionalized CNTs have been shown to alter neurite branching, length, and density, as well as the number of growth cones, but the exact mechanism behind these changes is unclear. It has been suggested that the CNT surface charge or polarity may have an influence. ${ }^{[267]}$ For example, cells exposed to more positively charged surfaces display more neurite branching and growth cones. ${ }^{[240]}$ Bardi et al. coated MWCNTs with a surfactant (i.e., Pluronic F127) and successfully injected them into the cerebral cortices of mice without causing the degradation of resident neurons. They suggested the nanotubes have a protective effect by reducing the toxicity of the Pluronic F127. ${ }^{[268]}$ In order to permanently modify the electrode substrate, CNTs can be covalently functionalized with specified 
chemical groups. Malarkey et al. functionalized SWCNTs with polyethylene glycol (PEG) and assessed their toxicity using hippocampal neurons. ${ }^{[269]}$ Neurite extensions were fewer but longer when cultured on SWCNT-PEG. Functionalized MWCNTs with cell adhesion proteins such as GRGDSP from fibronectin and IKVAV from laminin were interfaced with tumor cells (Jurkat) and, most importantly, neurons (Figure 9e-h). ${ }^{[270]}$ There was no significant loss of cell viability upon incubation of Jurkat cells as compared with untreated cells and control peptides. The functionalized MWCNTs did not appear to alter the neuronal morphology, viability, and basic functions. Hippocampal neurons cultured in contact with modified MWCNTs showed spontaneous post-synaptic currents, membrane capacitance, and resistance (Figure 9f). ${ }^{[270]}$ The number of functional units also has an influence on the toxicity of CNTs. It was shown that as the degree of sidewall functionalization of CNTs increased, the toxicity of the CNTs decreased significantly. ${ }^{[271]}$

CNTs have been also investigated for differentiation of various types of progenitors and stems cells. ${ }^{[257,272-276]}$ Understanding how CNTs promote neuronal stem cell differentiation is valuable for a number of potential neural applications, including in vitro cell studies, neural electrode coatings, and nerve regenerations. Tay et al. suggested that the nanoscale morphology provided by CNTs might play a role in regulating differentiation of mesenchymal stem cells (MSCs). They cultured MSCs on functionalized SWCNTs in the absence of a specific differentiation medium. ${ }^{[277]}$ MSCs grew and proliferated on the SWNT films, and neurogenic markers were upregulated. In another study, the lithography technique was utilized to produce SWCNT patterns. The cell culture experiments revealed that that MSCs preferentially attach to the patterns, inducing cell spreading, increased elongation, and focal adhesion contacts along the pattern axis. ${ }^{[278]}$ Kotov and co-workers developed a layer-by-layer (LBL) assembly technique for the fabrication of SWCNTs and studied the differentiation of neural stem cells (NSCs) to neurons, astrocytes, and oligodendrocytes. ${ }^{\text {[241] }}$ LBL assembly can be used to produce film coatings with precise thicknesses on the order of nanometers. The interaction between the layers is through electrostatic charges produced by two oppositely charged polyelectrolytes. ${ }^{[279]}$ The differentiation of NSCs on a poly(ethyleneimine) (PEI)-functionalized SWCNT surface was compared with conventional poly(L-ornithine)-coated surface (Figure 10a). Neural processes developed on PLO-coated substrates remained longer than those developed on PEI/SWCNT-coated substrates; however, the differences were not very significant. (Figure 10b) The authors showed that there was no noticeable difference between the viability of neurospheres on PEI/SWCNTand PLO-coated substrates. The viability assessment indicated that PEI/SWCNT-coated substrates were as biocompatible as PLO-coated substrates in supporting neurosphere differentiation. Immunostaining results on PLO- and PEI/SWCNT-coated substrates were comparable (Figure 10c). Both PEI/SWCNT- and PLO-coated substrates supported differentiation of neurospheres into the three primary neural cell types: neurons, astrocytes, and oligodendrocytes (Figure 10d). ${ }^{[241]}$ Geith et al. used SWCNTs to simultaneously culture and electrically stimulate a neuroblastoma cell line. Their substrate to stimulate the neurophysiological activity of neuroblastoma cells was designed by using layer-by-layer deposition to create a SWCNT film between two electrode sites. Their electrophysiological measurements results indicated there is no difference between the electrical excitation of neurons when current is passed through the LBL coating and traditional neuronal excitation 
associated with the opening of classical voltage-gated cation channels. ${ }^{[239]}$ Taken together, the work explored here and other studies elucidate the importance of cell-CNT electrical interactions for the development of CNT base-nanomaterials for neural interfaces. ${ }^{[130]}$

5.2.2. Neural Recording and Stimulation-CNTs have excellent electrical conductivity, physical properties, and biocompatibility, which makes them a good candidate material for long-lasting brain machine interfaces. ${ }^{[24,127,226,227,280-289]}$ Recent studies have shown that CNTs are able to promote cell attachment, growth, and differentiation of neurons. ${ }^{[127,240,241,290]}$ CNTs have the ability to improve neural recording and stimulation of neural microelectrodes because of their low impedance and the high charge transfer of CNT interfaces. ${ }^{[28,29,127]}$ Prato and co-workers cultured hippocampal neurons on glass substrates modified with purified MWCNTs. ${ }^{[127]}$ The authors studied how neurons were able to reconstruct a functional network when integrated to non-functionalized MWCNTs. Cultured hippocampal neurons grew on a conductive MWCNTs mesh that supported dendrite elongation and cell adhesion. They reported that the frequency of spontaneous synaptic activity was significantly enhanced in comparison with control neurons grown on pure glass coverslips (controls) (Figure 10e and 10f). As shown in Figure 10g, neurons grown on MWCNT substrates exhibited a 4-fold increase in the frequency of spontaneous post-synaptic currents and a twofold higher frequency response of action potential, compared with the controls. The increase in the efficacy of the neural signal transmission may be related to the specific properties of CNTs, such as the high electrical conductivity and high effective surface area. They suggested that that the increase in the efficacy of neural signal transmission might be related to direct electronic current transfer and redistribution of charge along the surface of the cell membrane provided by the nanotubes. ${ }^{[127]}$

Keefer et al. enhanced the contact between an implanted neural electrode and the surrounding tissue using MWCNTs. ${ }^{[28]}$ The authors demosntrated that conventional MEAiridium oxide electrodes and tungsten and stainless-steel microelectrodes were able to be modified with MWCNTs using electrochemical techniques (Figure 11a). The electrical measurements of CNT-coated electrodes indicated decreased impedance (e.g., at a frequency of $1 \mathrm{kHz}$ from $940 \mathrm{k} \Omega$ to $38 \mathrm{k} \Omega$ for MEA electrodes), and an increase in charge transfer (e.g., approximately 40-fold for MEA electrodes) (Figure 11c and 11d). CNT-coated MEA electrodes were suitable for neuronal growth and were functional for at least three months, being stable under physiological conditions. The stimulation data confirmed that stimulus pulses that were passed through the CNT-coated electrodes were much more effective in evoking a neuronal response than stimuli introduced through the control electrodes. The in vivo recording of CNT-coated microwire electrodes in the motor cortex of anaesthetized rats and the visual cortex area of monkeys showed that the amplitude of CNT-coated electrode recording was increased compared with the control (Figure 11b). These results demonstrated that CNT-modified electrodes are robust, and have greatly decreased impedances, lower susceptibility to noise, enhanced the quality of recording signals, and increased ability to activate neurons when used for electrical stimulation. ${ }^{[28]}$

More recent work by Cellot et al. addressed the emergence of electrical shortcuts between CNTs and neuronal membranes (Figure 11e). ${ }^{[29]}$ The authors used single-cell 
electrophysiology techniques and electron microscopy analysis to demonstrate that CNTs improve the responsiveness of neurons by forming tight contacts with the cell membranes, which may create electrical shortcuts between the proximal and distal compartments of the neuron. Purified CNTs (both SWCNTs and MWCNTs) were deposited on glass substrates developing a thin film about 50-70 $\mathrm{nm}$. Rat hippocampal neurons cultured on CNT substrates showed the presence of a significant increase in synaptic activity, compared with control substrates (uncoated coverslips) (Figure 11f). Electrical recordings showed that neurons grown on CNT carpets were more prone to generating back-propagating action potentials, a neuronal regenerative property known to be involved in the regulation of local synaptic feedback and in the release of chemical messengers. Interestingly, they showed that CNT-induced modification of the dendritic electrogenic properties resulted in an increase in single-cell excitability. The authors proposed that CNTs are able to re-engineer neuronal integrative properties in vitro. In order to prove that CNTs can mediate their effects via the coexistence of both conductivity and nanostructure, the authors cultured neurons on materials different from CNTs, but presenting either comparable roughness or comparable electrical conductivity. Self-assembling peptide RADA 16 substrates were used to mimic the three-dimensional nanostructure of CNTs in the absence of electrical conductivity, and iridium oxide substrates to reproduce the conductivity in the absence of the threedimensional nanostructure of the CNTs. They successfully showed that, in both cases, these substrates were unable to replicate CNT effects on neuronal regenerative properties and excitability. ${ }^{[29]}$ In another study, Prato and co-workers used the micro-contact printing technique to deposit functionalized MWCNTs onto arrays of titanium nitride (TiN), creating CNT microelectrode arrays with well-defined electrical and morphological properties. ${ }^{[291]}$ To accomplish this task, polydimethylsiloxane (PDMS) stamps produced from microfabricated molds were used to transfer MWCNT films (Figure 11g and 11h). They showed that functionalized MWCNT microelectrodes exhibit electrochemical and structural properties favorable for both neural recording and electrochemical detection of neurotransmitters, such as dopamine. MWCNT-functionalized electrodes showed the ability

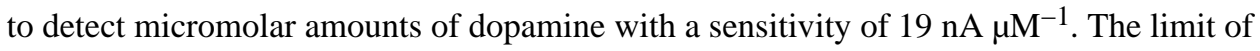
detection (LOD) of dopamine was $1 \mu \mathrm{M}$ for each MWCNT-coated electrode, compared with an LOD of $10 \mu \mathrm{m}$ at TiN electrodes. In addition, electrophysiological measurements from cultured hippocampal neurons showed that MWCNT microelectrodes had recording properties superior to those of commercial TiN microelectrodes under long-term cell-culture conditions (Figure 11i-k). [291]

\subsection{Graphene}

Silicon and metals have been frequently used in neuroprosthetic devices. ${ }^{[15,17,21,33,113,292-294]}$ However, there are some limitations in using them for biomedical applications, such as their poor stability in biological environments, relatively high electrical noise, and rigid mechanical properties, which damage the surrounding tissue. ${ }^{[71,295,296]}$ Several attempts have been made to find other potential materials and many researchers believe that graphene might be an excellent candidate based on its unique properties, including its electrical conductivity and mechanical stability. ${ }^{[297-303]}$ Graphene is a two-dimensional single-layer sheet of $\mathrm{sp}^{2}$-hybrid carbon atoms in a hexagonal arrangement. ${ }^{[304]}$ In the 1960 s, graphene research drastically increased, allowing researchers 
to understand the cause of the superior conductivity of graphite intercalation compounds and find suitable applications for the material. ${ }^{[305-307]}$ Graphene has several exceptional properties, including high elastic modulus (ca. 1.0 TPa), ${ }^{[308]}$ remarkable thermal conductivity $\left(3000 \mathrm{~W} \mathrm{~m}^{-1} \mathrm{~K}^{-1}\right),{ }^{[309]}$ high electron mobility $\left(200000 \mathrm{~cm}^{2} \mathrm{~V}^{-1} \mathrm{~s}^{-1}\right),{ }^{[310]}$ excellent electrical conductivity $\left(1 \mathrm{~S}^{-1}\right),{ }^{[309]}$ and low resistivity (ca. $10^{-6} \Omega$ ), as a substrate at room temperature. ${ }^{[311-313]}$ The possibility of easy functionalization and good biocompatibility make graphene suitable for biomedical applications. ${ }^{[306,307,311-318]}$ Graphene has a large specific surface area $\left(2630 \mathrm{~m}^{2} \mathrm{~g}^{-1}\right)^{[319,320]}$ and good chemical stability. ${ }^{[321]}$ These properties excite the scientific community to utilize graphene as an attractive complement to silicon for neural applications. This part of the report introduces the applications of graphene-based materials for neural interfaces.

5.3.1. Biocompatibility and Cell-Interaction-Two of the major concerns of using graphene for neural interfaces involves the biocompatibility of graphene and interactions between cells and graphene. Several groups have studied the biocompatibility and cytotoxicity of graphene in vitro in order to assess its potential for in vivo neural recording and stimulation. ${ }^{[322-325]}$ It has been demonstrated that polylysine-coated graphene films could serve as a good substrate for culturing mouse hippocampal neurons while promoting neurite sprouting and outgrowth during early developmental phases. ${ }^{[324]}$ Bendali et al. built a more realistic biocompatibility study by examining the survival and growth of adult primary retinal ganglion neurons from eight-week-old rats on glass and graphene-coated sapphire substrates. ${ }^{[322]}$ Chemical vapor deposition (CVD)-grown graphene was wettransferred to sapphire substrates. Both the substrates were coated with a peptide (poly(Dlysine) and laminin), which is useful for improving cellular attachment. Bare (non-peptidecoated) glass and graphene substrates were also prepared to evaluate the actual toxicity of a bottom substrate underneath the peptide coating without any coating-related masking effect. The toxicity test on bare substrates is especially meaningful for future long-term in vivo studies where coated peptides often dissolve away or degrade, leaving the bottom substrate intact. After their assessment on cell survival, cell body area, and total outgrowth of cultured neurons on all the prepared substrates, the authors confirmed that adult neurons could survive and grow well on bare graphene, as on bare glass, peptide-coated glass, or peptidecoated graphene substrates. As shown in Figure 12a, the regions on a sapphire substrate selectively-coated with graphene guided neurites to their edges. The authors explained this behavior by oxygen groups attached to the graphene edge. Oxygen groups are expected to render the graphene regions hydrophilic and result in improved cell adhesion and viability. ${ }^{[322,326]}$ With an increasing interest in utilizing stem cells for neural regeneration, Ning et al. made 3D graphene foams as a three-dimensional niche for neural stem cells (NSCs) (Figure 12b). ${ }^{[323]}$ NSCs cultured on graphene foams formed a good neural network and cell adhesion. As shown in Figure 12c, NSCs proliferated broadly and formed a strong interaction with the surface of a graphene-foam scaffold via the cell filopodia. These results demonstrated that $3 \mathrm{D}$ graphene-foam scaffolds are a promising material to significantly improve the differentiation of NSCs into neurons and astrocytes. ${ }^{[323]}$ Biris and co-workers found the concentration-dependent cytotoxicity of PC12 cells by MTT (3-[4,5dimethylythiazol-2-yl]-2,5 diphenyltetrazolium bromide) assay after exposing the cells to graphene for $24 \mathrm{~h}$. The authors compared the cytotoxicity effects of graphene and SWCNTs, 
which share almost identical chemical structure, with graphene. Their results indicated that, at low concentrations, graphene induced a more-intense toxic response than SWCNTs. As the concentration increases, the induced cytotoxic effects reverse, with graphene showing a lower activity. ${ }^{[325]}$ The authors proposed two different toxicity mechanisms for graphene and SWCNTs, related to the different shapes of these nanomaterials. The tubular shape of SWCNTs is expected to promote stronger interactions of SWCNTs with cellular systems. They also examined the effect of graphene on the morphology of PC12 cells: the cell membrane was intact after exposure to graphene, but some small graphene aggregates were bound on the surface of PC12 cells without damaging the cells. ${ }^{[325]}$

\subsubsection{Neural Recording/Stimulation and Neurochemical Detection-Obtaining} quantitative information of neuronal activity is one core task in neuroscience. ${ }^{[298]}$ Graphene has been used in cellular interfaces and electrical recording due to its appealing physicochemical properties. ${ }^{[297,299,306,317]}$ Hess et al. developed arrays of graphene-based solution-gated field-effect transistors (G-SGFETs) for the extracellular detection of electrical signals from cardiomyocyte-like HL-1 cells. Graphene was prepared by chemical vapor deposition (CVD) and transferred onto sapphire substrates (Figure 12d). ${ }^{[297]}$ The experimental measurements revealed that graphene SGFETs had low noise and large transconductive sensitivity. The effective gate noise can be derived from the measured noise power spectral density and the device transconductance. The gate noise was as low as 6.5 $\mu \mathrm{V}$ for graphene SGFETs, much lower than that for silicon-based SGFETs at the maximum transconductance (Figure 12e). Based on the measured gate noise, graphene SGFETs produced a SNR of 10, similar to that which has been reported as a state-of-the-art recording device based on microelectrode arrays. ${ }^{[297,327]}$ The authors suggested that a high SNR of graphene SGFETs resulted from the large interfacial capacitance of the graphene SGFETs and the high charge mobility of carriers in graphene. ${ }^{[297]}$

In order to reduce the mechanical mismatch between the graphene and the surrounding tissue and enhance the electrical conductivity of the hydrophobic graphene, ${ }^{2298,299]}$ integrated flexible graphene electrodes have been developed. ${ }^{[297,328]}$ Chen et al. designed a flexible, hydrophilic graphene microprobe to measure action potentials from the axons located in the abdominal nerve cord of crayfish (Figure 12f). ${ }^{[298]}$ Graphene-coated SU-8 substrates were treated by steam plasma to become hydrophilic. The steam plasma treatment decreased the average contact angle of the graphene surface from $91.1^{\circ} \pm 5.6^{\circ}$ to $41^{\circ} \pm 4.7^{\circ}$. They also found that the SNR of the action potentials measured using a hydrophilic graphene microprobe $(27.8 \pm 4.0)$ is greater than SNRs that using a hydrophobic graphene microprobe $(20.3 \pm 3.3)$ and a glass suction pipette $(19.5 \pm 4.0)$ under the same conditions (Figure 12g). ${ }^{[298]}$ The results clearly showed that graphene can be further used for in vivo long-term neural recording. Recently, Heo et al. fabricated a flexible, transparent, and noncytotoxic graphene and poly(ethylene terephthalate) stimulating electrode to provide noncontact stimulation to cultured human neuroblastoma cells with a specific strength, and allow optical examination of the cells' morphological changes in relation to stimulation. ${ }^{[329]}$ The results showed that stimulation with a weak electric field as low as $4.5 \mathrm{mV} \mathrm{mm}^{-1}$ promoted cell-to-cell coupling, whereas high electric field stimulation facilitated cell-to-cell decoupling. ${ }^{[329]}$ The authors identified the high field enhancement factor of a graphene 
layer, related to its small thickness, as a major cause for improved in vitro cell-to-cell coupling in a weak electric field. Electrical stimulation using graphene may become more effective than previous methods used for modulating cell couplings in cell transplantation therapy for different neurological disorders due to high conductivity and transmittance of graphene. ${ }^{[314,329-331]}$

Recent advances in electrochemical sensors focus on achieving improved sensor performance such as high selectivity and sensitivity, low detection limit, and good biocompatibility. ${ }^{[332-334]}$ As electrochemical oxidation and reduction reactions occur in close proximity to the electrode, finding the most effective electrode material has a significant impact on the performance of electrochemical biosensors. ${ }^{[332,335]}$ Graphene has been used as an electrode material for both non-enzymatic and enzymatic biosensors.

Typical graphene electrodes are designed by drop-casting pristine or $\mathrm{N}$-doped graphene on bare electrodes. Non-enzymatic sensing is based on measurement of the changes in electrical properties of graphene on interaction with an analyte while enzymatic sensing is based on a recognition molecule on the graphene-modified electrode that interacts with the analyte. ${ }^{[336-342]}$ Dopamine (DA) is an electroactive neurotransmitter, playing an important role in the CNS. ${ }^{[343,344]}$ The main challenge in the selective, electrochemical detection of DA is the interference from other electrochemically active materials, such as ascorbic acid (AA), whose concentration in the brain is 100-1000 times higher than that of DA and oxidation potential is very similar to that of DA. ${ }^{[345]}$ Graphene-based electrodes have been developed for detection of DA in the micromolar range in the presence of AA and uric acid (UA) via enzyme-free electrochemical biosensing. ${ }^{[346-350]}$ Dong and co-workers successfully utilized chemically reduced graphene oxide-modified glassy carbon (CRGO/GC) electrodes for detection of neurotransmitter DA and AA (Figure 12h-k). ${ }^{[351]}$ The authors showed that CR-GO/GC electrodes demonstrated more favorable electron transfer kinetics and higher DA sensitivity than graphite-modified glassy carbon (graphite/GC) and glassy carbon (GC) electrodes. With the applied potential of $0.45 \mathrm{~V}$, the relevant physiological levels $(0.2 \mathrm{mM})$ of AA and DA, show significant interference, respectively, to ethanol $(2 \mathrm{mM})$ detection, because the species would be oxidized below $0.35 \mathrm{~V}$ on the CRGO/GC electrode (Figure 12j and 12k). They suggested that coating a thin film of Nafion polymer as a preselective barrier would eliminate the interference. ${ }^{[351]}$ Wang et al. designed graphene-modified glassy carbon (GR/GC) electrodes that were applied in the selective determination of DA with a linear range from $5 \mu \mathrm{M}$ to $200 \mu \mathrm{M}$ in a large excess of AA. Chitosan (GC) was coated as preselective layer on the surface of GC to repel AA. Positively charged DA was more sensitive on GR-CS/GC whereas negatively charged AA was more inhibited. The authors used cyclic voltammetry to detect DA on GR-CS/GC, CS/GC and GC electrodes. The voltage was swept between $-0.1 \mathrm{~V}$ and $0.8 \mathrm{~V}$ at a scan rate $50 \mathrm{mV} \mathrm{s}^{-1}$. The observed well-defined and resolved voltammetric peaks for the direct oxidation of DA on GR-CS/GC compared with CS/GC or GC electrodes. ${ }^{[352]}$ Based on their findings, graphene-modified electrodes detect DA with much sharper and larger oxidation and reduction peaks than other components. A maximum surface-area-to-volume ratio and high density of edge-plane-like defective sites of graphene make it a more favorable material for a faster electron transfer for the oxidation of DA and AA. ${ }^{[346]}$ 


\subsection{Nanowires}

Microfabricated electrode arrays (MEAs), micropipette electrodes, and planar silicon field transistor arrays (FET) have been used for intracellular and extracellular recording of action potentials. ${ }^{[353-359]}$ MEAs are too bulky to detect neural activity at the level of individual axons, and dendrites and cannot produce as high an SNR as conventional micropipette electrodes. ${ }^{[360-362]}$ On the other hand, micropipette electrodes penetrate into cells for intracellular recording but they are difficult to multiplex. ${ }^{[363,364]}$ The aforementioned problems associated with MEAs and micropipette electrodes can be solved by planar FET arrays for large-scale mutiplexing. ${ }^{[353,358,365]}$ The local amplification of transistors eliminates the need for the weak signals to travel through long wires before being amplified. ${ }^{[360]}$ FETs can also record electric potentials inside cells and can be made much smaller than micropipettes and microelectrodes. ${ }^{[353,366]}$ These properties make FETs suitable for multiplexed measurements of neuronal activities. However, planar FET arrays have limited spatial and temporal resolution and relatively large sizes (ca. $10 \mu \mathrm{m}$ ), and their interelectrode spacing $(>10 \mu \mathrm{m}$ ), which has made recording and stimulation of neuronal activity at the level of individual axons and dendrites impossible. The planar shape also creates electrolyte layer between the neuron and transistor, which results in a large leakage of the potential signal. ${ }^{[360]}$ These deficiencies have prompted researchers to develop nanowire (NW) transistor arrays for recording and stimulating neuronal activity. ${ }^{[31,364,367-369]}$

In contrast to planar FETs, 2D and 3D nanowire field-effect transistors (NWFETs) exhibit improved sensitivity and SNR due to their high surface-to-volume ratio and smaller neuronNW electrode distance. ${ }^{[367,370-372]}$ The typical diameter of NWs is less than $50 \mathrm{~nm}$, and NWFET arrays can also be fabricated with several micrometers or less between the wires, which defines the spatial resolution. ${ }^{[360,367]} \mathrm{NW}$ hybrid junction sizes are about 0.01 to 0.02 $\mu \mathrm{m}^{2}$, about three orders of magnitude smaller than MEAs and planar FETs and similar to the size of natural synapses. ${ }^{[364]}$ The extremely small electrode size provides outstanding spatial resolution without the need of integrating and averaging multiple potential changes from axons and dendrites of a single neuron. ${ }^{[306,353,364,367]}$

5.4.1. Biocompatibility and Electrode-Tissue Interaction-NW toxicity studies are very important for in vivo neural application of these nanomaterials. In addition, the biocompatibility of NWs must also be studied for an unfavorable, but possible case when NWs detach from the substrate during or after neural implantation. ${ }^{[373,374]}$ Hällström et al. investigated the interaction between gallium phosphide nanowires (GaPNWs) and mouse dorsal root ganglia (DRG) cells. ${ }^{[375]}$ The authors reported three mechanisms for cell growth on the GaPNWs: cells grow either on top of, at the bottom of, or in between the GaPNWs, as shown in Figure 13a-c, respectively. Vertical GaPNWs could not only support cell adhesion and axonal outgrowth better than planar GaP substrates, but also penetrated the cellular membrane without damaging or killing the cells. ${ }^{\left[{ }^{[35]}\right.}$ Linsmeier et al. evaluated the biocompatibility of GaPNWs in the rat brain striatum. ${ }^{[370]}$ The GaPNWs were grown in a standard commercial metal organic vapor phase epitaxy reactor for $4 \mathrm{~min}$ at a working pressure of $10^{4} \mathrm{~Pa}$. The resulting single-crystalline GaPNWs had a diameter of $80 \mathrm{~nm}$ and a length of $2 \mu \mathrm{m}$, with low tapering and high vertical yield. The authors observed no 
noticeable difference in the neuronal fraction between the brain slices obtained from the GaPNWs implanted rats and the controls during 12-week implantation. They also reported no evidence of sub-acute or chronic toxicity of GaPNWs. The authors demonstrated that GaPNW implantation elicited a rather large astrocyte reaction during the first week; however, this activation declined over time. GaPNW-implantation also induced a microglial response, which declined over time. They successfully showed that neurons could grow on GaPNW substrates. ${ }^{[370]}$ Roth et al. reported that silicon-nanowire field-effect transistor (SiNW-FET) arrays along with poly(L-lysine) (PLL) patterning on the arrays could be used for the control of neuronal adhesion and growth, axo-dendritic polarity, and network connectivity. ${ }^{[376]}$ They showed that patterned PLL on top of the SiNW-FET could provide a high percentage of axons along the specific pathway (ca. 87\%), in comparison with controls. This high success of axonal control resulted in the fabrication of neuronal microcircuits of any geometry on the basis of an appropriate associa tion of these elementary patterns. The SiNW-FET devices containing 89 SINWs, $100 \mathrm{~nm}$ in width, and a few micrometers in length were fabricated. The SiNW-FETs were organized into specific arrays dedicated to the recording and stimulation of chain, triangle, or square neuronal networks. The PLL patterns were aligned on the SiNW-FET array using an optical photolithography method. Figure 13d shows an example of the precision in neurite positioning above a parallel array of SiNWFETs coated with PLL.

5.4.2. Intracellular and Extracellular Recordings-In order to provide more accurate information on signals travelling along the cell body and neuronal projections, effective contact between the neuron and the NWFET array must be accomplished. NWs can protrude from the substrate surface and form tighter junctions between a cell and the surface, which may improve cellular adhesion and NW/cell electrical coupling. ${ }^{[8,371,377-380]}$ Patolsky et al. developed 2D, high-yield, reproducible, and scalable SiNW-FET arrays with controllable multisite inputs to stimulate, detect, and inhibit neuronal signals of individual cultured mammalian neurons (Figure 13e and 13f). ${ }^{[364]}$ The SiNW-FET arrays (20 nm) were fabricated by: i) assembling oriented p- and/or n-type SiNWs; ii) patterning polylysine to direct the neurite growth along the NW array ensure successful neuron-NW electrical contact; and iii) providing growth factor for improved neuron cell growth. ${ }^{[364]}$ Both intracellular stimulation indicated by a red arrow in soma and extracellular NW-based stimulation indicated by a green arrow on NW1 could be produced with the developed SiNW-FET arrays (Figure 13e). The intracellular potential and conductance at the microelectrode and the NWFET were detected after stimulating either the cell body or the SiNW-axon contact with a glass microelectrode. By stimulating a NW (i.e., NW1 and NW6) and recording signal propagation detected by following the NWs for each dendrite and axon, they calculated signal propagation rates of $0.15 \pm 0.04$ and $0.46 \pm 0.06 \mathrm{~m} \mathrm{~s}^{-1}$ for dendrites and axons, respectively (Figure 13e). Simul taneous recording of signal propagation axons and dendrites was notably differentiated from previous studies using glass microelectrodes. ${ }^{[363,372,381-383]}$ Finally, a good alignment of neuronal growth was observed when 50 addressable NW devices were used as an array over an axon with a length of 500 $\mu \mathrm{m}$ although the specific polarity of growth was not controlled (Figure 13g). The authors also fabricated devices containing $150 \mathrm{NWs}$ with an interdevice distance of only $400 \mathrm{~nm}$ and successfully used this as a platform for directed neuronal growth. ${ }^{[364]}$ Qing et al. later made 
further advances on designing aligned SiNW arrays on transparent quartz substrates to investigate the functional connectivity in neuronal networks and image individual cell bodies at both upper and lower surfaces in acute brain slices. ${ }^{[367]}$ Their devices were able to access and identify different regions of the pyramidal cell layer and lateral olfactory tract on less than $10 \mu \mathrm{m}$ scale. NW devices showed signal amplitudes from 0.3 to $3.0 \mathrm{mV}$, which were higher than MEAs and planar FETs. The authors suggested that the nanomorphology might have contributed to better attachment of the active neurons, leading to a higher SNR. ${ }^{[367]}$ Using synaptic and ion-channel blockers during NW device sensing, the authors were able to assign potential signals to presynaptic firing and postsynaptic depolarization. The NW devices also had sub-millisecond temporal resolution, which helped in accurately mapping the fast communication of large populations of neurons. ${ }^{[367]} \mathrm{NW}$ probes are noninvasive and mechanically more compliant then other structures, causing minimum damage. ${ }^{[370]}$

Most nanoscale FETs are less invasive than metal-based microelectrodes, but it is difficult to use them for localized and 3D sensing of neuronal activities due to their planar shapes. In addition, they are still rigid and can physically harm the surrounding cells. Lieber and coworkers designed a device that has a $3 \mathrm{D}$, kinked nanoFET SiNW probe attached to a flexible SU-8 microribbon substrate used for intracellular recording. ${ }^{[384]}$ Figure $14 a-c$ show an 80 nm-diameter, doubly kinked SiNW with an intervening segment length $(L)$ of ca. $160 \mathrm{~nm}$ between the kink units. The authors varied the reactant pressure during the SiNW growth to control the cis-trans conformations between neighboring kink units. Applying multiple kinks produced an acute SiNW probe tip with a $60^{\circ}$ tip angle. During SiNW synthesis, they doped the SiNWs to integrate the source/drain connections and nanoscale FET channel on top of the SiNWs. A kinked nanoFET SiNW was then placed on an SU-8 substrate, which provided flexibility and support to the device. They used the interfacial stress between the materials to lift off the device from the substrate as a free-standing device. The probe height and angle could be controlled using the built-in stress in the free-standing part of the metal interconnects on SU-8 substrate. The $60^{\circ}$ acute angle of the free-standing device stayed intact even after all the fabrication steps. The authors measured the conductance versus reference potential of the kinked nanowire devices on SU-8 substrates to determine the device sensitivity (which ranged from 4 to $8 \mu \mathrm{S} \mathrm{V}^{-1}$ ). The conductance and sensitivity of the 3D nanoFET probes were studied at varying tip heights to demonstrate the feasibility of the probes for sensing soft and motile biological systems. The authors observed $<20 \mathrm{nS}$ conductance change for $\mathrm{a} \pm 10 \mu \mathrm{m}$ change in probe height, which is equivalent to $<0.31 \%$ fluctuation in the total device conductance. Repetitive bending also did not affect the FET performance of 3D nanoscale FET probes. 3D SiNW probes were able to detect voltage changes corresponding to changing $\mathrm{pH}$ levels, as small as $0.02 \mathrm{pH}$ units, in phosphate buffered saline (PBS). In addition, 3D nanoscale FET probes did not exhibit any change in their sensitivity in air up to 8 months. They then recorded intracellular potentials with the 3D nanoscale FET probes, modified with unilamellar vesicles of phospholipid bilayers (1,2dimyristoyl-sn-glycero-3-phosphocholine or DMPC) (Figure 14c and 14d). The phospholipid coating resulted in $<1 \%$ changes in both the nanoFET conductance and sensitivity. They monitored the potential change of phospholipid-coated nanoFET probe as a single HL-1 cell was brought into contact and away from the probe using a glass 
micropipette (Figure 14d). The intracellular potential was kept at $-50 \mathrm{mV}$ with a micropipette. After the probe was internalized in the cell, the potential of the phospholipidcoated nanoFET probe decreased from $0 \mathrm{mV}$ and was maintained at a relatively constant value of $-46 \mathrm{mV}$ during the internalization. When the cell was detached from the probe, the potential returned to $0 \mathrm{mV}$. NanoFET probes without a phospholipid coating did not show any noticeable change as the cell was moved into contact and then retracted (Figure 14d). Their results showed the potential of the nanoFET probe as a new tool to replace a traditional patch-clamp pipette with many advantages ${ }^{\left[{ }^{[34]}\right.}$ NanoFET probes provide simple electrical recording without the need for resistance compensation, less-invasive intracellular recording without any solution exchange with cells, and high spatial and temporal resolution for recording due to their ultrasmall size.

Due to difficulty in multiplexing kinked SiNWs, it is hard to monitor intracellular signals from a group of cells with a kinked nanoFET SiNW probe. Duan et al. built a branched intracellular nanotube FET (BIT-FET) by integrating $\mathrm{SiO}_{2}$ nanotubes on top of a nanoscale FET (Figure 14e and 14f). ${ }^{[385]}$ The authors created a branched intracellular nanotube FET (BIT-FET) combining a silicon nanowire FET detector and an electrically insulating $\mathrm{SiO}_{2}$ nanotube that connected the FET to the intracellular fluid (cytosol). The nanotube was built on top of the planar FET; thus the BIT-FET took full advantage of the high density of planar nanoFETs. ${ }^{[384]}$ To make the BIT-FET devices, a germanium nanowire branch was first grown from a gold nanodot on top of a silicon nanowire during the vapour-liquid-solid mechanism (Figure 14f). A germanium nanowire was used as a sacrificial template for the silicon nanotube. After defining source/drain (S/D) contacts on each side of germanium nanowires, a controlled-thickness $\mathrm{SiO}_{2}$ layer was deposited by atomic-layer deposition (ALD). The topmost part of the $\mathrm{SiO}_{2}$ shell was removed with buffered hydrofluoric acid to expose the germanium core. Then, the germanium nanowire was etched away to leave a hollow $\mathrm{SiO}_{2}$ nanotube on a silicon nanowire (Figure 14f). For the germanium nanowire with $50 \mathrm{~nm}$ diameter and the $\mathrm{SiO}_{2}$ with $50 \mathrm{~nm}$ thickness that were used, the very tip of the nanotube had an outer diameter of $55 \mathrm{~nm}$, which increased to a maximum of $150 \mathrm{~nm}$ at a distance of ca. $2.2 \mu \mathrm{m}$ from the tip. To study the effect of adding $\mathrm{SiO}_{2}$ nanotubes to the FET, two FET devices (a BIT-FET and a conventional FET) were fabricated on the same silicon nanowire. Based on conductance versus water gate-potential measurements for those two FET devices, and $\mathrm{SiO}_{2}$ nanotube after germanium removal the sensitivity of the BIT-FET increased from the initial value of $-170 \mathrm{nS} / \mathrm{V}$ to $-4530 \mathrm{nS} / \mathrm{V}$. This demonstrated that BITFET devices responded selectively and with high sensitivity to the solution inside the nanotubes rather than outside, which is beneficial for intracellular recording. For fast cellular recording, the authors characterized the temporal resolution of the BIT-FET device by applying a pulsed potential with a rise/fall time of $0.1 \mathrm{~ms}$, a duration of $1 \mathrm{~ms}$, and an amplitude of $100 \mathrm{mV}$. The BIT-FET could record potential changes with a time resolution of minimum $0.1 \mathrm{~ms}$. The authors used the BIT-FETs to record intracellular potentials from pulsing embryonic chicken cardiomyocyte cells. For effective internalization of the device in the cell, phospholipids were used to modify the $\mathrm{SiO}_{2}$ nanotubes. The cardiomyocyte cells cultured on thin pieces of polydimethylsiloxane (PDMS) were brought into contact with the $\mathrm{SiO}_{2}$ nanotube of a BIT-FET device. Before the transition to an intracellular signal, the signal exhibited a relatively flat baseline with small biphasic peaks that had amplitudes of 
ca. 5-8 $\mathrm{mV}$ in the duration of ca. $1 \mathrm{~ms}$, with a frequency of ca. $1 \mathrm{~Hz}$. These peaks coincide with cell breathing and are in agreement with previously reported extracellular recording. ${ }^{[371]}$ The baseline then drops to $-35 \mathrm{mV}$, and new peaks appear with an amplitude of 75-100 mV and a duration of ca. $200 \mathrm{~ms}$. These new peaks represented different phases of the cardiac intracellular action potentials, including initial depolarization, a plateau phase, rapid repolarization, hyperpolarization, and a return to the baseline. The smooth transition between extracellular and intracellular recordings and the stable signal quality during the intracellular recording indicate that the phospholipid fused on the $\mathrm{SiO}_{2}$ nanotube may have helped during the insertion of the BIT-FET into the cell. The insertion of the nanotube into the cell did not cause any cell death or degradation of the nanotube during the recording, which often occurs during intracellular recording with glass micropipettes. Interestingly, the authors found no blockage of the $\mathrm{SiO}_{2}$ nanotube during multiple intracellular recording cycles of the device. ${ }^{[353]}$ This work has the potential to be extended to a larger array with more nanowire FETs for multiplexed recording at a higher density.

Although previous examples represent major advances in cell-electrode coupling using SiNWs, these methods lack the scalability required to perform simultaneous measurements of multiple neurons. Recently, Park and co-workers developed vertical SiNW electrode arrays (VNEA) that could address this issue and were able to simultaneously stimulate and record multiple neurons. The electrode array consisted of: i) silicon substrates, so that each pad could be independently addressed; and ii) a $3 \times 3$ array of nine SiNWs (diameter: 150 $\mathrm{nm}$; length: $3 \mu \mathrm{m}$; pitch: $2 \mathrm{~mm}$ ) at the center of each recording and stimulation pad. Each nanowire was composed of a doped silicon core encapsulated by a silicon dioxide shell, and the tip of the nanowire was then covered with sputtered titanium/gold (Figure 14i).

Electrical contacts with each cell were established by the silicon core and metal tip. The silicon dioxide shell established a tight sealing to the cell membrane and prevented current leakage. The authors showed that VNEA could intracellularly record and stimulate neuronal activity in dissociated cultures of rat cortical neurons in parallel. As shown in Figure 14j, current pulses injected into neurons via the nanowires reliably evoked neuronal action potentials, as recorded by means of a simultaneous whole-cell patch clamp. Furthermore, the VNEA could be used to monitor individual action potentials evoked by the patch pipette. For single-unit recording, the SNR for VNEA recordings was typically 100 or greater (Figure 14j). When the authors averaged multiple waveforms obtained under identical experimental conditions, they were able to improve the SNR to $>1000$. These results suggested that the multiplexed stimulation and recording capabilities of the VNEA platform and its compatibility with conventional patchclamp and fluorescence microscopy techniques enable comprehensive examination of the functional connectivity in neuronal circuits beyond traditional connected-pair studies. Suyatin and co-workers developed a new type of neural electrode with vertical gallium phosphide nanowires (GaPNWs) and performed acute in vivo neural recordings in the rat cerebral cortex with their electrode (Figure 13h-j). The sensing part of the electrode was made of a gold metal film deposited on top of an array of vertically aligned GaPNWs with diameter of $70 \mathrm{~nm}$ and length of $5 \mu \mathrm{m}$ (Figure 13h). Hard GaPNWs are used as a backbone for metal nanostructured electrodes to provide excellent mechanical properties. Even after multiple times of implantation, a GaPNW electrode could withstand multiple rat pia mater and stay intact with only some tissue deposition observed 
on the surface of the electrode (Figure 13j). Multiple GapNWs were electrically connected underneath the insulating layer to reduce the electrode impedance. The GaPNW electrode showed comparable impedance to conventional metal microelectrodes with linear frequency dependence on a logarithmic scale. Neural recordings of stimulated intracortical field potentials were simultaneously performed with the GaPNW electrode and microwire electrode. With an easy control of the NW geometry, and spatial patterning with a high accuracy, the researchers plan to use the GaPNW-based electrode as a good platform to study the properties of nanostructured neural interfaces in vivo. Although there are still challenges in improving the sensitivity and spatial and temporal resolutions of the NW devices, previous work has clearly shown the potential of using the device for understanding neural circuitry and synaptic processing, which could eventually help reveal the secrets of the brain.

\subsection{Hybrid Nanomaterials}

As discussed earlier, the design and development of new materials that optimize neural interfaces with satisfactory sensitivity are great challenges in applying neural electrodes for neural recording and stimulation. ${ }^{[24]}$ Besides the modification of neural electrodes with a single electroactive material, such as CPs, CNTs, graphene or silicon NWs, researchers are also seeking composite materials for the purpose of reducing the mechanical mismatch at the neural tissue interface, increasing the stability and biocompatibility while maintaining the functionality of the electrode. ${ }^{[38,39,109,280,386-391]}$ Table 2 provides an overview of the published reports utilizing different hybrid materials for interfacing with the nervous system. An important polymeric material that is often utilized as a component of the composite materials is hydrogel (HG). HGs are a type of water-swollen, cross-linked (chemical crosslinking by covalent bonds or physical crosslinking by hydrogen bonds or strong Van der Waals interactions between the polymer chains) hydrophilic polymeric network. ${ }^{[39,172,392,393]}$ They have been widely used in tissue engineering and drug delivery because their water content and mechanical properties can be tailored to match the biological tissue. They have excellent diffusive properties for the release of growth factors,${ }^{[394]}$ anti-inflammatory drugs, ${ }^{[38]}$ and other molecules. ${ }^{[393]}$ For example, they can act as mechanical buffer zone between the hard silicon-based electrode (ca. $150 \mathrm{GPa}$ ) and the soft brain tissue (ca. $100 \mathrm{kPa}$ ). ${ }^{[109]} \mathrm{HG}$ scaffolds are attractive materials for altering the mechanical properties of neural probes and reducing tissue responses at the electrode-tissue interface. ${ }^{[388]}$

\subsubsection{Interpenetrating Polymer Networks (IPNs) of Hydrogels-An ionic} conductive composite HG containing two crosslinked polymers has been reported to

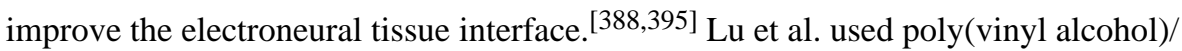
poly(acrylic acid) IPNs (PVA/PAA IPNs) to coat poly(dimethylsiloxane) (PDMS)-based neural electrodes. ${ }^{[388]}$ The water content of this IPNs gel can be tuned by changing the PAA composition. The electrochemical impedance spectroscopy (EIS) measurement showed that the impedance of the activated iridium oxide film (AIROF) microelectrode after coating with PVA/PAA IPNs films at $1 \mathrm{kHz}$ was slightly higher than that of the uncoated AIROFs microelectrode. Also, there was a decrease from ca. $55 \mathrm{mC} \mathrm{cm}^{-2}$ to ca. $48 \mathrm{mC} \mathrm{cm}^{-2}$ in terms of the charge storage capacity (CSC) after coating the AIROFs microelectrode with 
PVA/PAA IPN films. The reason was thought to be the lower ion-transfer rate in the film. PC12 cells were employed to study the neurite extensions on the PVA/PAA IPNs coatings and much better cytocompatibility was observed on the PVA/PAA IPNs coating than on PDMS. The glial fibrillary acidic protein (GFAP) immunoreactivity of the PDMS implants with PVA/PAA IPN-coating films in vivo was significantly lower than that of implants without coating. This work expanded the available stategies for neural electrode modification. ${ }^{[388]}$

5.5.2. Hydrogel/Conducting Polymer Composites-Although the surface mechanical requirement and reduction of tissue response can be met by using the HG IPN composite material described above, the ability to transmit electrical stimuli is weakened because the polymer cannot conduct electrons efficiently. ${ }^{[396]} \mathrm{HG} / \mathrm{CP}$ composites with the benefits of both CPs and HGs (also named semi-IPNs) are believed to be able to meet the essential design requirements of an ideal neural interface. ${ }^{[38,123,153,154,397]}$ Ppy has been successfully grown in an alginate gel, coating the microelectrode. ${ }^{[176,387]}$ EIS measurements showed that, at the biologically important frequency of $1 \mathrm{kHz}$, the minimum impedance of this Ppy-modified HG was $7 \mathrm{k} \Omega$. This is much lower than the minimum impedance of Ppy film (ca. $100 \mathrm{k} \Omega$ ). In other work, the PEDOT/alginate electrode was applied in the auditory cortex to test the neural recording quality. ${ }^{[123]}$ As the HG layer became thicker, both the recording functionality determined by the clearly detectable units and the average SNR decreased. However, the subsequent polymerization of PEDOT on the electrode sites recovered the lost functionality of the electrodes caused by the HG coatings that were $30 \mu \mathrm{m}$ in thickness. Unfortunately, the spatial distribution of the target neurons around the implanted electrode was affected and this led to low signal detection. Reswelling of the dehydrated HG composite would push away the recordable neurons from the electrode surface. ${ }^{[123]}$

To increase the surface area of HG-coated electrode, Abidian et al. modified microelectrodes with PEDOT nanotubes (NTs) and grew PEDOT in HG matrices (Figure 15a and 15b). ${ }^{[38]}$ According to EIS and cyclic voltammetry results, the combination of PEDOT NTs and PEDOT in the HG exhibited the minimum impedance and maximum charge storage capacity (Figure 15c). The impedance at $1 \mathrm{kHz}$ of the PEDOT NT $+\mathrm{HG}+$ PEDOT group was $2.5 \mathrm{k} \Omega$, which is significantly lower than that of bare gold electrodes $(783.3 \mathrm{k} \Omega$ ). On the other hand, the charge storage capacity increased significantly from 1.28 $\mathrm{mC} \mathrm{cm}{ }^{-2}$ (bare gold) to $223.8 \mathrm{mC} \mathrm{cm}^{-2}$ in the case of PEDOT NTs + HG + PEDOT. These promising results highlight the potential of using such soft and highly conductive material for neural prostheses. ${ }^{[38]}$ Green et al. provided a better method to evenly distribute PEDOT in heparin methacrylate (Hep-MA) HGs and claimed it to be a true hybrid material (Figure 14e). ${ }^{[39]}$ This hybrid increased the final charge storage capacity by $37 \%$ (from 46 up to 73 $\mathrm{mC} \mathrm{cm}{ }^{-2)}$ and decreased the impedance of the Pt electrodes from $500 \Omega$ to $75 \Omega$ at $100 \mathrm{~Hz}$. In addition, this conductive $\mathrm{HG}$ promoted neuronal cell interactions and cell growth (Figure 15d). This HG system was well suited for the incorporation of biomolecules to improve tissue-electrode interactions. So far, $\mathrm{CP} / \mathrm{HG}$ composites are more frequently used than the other HG-based composite materials described here for neural electrode modification to improve neural prostheses. ${ }^{[39]}$ 
5.5.3. Hydrogel/Carbon Nanotube Composites-It is known that chemically inert CNTs are more stable than CPs in terms of electroactivity in biological environments (CPs will lose their conductivity as they oxidize in water). ${ }^{[390]}$ With the trend of engineering 3D electrode interfaces, CNTs are also combined with HGs to produce a bioactive interface, reduce the reactive response, and promote long-term implantation. ${ }^{[386,391,398]}$ One example is a hybrid material between poly(ethylene glycol) diacrylate (PEGDA) and SWCNTs. ${ }^{[386]}$ The PEGDA macromers were covalently bonded to the gold substrate pretreated with cysteamine. The HG matrix was then formed by subsequent photopolymerization. This system possessed good electrochemical performance with the electron-transfer resistance $\left(R_{\mathrm{ct}}\right)$ decreasing from $428 \mathrm{k} \Omega$ (pure $\mathrm{HG}$ ) to $42.5 \mathrm{k} \Omega$ ((PEGDA)/SWCNTs). Another advantage of this biomimetic hybrid gel is its excellent adhesion property to electrodes, which is crucial for chronic implantation. Agarose/SWCNTs were also fabricated into conductive biohybrid nanocomposite fibers (Figure 15f). ${ }^{[398]}$ These hydrated fibers had not only mechanical properties that matched brain tissue, but also stable electrical conductivity $\left(135 \pm 55 \mathrm{~S} \mathrm{~cm}^{-1}\right)$. The in vivo biocompatibility evaluation (Figure $\left.15 \mathrm{~g}\right)$ revealed that the resulting extent of glia extension was quite close to that of other biocompatible materials such as silicon. This hybrid is promising in the biointerfacing area. ${ }^{[398]}$

5.5.4. Hydrogel/Graphene Composites-Since the biocompatibility of graphene and HG toward neuron cells has been confirmed, ${ }^{[172,399]}$ some preliminary research has applied graphene/HG composites in drug delivery, ${ }^{[400,401]}$ neural tissue engineering ${ }^{[402]}$ and biosensing ${ }^{[403]}$ applications. A strategy of making a graphene-poly $(\mathrm{N}, \mathrm{N}-$ dimethylacrylamide) (PDMAA) cross-linking structure based on graphene networks was reported by Hou et al. ${ }^{[402]}$ Compared with gold, whose impedance was $0.8 \mathrm{M} \Omega$ at $1 \mathrm{kHz}$, and modified Ppy and PEDOT films, with impedances of 15 and $130 \mathrm{k} \Omega$, respectively, the graphene/PDMAA HGs had a much lower impedance value of $1.3 \mathrm{k} \Omega$. The low impedance resulted in effective transition between ionic and electronic current flows. The PC12 cell line was used as model to characterize the neuronnal biocompatibility with the composite. The results supported that the graphene/PDMAA HGs had good biocompatibility, and neuron cells attached well on the graphene PDMAA HG substrates.

5.5.5. Conducting Polymer/Carbon Nanotube Composites- $\mathrm{CP} / \mathrm{CNT}$ composites are also helpful for increasing electron transfer ability. ${ }^{[404]}$ Typical existing CP/CNT composites are PEDOT/MWCNTs, ${ }^{[405]}$ Ppy/SWCNTs, ${ }^{[280]}$ Ppy/MWCNTs, ${ }^{[406]}$ and PANI/ SWCNTs. ${ }^{[407]}$ For Ppy/SWCNTs homogeneous hybrid films, it was reported that the safe charge injection $\left(Q_{\text {inj }}\right)$ limit could be increased to ca. $7.5 \mathrm{mC} \mathrm{cm}^{-2}$ while pure Pt electrode had only $0.2 \mathrm{mC} \mathrm{cm}^{-2 .[280]} \mathrm{Ppy} / \mathrm{SWCNTs}$ have been proved to be more efficient in supporting PC12 cell growth (Figure 16a) and to induce a significantly lower tissue response (Figure 16b and 16c). These features are beneficial for chronic implantable neural probes. A multilayered structure of Ppy/MWCNTs was reported by Chen et al. ${ }^{[406]}$ Multilayered Ppy/ MWCNTs fabricated the by layer-by-layer (LBL) method (Figure 16d) had a charge storage capacity 660 times higher than that of a bare Au electrode (Figure 16e). After 500 cycles of CV scan, the charge storage capacity loss of Ppy/MWCNT electrode was $20 \%$. In the dendrite extension study, the PC12 cells grown on the LBL Ppy/MWCNTs showed a larger average neurite length than the CO-poly group (film of MWCNTs, Ppy mixture made by 
electrochemical polymerization) and the mPpy group (Ppy film prepared by electrochemical polymerization) (Figure 16f). For a PEDOT/MWCNT film-coated electrode, the $Q_{\text {inj }}$ value was reported to be $6.2 \mathrm{mC} \mathrm{cm}^{-2 .[404]}$ However, the PEDOT/MWCNTs film was more prone to delaminating compared with Ppy/MWCNT; thus, its mechanical properties need enhancement for long term use.

\subsubsection{Graphene/Conducting Polymer and Graphene/Carbon Nanotube}

Composites-Graphene-based composites are usually produced by the reduction of graphene oxide (GO). ${ }^{[389,408-412]}$ Ppy/GO composites have been made based on their electrostatic interaction. For neural interface applications, the surface features of the neural probe and the electrical properties of the Ppy/GO composites (Figure 16g) have been investigated. ${ }^{[408]}$ The low impedance of Ppy/GO $(26 \mathrm{k} \Omega$ ) was thought to be due to the increased roughness of the Ppy/GO film. The impedance also decreased as the deposition charge density was raised. Also, the charge transport ability of this composite increased when the GO composition was raised (from $0.94 \mathrm{mC} \mathrm{cm}^{-2}$ for bare Pt electrode to 278.83 $\mathrm{mC} \mathrm{cm}{ }^{-2}$ for Ppy/GO (coating)). The reason was considered to be the increased $\pi-\pi$ stacking between the Ppy and the GO. The morphology of the Ppy/GO coatings was related to the GO content in the electrolyte and the applied charge density (Figure 16h). In another study, PEDOT/GO film demonstrated its advantages over a control PEDOT/PSS film in its cytotoxicity and effect on neuron outgrowth. ${ }^{[389]}$ Subsequently, functionalized PEDOT/GO film with laminin peptide on the surface of PEDOT/GO enhanced neuron growth. As for graphene/ CNTs (Figure 16i-k), the integration of the high longitudinal conductivity of the CNTs and the unique surface charge density of graphitic foliates endowed this composite higher capacitive properties and charge storage ability. ${ }^{[412]}$ Table 2 lists the composite materials for neural interfaces reported in recent years.

\section{Summary: Challenges, Opportunities, and Outlook}

Large-scale recordings from neurons reveal the information available from the interaction of the neuronal ensembles. In addition, recording from a large number of neurons will reduce the number of animals and their maintenance cost. Massive parallel recording from multiple single neurons requires high-density neural electrode arrays. ${ }^{[16]}$ While microwire arrays can record the neuronal activities from large number of neurons, ${ }^{[413,414]}$ because of the massive tissue replacement by microwire arrays, monitoring a large number of neurons using these electrodes increases tissue damage. An ideal recording electrode has a small volume to minimize tissue damage, a large number of recording sites to monitor multiple single neurons, and small surface geometry recording sites to increase the selectivity to individual neurons. However, these competing requirements are difficult to achieve using microwire technology. Single shank micromachined silicone electrode arrays can solve the technical limitations of microwire electrodes since with the same amount of tissue displacement; the number of small recording site can be substantially increased for large-scale and sensitive recordings. ${ }^{[3]}$ The chronic performance of neural electrodes in neuroprosthetic devices depends on the physical, chemical, mechanical, and electrical properties of the electrodetissue interface. An ideal neural interface should have the following material design criteria: i) stable electrical properties, including low impedance, and stable conducting and insulating properties to enhance the SNR of signal recording and suppress tissue damage during neural 
stimulation; ii) appropriate mechanical properties such as softness and flexibility to minimize the mechanical trauma during electrode insertion and brain micromotion; and iii) acceptable chemical and physical properties to promote the biocompatibility of the electrode-tissue interface. ${ }^{[24,158]}$

\subsection{Biocompatibility of Materials}

The failure of chronic neural implants has been linked to the biocompatibility of the interface, which induces a foreign body response of the neural tissue to the implanted electrodes. The biocompatibility of the interface ultimately rests on the specifics of the material properties (i.e., the physical, chemical, electrical and mechanical properties), and enables a long-lasting functional interface. An immense amount of effort has been made in development of neural interfaces that relieve local inflammation induced by the electrode implantation, a major contributor in the failure of neural probes. The majority of previous studies have suggested that the chemical, physical, and mechanical properties of implanted electrodes are important factors for suppressing chronic tissue encapsulation. ${ }^{[1,18,101]}$ The electrode size, electrode tip shape, cross-sectional area, and surface roughness have all been modified to elicit minimum tissue responses. ${ }^{[1,18,19,68,101]}$ However, studies by Szarowski et al. demonstrate that while these properties can control the initial wound-healing response, the chronic formation of glial scarring is not prevented. ${ }^{[19]}$ A number of groups has shown that roughening of surface of neural electrodes using laser pattering, electroplating of metals, or conducting polymers can not only improve the electrical properties, but also encourage neuronal cell attachments through mimicking ECM morphologies. ${ }^{[57,180,415]}$ Furthermore, development of neural probes that are more biologically transparent to tissue and have subcellular structures can significantly enhance the biocompatibility of the interface and reduce encapsulation. ${ }^{[113,416]}$ To improve tissue-electrode interactions and minimize the chronic response, multiple material-based strategies have been implemented to control the molecular and cellular aspects of the immune response and prevent electrode failure. ${ }^{[18,60,97]}$ One approach to modulate the inflammatory response and achieve better integration of the neural probes with brain tissue is the chemical modification of neural probe surfaces with antiinflammatory compounds, adhesion proteins, or bioactive molecules. ${ }^{[41,71,93,113-118]}$ The chemical modifications also include biological modifications such as coating with hyaluronic acid, peptides, polysaccharides, and neurotrophins ${ }^{[93,119-121]}$ and non-biological modifications, such as hydrogels, ${ }^{[121,122,124]}$ conducting polymers, ${ }^{[52,96,125,126]}$ and carbon nanotubes. ${ }^{[127-130]}$ The design and development of new materials that generate seamless neural interfaces with a high degree of sensitivity is a great challenge in applying neural electrodes for recording neural activity both in vitro and in vivo. Maintaining a high degree of electrode sensitivity is essential, especially when measuring single-unit action potentials with signals on the order of microvolts. Long-term stability is another challenge that has motivated the design of novel materials.

\subsection{Electrical Properties}

Signal transduction, impedance, and long-term electrical stability of neural electrodes should be considered during neural recording and stimulation. Tissue conducts bioelectric signals by ions, whereas metals conduct charge by electrons. Therefore, signal transduction at the 
electrode-tissue interface is a conversion of ions to electrons or vice versa, depending on the applications. Transduction between the ionically conducting tissue and the electronically conducting electrode is primarily through capacitive currents and/or Faradaic currents from reversible reduction-oxidation reactions at the electrode surface. ${ }^{[214]}$ Development of new material coatings that facilitate ion-electron signal transduction is essential for the longterm electrical stability of neural electrodes. CPs are attractive for the material coating of neural electrodes as they have both ionic and electronic conductivity. ${ }^{[148]} \mathrm{CPs}$ are able to mediate transfer charge from the underlying metallic electrode to the surrounding tissues by movement of ions into or out of CPs. These ions are available either in the $\mathrm{CP}$ as a dopant or extracellular fluid. A potential challenge is the toxicity of a mobile dopant to the surrounding tissue; therefore, the selection of small dopants must be carefully considered. Large dopants such PSS may prevent this issue as they will be immobilized within the CP structure. ${ }^{[202,206]}$ Achieving a very low impedance electrode-tissue interface is important for maintaining and improving signal quality for both recording and stimulation. ${ }^{[217]}$ Neural microelectrodes often exhibit high initial electrode impedance because of their small surface area. As the electrode size goes to the micro- and nanoscale for higher selectivity, the impedance of electrode site dramatically increases, and consequently, the quality of signal recordings decreases. Thus, there is a trade off between the size (selectivity) and quality of recordings (sensitivity) in neural microelectrodes. Several studies have been conducted to explore strategies to decrease the initial impedance of electrode sites. These strategies include: employing metals ${ }^{[35]}$ and metal oxides, ${ }^{[217]}$ and applying bias voltage pulses. ${ }^{[417]}$

Conductive nanomaterials are able to significantly reduce the impedance of microelectrodes by creating an enormous effective surface area at the electrode-tissue interface. In addition nanostructured materials can alter the structure and function of microelectrodes to reconcile the conflicting requirements for smaller size, favorable electrical characteristics, and biocompatibility.

\subsection{Mechanical Stability}

Microfabricated silicon electrodes such as Utah array and Michigan electrodes have been widely used for neural prosthetic devices. ${ }^{[418,419]}$ These microelectrodes are mechanically stable because they are non-reactive in a biological environment. However, these stiff silicon-based neural electrodes create mechanical trauma on insertion that initiates an inflammatory response. Moreover, the mechanical mismatch between the rigid electrode and the soft tissue results in tissue damage if micromotion of the electrode occurs. ${ }^{[18,420]}$ Thus, a key technical challenge of rigid electrodes is the mechanical mismatch between the compliant brain tissue and the electrode substrate. While flexible polyimide and parylene electrodes may improve this issue, ${ }^{[421]}$ the electrodes were not stiff enough to pierce brain tissue on their own and these constructs are difficult to place into the neural tissue. ${ }^{[422]}$ Ultrathin surface microelectrodes with a thickness of $<10 \mu \mathrm{m}$ have been mechanically supported by a $5-15 \mu \mathrm{m}$ layer of bioresobable silk, to be able to effectively manipulate flexible neural probes for processing and implanting into brain tissue. ${ }^{[94]}$ Dissolvable and degradable polymers can be utilized for the next generation of penetrating microelectrodes. Rigid silicon-based electrodes have an elastic modulus of ca. $150 \mathrm{GPa}$. Whereas flexible electrode arrays have a significantly lower stiffness of ca. $5 \mathrm{GPa}$, an optimal neural electrode will have an elastic modulus close to that of neural tissue (ca. $100 \mathrm{kPa}) \cdot{ }^{[423]}$ Hydrogels can 
provide an ultrasoft intermediate layer between the flexible electrode and the surrounding tissue. Hydrogels have elastic modulus close to neural tissue, which can be tunable by the crosslink density. ${ }^{[424]}$ Hydrogel tubes of poly(2-hydroxyethyl methacrylate-co-methyl methacrylate) (p(HEMA-co-MMA) have been produced with elastic moduli up to $400 \mathrm{kPa}$, for interfacing with the peripheral nerve. These tubes therefore had similar mechanical properties to those of the spinal cord, which has a reported elastic modulus range between 200 and $600 \mathrm{kPa} \cdot{ }^{[425]}$ Ionically cross-linked alginate is a good supporting material for flexible penetrating electrodes because they: i) have an elastic modulus of $10-150 \mathrm{kPa}$; ii) are easy to fabricate; iii) are biocompatible and biodegradable; and iv) facilitate electrode insertion by dehydration before the insertion. ${ }^{[426]}$ The biocompatible and biodegradable nature of alginate gel is ideal for interfacing, as it eliminates microinjuries and minimizes mechanical mismatch. ${ }^{[38]}$ However, they move the electrode away from the target cells after swelling in tissue. Research groups have developed methods to reconnect the neurons with the electrode site by growing CPs within the hydrogel. ${ }^{[38,39,153]}$ Anti-inflammatory drugs and neurotrophic factors can be incorporated into the hydrogel ${ }^{[38]}$ and $\mathrm{CPs}^{[36]}$ to reduce the inflammatory response, attract the neural processes toward the electrodes, and promote neuronal survival. ${ }^{[37]}$

The current state of neural prosthetic devices clearly indicates significant advances in materials science approaches have taken place over the last several years. These strategies include: i) optimizing the size, shape, tip geometry, texture, flexible substrate, and biodegradable coating to minimize initial trauma and micromotion damage to the brain; ii) employing metals, metal oxides, conducting polymers, carbon nanotubes, silicon nanowires, graphene, and composites to decrease the initial impedance of the electrode; iii) applying bioactive coatings such as neurotrophins to enhance the growth of neuronal processes and the systemic or local delivery of anti-inflammatory drugs to reduce the reactive tissue response and gliosis. Therefore, with material considerations as the central theme, researchers should explore new methodologies for developing a viable interface with longterm functionality in the near future. Ideally, a neural electrode should be integrated in the tissue as a compliant flexible material resulting in minimal disturbance to the tissue. The electrode should also provide side branches in the form of flexible soft nanoscale leaflets to reach a larger number of neurons to interpenetrate the tissue much better. Manufacture of these interfaces is limited to the physical and chemical properties of the available materials. Development of new hybrid nanomaterials that are capable of extending side branches after implantation and incorporating neuronal stems cells for integration with neural tissue will help for the design of seamless neural interfaces.

\section{Acknowledgments}

This work was supported by the Material Research Institute and start-up funds at Pennsylvania State University.

\section{References}

1. Nicolelis MA. Nat Rev Neurosci. 2003; 4:417. [PubMed: 12728268]

2. Schwartz AB, Cui XT, Weber DJ, Moran DW. Neuron. 2006; 52:205. [PubMed: 17015237]

3. Kipke DR, Shain W, Buzsaki G, Fetz E, Henderson JM, Hetke JF, Schalk G. J Neurosci. 2008; 28:11830. [PubMed: 19005048] 
4. Hatsopoulos NG, Donoghue JP. Annu Rev Neurosci. 2009; 32:249. [PubMed: 19400719]

5. Marg E, Adams JE. Electroencephalography and Clin Neurophysiol. 1967; 23:277.

6. Evarts EV. J Neurophysiol. 1966; 29:1011. [PubMed: 4961643]

7. Wolpaw JR, Birbaumer N, McFarland DJ, Pfurtscheller G, Vaughan TM. Clin Neurophysiol. 2002; 113:767. [PubMed: 12048038]

8. Lebedev MA, Nicolelis MAL. Trends Neurosci. 2006; 29:536. [PubMed: 16859758]

9. Wolpaw JR, McFarland DJ. Proc Natl Acad Sci USA. 2004; 101:17849. [PubMed: 15585584]

10. Benabid AL, Chabardes S, Mitrofanis J, Pollak P. Lancet Neurol. 2009; 8:67. [PubMed: 19081516]

11. Velliste M, Perel S, Spalding MC, Whitford AS, Schwartz AB. Nature. 2008; 453:1098. [PubMed: 18509337]

12. Taylor DM, Tillery SIH, Schwartz AB. Science. 2002; 296:1829. [PubMed: 12052948]

13. Hochberg LR, Bacher D, Jarosiewicz B, Masse NY, Simeral JD, Vogel J, Haddadin S, Liu J, Cash SS, van der Smagt P, Donoghue JP. Nature. 2012; 485:372. [PubMed: 22596161]

14. Wise KD. IEEE Eng Med Biol Mag. 2005; 24:22. [PubMed: 16248114]

15. Rousche PJ, Normann RA. J Neurosci Methods. 1998; 82:1. [PubMed: 10223510]

16. Buzsaki G. Nat Neurosci. 2004; 7:446. [PubMed: 15114356]

17. Vetter RJ, Williams JC, Hetke JF, Nunamaker EA, Kipke DR. IEEE Trans Biomed Eng. 2004; 51:896. [PubMed: 15188856]

18. Polikov VS, Tresco PA, Reichert WM. J Neurosci Methods. 2005; 148:1. [PubMed: 16198003]

19. Szarowski DH, Andersen MD, Retterer S, Spence AJ, Isaacson M, Craighead HG, Turner JN, Shain W. Brain Res. 2003; 983:23. [PubMed: 12914963]

20. Serruya MD, Hatsopoulos NG, Paninski L, Fellows MR, Donoghue JP. Nature. 2002; 416:141. [PubMed: 11894084]

21. Kipke DR, Vetter RJ, Williams JC, Hetke JF. IEEE Trans Neural Syst Rehabil Eng. 2003; 11:151. [PubMed: 12899260]

22. Nicolelis MAL. Proc Natl Acad Sci USA. 2003; 100:11041. [PubMed: 12960378]

23. Wallace GG, Spinks GM. Chem Eng Prog. 2007; 103:S18.

24. Kotov NA, Winter JO, Clements IP, Jan E, Timko BP, Campidelli S, Pathak S, Mazzatenta A, Lieber CM, Prato M, Bellamkonda RV, Silva GA, Kam NWS, Patolsky F, Ballerini L. Adv Mater. 2009; 21:3970.

25. Green RA, Lovell NH, Wallace GG, Poole-Warren LA. Biomaterials. 2008; 29:3393. [PubMed: 18501423]

26. Silva GA. Nat Rev Neurosci. 2006; 7:65. [PubMed: 16371951]

27. Abidian MR, Wee ATS, Malliaras GG. J Mater Chem B. 2013; 1:3727.

28. Keefer EW, Botterman BR, Romero MI, Rossi AF, Gross GW. Nat Nanotechnol. 2008; 3:434. [PubMed: 18654569]

29. Cellot G, Cilia E, Cipollone S, Rancic V, Sucapane A, Giordani S, Gambazzi L, Markram H, Grandolfo M, Scaini D, Gelain F, Casalis L, Prato M, Giugliano M, Ballerini L. Nat Nanotechnol. 2009; 4:126. [PubMed: 19197316]

30. Patolsky F, Timko BP, Yu G, Fang Y, Greytak AB, Zheng G, Lieber CM. Science. 2006; 313:1100. [PubMed: 16931757]

31. Suyatin DB, Wallman L, Thelin J, Prinz CN, Jorntell H, Samuelson L, Montelius L, Schouenborg J. Plos One. 2013; 8:e56673. [PubMed: 23431387]

32. Abidian MR, Ludwig KA, Marzullo TC, Martin DC, Kipke DR. Adv Mater. 2009; 21:3764.

33. Cogan SF. Annu Rev Biomed Eng. 2008; 10:275. [PubMed: 18429704]

34. Turner JN, Shain W, Szarowski DH, Andersen M, Martins S, Isaacson M, Craighead H. Exp Neurol. 1999; 156:33. [PubMed: 10192775]

35. Cui XY, Wiler J, Dzaman M, Altschuler RA, Martin DC. Biomaterials. 2003; 24:777. [PubMed: 12485796]

36. Green RA, Lovell NH, Poole-Warren LA. Acta Biomater. 2010; 6:63. [PubMed: 19563922]

37. Yue Z, Moulton SE, Cook M, O’Leary S, Wallace GG. Adv Drug Delivery Rev. 2013; 65:559. 
38. Abidian MR, Martin DC. Adv Funct Mater. 2009; 19:573.

39. Green RA, Hassarati RT, Goding JA, Baek S, Lovell NH, Martens PJ, Poole-Warren LA. Macromol Biosci. 2012; 12:494. [PubMed: 22344960]

40. Wise KD. Proc IEEE. 2008; 96:1184.

41. Grill WM, Norman SE, Bellamkonda RV. Annu Rev Biomed Eng. 2009; 11:1. [PubMed: 19400710]

42. Mountcastle VB. J Neurophysiol. 1957; 20:408. [PubMed: 13439410]

43. Rosenthal F. Brain Res. 1972; 36:251. [PubMed: 5009638]

44. Rall W. Biophys J. 1962; 2:145. [PubMed: 14490040]

45. Henze DA, Borhegyi Z, Csicsvari J, Mamiya A, Harris KD, Buzsaki G. J Neurophysiol. 2000; 84:390. [PubMed: 10899213]

46. Bellamkonda RV, Zhong Y. J R Soc Interface. 2008; 5:957. [PubMed: 18477539]

47. McConnell GC, Rees HD, Levey AI, Gutekunst C-A, Gross RE, Bellamkonda RV. J Neural Eng. 2009; 6:056003. [PubMed: 19700815]

48. Schwartz AB. Annu Rev Neurosci. 2004; 27:487. [PubMed: 15217341]

49. Schwartz AB, Kipke DW, Perepelkin PD. Smart Structures and Materials 1996: Smart Sensing, Processing, and Instrumentation. 1996; 2718:530.

50. Lagoa CE, Bartels J, Baratt A, Tseng G, Clermont G, Fink MP, Billiar TR, Vodovotz Y. Shock. 2006; 26:592. [PubMed: 17117135]

51. Leach JB, Achyuta AK, Murthy SK. Front Neuroeng. 2010; 2:18. [PubMed: 20161810]

52. Ludwig KA, Uram JD, Yang J, Martin DC, Kipke DR. J Neural Eng. 2006; 3:59. [PubMed: 16510943]

53. Biran R, Martin DC, Tresco PA. Exp Neurol. 2005; 195:115. [PubMed: 16045910]

54. Schmidt S, Horch K, Normann R. J Biomed Mater Res. 1993; 27:1393. [PubMed: 8263001]

55. Fournier E, Passirani C, Montero-Menei CN, Benoit JP. Biomaterials. 2003; 24:3311. [PubMed: 12763459]

56. Liu B, Hong JS. J Pharmacol Exp Ther. 2003; 304:1. [PubMed: 12490568]

57. Abidian MR, Corey JM, Kipke DR, Martin DC. Small. 2010; 6:421. [PubMed: 20077424]

58. Anderson JM. Annu Rev Mater Res. 2001; 31:81.

59. Rothschild RM. Front Neuroeng. 2010; 3

60. Bellamkonda RV, Pai SB, Renaud P. MRS Bull. 2012; 37:557.

61. Saadoun S, Papadopoulos MC, Watanabe H, Yan D, Manley GT, Verkman AS. J Cell Sci. 2005; 118:5691. [PubMed: 16303850]

62. Yoshida S, Yoshida A, Ishibashi T, Elner SG, Elner VM. J Leuko cyte Biol. 2003; 73:137.

63. Takeuchi A, Miyaishi O, Kiuchi K, Isobe K. J Neurosci Res. 2001; 65:38. [PubMed: 11433427]

64. Stensaas SS, Stensaas LJ. Acta Neuropathol. 1976; 35:187. [PubMed: 782142]

65. Mofid MM, Thompson RC, Pardo CA, Manson PN, Vander Kolk CA. Plast Reconstr Surg. 1997; 100:14. [PubMed: 9207654]

66. Winn SR, Aebischer P, Galletti PM, Biomed J. Mater Res. 1989; 23:31.

67. He, W.; Bellamkonda, RV. Indwelling Neural Implants: Strategies for Contending with the In Vivo Environment. Reichert, WM., editor. CRC Press; Boca Raton, FL, USA: 2008.

68. Edell DJ, Toi VV, McNeil VM, Clark LD. IEEE Trans Biomed Eng. 1992; 39:635. [PubMed: 1601445]

69. Maynard EM, Hatsopoulos NG, Ojakangas CL, Acuna BD, Sanes JN, Normann RA, Donoghue JP. J Neurosci. 1999; 19:8083. [PubMed: 10479708]

70. Biran R, Martin DC, Tresco PA. J Biomed Mater Res A. 2007; 82A:169. [PubMed: 17266019]

71. Moxon KA, Hallman S, Aslani A, Kalkhoran NM, Lelkes PI. J Biomater Sci, Polym Ed. 2007; 18:1263. [PubMed: 17939885]

72. Rao SS, Winter JO. Front Neuroeng. 2009; 2:6. [PubMed: 19668707]

73. Garde K, Keefer E, Botterman B, Galvan P, Romero MI. Front Neuroengin. 2009; 2:5. 
74. Shoval A, Adams C, David-Pur M, Shein M, Hanein Y, Sernagor E. Front Neuroeng. 2009; 2:4. [PubMed: 19430595]

75. Schultz RL, Willey TJ. J Neurocytol. 1976; 5:621. [PubMed: 1003257]

76. Liu X, McCreery DB, Carter RR, Bullara LA, Yuen TG, Agnew WF. IEEE Trans Rehabil Eng. 1999; 7:315. [PubMed: 10498377]

77. Roitbak T, Sykova E. Glia. 1999; 28:40. [PubMed: 10498821]

78. Fawcett JW, Asher RA. Brain Res Bull. 1999; 49:377. [PubMed: 10483914]

79. Stichel CC, Muller HW. Cell Tissue Res. 1998; 294:1. [PubMed: 9724451]

80. Bovolenta P, Fernaud-Espinosa I. Prog Neurobiol. 2000; 61:113. [PubMed: 10704995]

81. Kubler A, Nijboer F, Mellinger J, Vaughan TM, Pawelzik H, Schalk G, McFarland DJ, Birbaumer N, Wolpaw JR. Neurology. 2005; 64:1775. [PubMed: 15911809]

82. McFarland DJ, Krusienski DJ, Sarnacki WA, Wolpaw JR. J Neural Eng. 2008; 5:101. [PubMed: 18367779]

83. Schwartz AB, Cui XT, Weber DJ, Moran DW. Neuron. 2006; 52:205. [PubMed: 17015237]

84. Hochberg LR, Serruya MD, Friehs GM, Mukand JA, Saleh M, Caplan AH, Branner A, Chen D, Penn RD, Donoghue JP. Nature. 2006; 442:164. [PubMed: 16838014]

85. Schalk G, Miller KJ, Anderson NR, Wilson JA, Smyth MD, Ojemann JG, Moran DW, Wolpaw JR, Leuthardt EC. J Neural Eng. 2008; 5:75. [PubMed: 18310813]

86. Scott SH. J Physiol (London, UK). 2008; 586:1217.

87. Stark E, Drori R, Abeles M. Cortex. 2009; 45:418. [PubMed: 18715554]

88. Donoghue JP. Neuron. 2008; 60:511. [PubMed: 18995827]

89. Ajemian R, Hogan N. J Motor Behav. 2010; 42:333.

90. Birbaumer N, Murguialday AR, Cohen L. Curr Opin Neurol. 2008; 21:634. [PubMed: 18989104]

91. Winter JO, Cogan SF, Rizzo JF 3rd. J Biomater Sci, Polym Ed. 2007; 18:1031. [PubMed: 17705997]

92. Grill WM, Norman SE, Bellamkonda RV. Annu Rev Biomed Eng. 2009; 11:1. [PubMed: 19400710]

93. Heiduschka P, Thanos S. Prog Neurobiol. 1998; 55:433. [PubMed: 9670213]

94. Kim D-H, Viventi J, Amsden JJ, Xiao J, Vigeland L, Kim Y-S, Blanco JA, Panilaitis B, Frechette ES, Contreras D, Kaplan DL, Omenetto FG, Huang Y, Hwang K-C, Zakin MR, Litt B, Rogers JA. Nat Mater. 2010; 9:511. [PubMed: 20400953]

95. Khodagholy D, Doublet T, Gurfinkel M, Quilichini P, Ismailova E, Leleux P, Herve T, Sanaur S, Bernard C, Malliaras GG. Adv Mater. 2011; 23:H268. [PubMed: 21826747]

96. Stice P, Gilletti A, Panitch A, Muthuswamy J. J Neural Eng. 2007; 4:42. [PubMed: 17409479]

97. Marin C, Fernandez E. Front Neuroeng. 2010; 3:8.10.3389/fneng.2010.00008 [PubMed: 20577634]

98. Kuperstein M, Whittington DA. IEEE Trans Biomed Eng. 1981; 28:288. [PubMed: 6262216]

99. Prohaska OJ, Olcaytug F, Pfundner P, Dragaun H. IEEE Trans Biomed Eng. 1986; 33:223. [PubMed: 3957371]

100. Blum NA, Carkhuff BG, Charles HK Jr, Edwards RL, Meyer RA. IEEE Trans Biomed Eng. 1991; 38:68. [PubMed: 2026434]

101. Rousche PJ, Pellinen DS, Pivin DP Jr, Williams JC, Vetter RJ, Kipke DR. IEEE Trans Biomed Eng. 2001; 48:361. [PubMed: 11327505]

102. Yuen TG, Agnew WF. Biomaterials. 1995; 16:951. [PubMed: 8562785]

103. Hatsopoulos NG, Ojakangas CL, Paninski L, Donoghue JP. Proc Natl Acad Sci USA. 1998; 95:15706. [PubMed: 9861034]

104. Kralik JD, Dimitrov DF, Krupa DJ, Katz DB, Cohen D, Nicolelis MA. Methods. 2001; 25:121. [PubMed: 11812202]

105. Kim S, Bhandari R, Klein M, Negi S, Rieth L, Tathireddy P, Toepper M, Oppermann H, Solzbacher F. Biomed Microdevices. 2009; 11:453. [PubMed: 19067174]

106. Cui XY, Hetke JF, Wiler JA, Anderson DJ, Martin DC. Sens Actuators, A. 2001; 93:8. 
107. Wise KD, Najafi K. Science. 1991; 254:1335. [PubMed: 1962192]

108. House PA, MacDonald JD, Tresco PA, Normann RA. Neurosurg Focus. 2006; 20:E4. [PubMed: 16711661]

109. Kim DH, Viventi J, Amsden JJ, Xiao J, Vigeland L, Kim Y, Blanco JA, Panilaitis B, Frechette ES, Contreras D, Kaplan DL, Omenetto FG, Huang Y, Hwang KC, Zakin MR, Litt B, Rogers JA. Nat Mater. 2010; 9:511. [PubMed: 20400953]

110. Rubehn B, Bosman C, Ostenveld R, Fries P, Stieglitz T. J Neural Eng. 2009; 6

111. Hollenberg BA, Richards CD, Richards R, Bahr DF, Rector DM. J Neurosci Methods. 2006; 153:147. [PubMed: 16352343]

112. Schmidt JA, Vonrecum AF. Biomaterials. 1992; 13:1059. [PubMed: 1493189]

113. Seymour JP, Kipke DR. Biomaterials. 2007; 28:3594. [PubMed: 17517431]

114. Zhong Y, Bellamkonda RV. Brain Res. 2007; 1148:15. [PubMed: 17376408]

115. Rennaker RL, Miller J, Tang H, Wilson DA. J Neural Eng. 2007; 4:L1. [PubMed: 17409469]

116. Leung BK, Biran R, Underwood CJ, Tresco PA. Biomaterials. 2008; 29:3289. [PubMed: 18485471]

117. Williams DF. Biomaterials. 2008; 29:2941. [PubMed: 18440630]

118. He W, McConnell GC, Bellamkonda RV. J Neural Eng. 2006; 3:316. [PubMed: 17124336]

119. Dodla MC, Bellamkonda RV. J Biomed Mater Res A. 2006; 78:213. [PubMed: 16892507]

120. Dodla MC, Bellamkonda RV. Biomaterials. 2008; 29:33. [PubMed: 17931702]

121. Azemi E, Stauffer WR, Gostock MS, Lagenaur CF, Cui XT. Acta Biomater. 2008; 4:1208. [PubMed: 18420473]

122. Crompton KE, Goud JD, Bellamkonda RV, Gengenbach TR, Finkelstein DI, Horne MK, Forsythe JS. Biomaterials. 2007; 28:441. [PubMed: 16978692]

123. Kim DH, Wiler JA, Anderson DJ, Kipke DR, Martin DC. Acta Biomater. 2010; 6:57. [PubMed: 19651250]

124. Frampton JP, Hynd MR, Williams JC, Shuler ML, Shain W. J Neural Eng. 2007; 4:399. [PubMed: 18057507]

125. Richardson RT, Wise AK, Thompson BC, Flynn BO, Atkinson PJ, Fretwell NJ, Fallon JB, Wallace GG, Shepherd RK, Clark GM, O’Leary SJ. Biomaterials. 2009; 30:2614. [PubMed: 19178943]

126. Asplund M, Thaning E, Lundberg J, Sandberg-Nordqvist AC, Kostyszyn B, Inganas O, von Holst H. Biomed Mater. 2009; 4:045009. [PubMed: 19636110]

127. Lovat V, Pantarotto D, Lagostena L, Cacciari B, Grandolfo M, Righi M, Spalluto G, Prato M, Ballerini L. Nano Lett. 2005; 5:1107. [PubMed: 15943451]

128. Gabriel G, Gomez R, Bongard M, Benito N, Fernandez E, Villa R. Biosens Bioelectron. 2009; 24:1942. [PubMed: 19056255]

129. Pancrazio JJ. Nanomedicine (London). 2008; 3:823.

130. Mazzatenta A, Giugliano M, Campidelli S, Gambazzi L, Businaro L, Markram H, Prato M, Ballerini L. J Neurosci. 2007; 27:6931. [PubMed: 17596441]

131. Dvir T, Timko BP, Brigham MD, Naik SR, Karajanagi SS, Levy O, Jin H, Parker KK, Langer R, Kohane DS. Nat Nanotechnol. 2011; 6:720. [PubMed: 21946708]

132. Layton, KN.; Abidian, MR. 5th Int. IEEE/EMBS Conf. Neural Engineering; IEEE; 2011. p. 298

133. Fincher CR, Ozaki M, Heeger AJ, Macdiarmid AG. Phys Rev B. 1979; 19:4140.

134. Heeger AJ. Angew Chem Int Ed. 2001; 40:2591.

135. Shirakawa H. Angew Chem Int Ed. 2001; 40:2575.

136. MacDiarmid AG. Angew Chem Int Ed. 2001; 40:2581.

137. Roncali J. Chem Rev. 1992; 92:711.

138. Xu LB, Chen W, Mulchandani A, Yan YS. Angew Chem Int Ed. 2005; 44:6009.

139. Groenendaal BL, Jonas F, Freitag D, Pielartzik H, Reynolds JR. Adv Mater. 2000; 12:481.

140. Baker CO, Shedd B, Innis PC, Whitten PG, Spinks GM, Wallace GG, Kaner RB. Adv Mater. 2008; 20:155. 
141. Smela E, Gadegaard N. Adv Mater. 1999; 11:953.

142. Wadhwa R, Lagenaur CF, Cui XT. J Controlled Release. 2006; 110:531.

143. De Giglio E, Sabbatini L, Colucci S, Zambonin G. J Biomater Sci: Polym Ed. 2000; 11:1073. [PubMed: 11211158]

144. George PM, LaVan DA, Burdick JA, Chen CY, Liang E, Langer R. Adv Mater. 2006; 18:577.

145. Gomez N, Schmidt CE. J Biomed Mater Res A. 2007; 81A:135. [PubMed: 17111407]

146. Berggren M, Richter-Dahlfors A. Adv Mater. 2007; 19:3201.

147. Isaksson J, Kjaell P, Nilsson D, Robinson ND, Berggren M, Richter-Dahlfors A. Nat Mater. 2007; 6:673. [PubMed: 17643105]

148. Deslouis C, ElMoustafid T, Musiani MM, Tribollet B. Electrochim Acta. 1996; 41:1343.

149. Guimard NK, Gomez N, Schmidt CE. Prog Polym Sci. 2007; 32:876.

150. Malliaras GG. Biochim Biophys Acta Gen Subj. 2013; 1830:4286.

151. Ravichandran R, Sundarrajan S, Venugopal JR, Mukherjee S, Ramakrishna S. J R Soc Interface. 2010; 7:S559. [PubMed: 20610422]

152. Green, R.; Duan, C.; Hassarati, R.; Goding, J.; Byrnes-Preston, P.; Suaning, GJ.; Poole-Warren, L.; Lovell, NH. 5th Int. IEEE/ EMBS Conf. Neural Engineering; IEEE; 2011. p. 566

153. Green RA, Baek S, Poole-Warren LA, Martens PJ. Sci Technol Adv Mater. 2010; 11

154. Green RA, Hassarati RT, Bouchinet L, Lee CS, Cheong GLM, Yu JF, Dodds CW, Suaning GJ, Poole-Warren LA, Lovell NH. Biomaterials. 2012; 33:5875. [PubMed: 22656446]

155. Green RA, Lovell NH, Poole-Warren LA. Biomaterials. 2009; 30:3637. [PubMed: 19375160]

156. Green RA, Matteucci PB, Hassarati RT, Giraud B, Dodds CWD, Chen S, Byrnes-Preston PJ, Suaning GJ, Poole-Warren LA, Lovell NH. J Neural Eng. 2013; 10:016009. [PubMed: 23283391]

157. Green RA, Williams CM, Lovell NH, Poole-Warren LA. J Mater Sci, Mater Med. 2008; 19:1625. [PubMed: 18214647]

158. Poole-Warren L, Lovell N, Baek S, Green R. Expert Rev Med Devices. 2010; 7:35. [PubMed: 20021239]

159. Liu X, Chen J, Gilmore KJ, Higgins MJ, Liu Y, Wallace GG. J Biomed Mater Res A. 2010; 94A: 1004. [PubMed: 20694967]

160. Liu X, Yue Z, Higgins MJ, Wallace GG. Biomaterials. 2011; 32:7309. [PubMed: 21745688]

161. Moulton SE, Higgins MJ, Kapsa RMI, Wallace GG. Adv Funct Mater. 2012; 22:2003.

162. Thompson BC, Richardson RT, Moulton SE, Evans AJ, O’Leary S, Clark GM, Wallace GG. J Controlled Release. 2010; 141:161.

163. Wallace GG, Moulton SE, Clark GM. Science. 2009; 324:185. [PubMed: 19359568]

164. Lundin V, Herland A, Berggren M, Jager EWH, Teixeira AI. Plos One. 2011; 6

165. Salto C, Saindon E, Bolin M, Kanciurzewska A, Fahlman M, Jager EWH, Tengvall P, Arenas E, Berggren M. Langmuir. 2008; 24:14133. [PubMed: 19053638]

166. Simon DT, Kurup S, Larsson KC, Hori R, Tybrandt K, Goiny M, Jager EH, Berggren M, Canlon B, Richter-Dahlfors A. Nat Mater. 2009; 8:742. [PubMed: 19578335]

167. Svennersten K, Larsson KC, Berggren M, Richter-Dahlfors A. Biochim Biophys Acta Gen Subj. $2011 ; 1810: 276$.

168. Cui XY, Lee VA, Raphael Y, Wiler JA, Hetke JF, Anderson DJ, Martin DC. J Biomed Mater Res. 2001; 56:261. [PubMed: 11340598]

169. Cui XY, Martin DC. Sens Actuators A. 2003; 103:384.

170. Cui XY, Martin DC. Sens Actuators B. 2003; 89:92.

171. Xiao YH, Cui XY, Hancock JM, Bouguettaya MB, Reynolds JR, Martin DC. Sens Actuators B. 2004; 99:437.

172. Abidian MR, Daneshvar ED, Egeland BM, Kipke DR, Cederna PS, Urbanchek MG. Adv Healthcare Mater. 2012; 1:762.

173. Abidian MR, Kim DH, Martin DC. Adv Mater. 2006; 18:405. [PubMed: 21552389]

174. Abidian MR, Martin DC. Biomaterials. 2008; 29:1273. [PubMed: 18093644] 
175. Abidian, MR.; Salas, LG.; Yazdan-Shahmorad, A.; Marzullo, TC.; Martin, DC.; Kipke, DR. In Vivo Evaluation of Chronically Implanted Neural Microelectrode Arrays Modified with Poly(3,4-ethylenedioxythiophene) Nanotubes. IEEE; 2007.

176. Kim, DR.; Abidian, M.; Martin, DC. Architecture and Application of Biomaterials and Biomolecular Materials, Materials Research Society. Wong, JY.; Plant, AL.; Schmidt, CE.; Shea, L.; Coury, AJ.; Chen, CS.; Barron, AE.; Klok, HA.; Saltzman, WM.; Chilkoti, A.; Luo, D.; Uhrich, K., editors. Vol. 1. 2004. p. 55

177. Miriani, RM.; Abidian, MR.; Kipke, DR. 30th Annu. Int. Conf. IEEE Eng. Med. Biol. Soc; IEEE; 2008. p. 1841

178. Urbanchek MG, Wei B, Egeland BM, Abidian MR, Kipke DR, Cederna PS. Plast Reconstr Surg. 2011; 128:270E.

179. George PM, Lyckman AW, LaVan DA, Hegde A, Leung Y, Avasare R, Testa C, Alexander PM, Langer R, Sur M. Biomaterials. 2005; 26:3511. [PubMed: 15621241]

180. Gomez N, Lee JY, Nickels JD, Schmidt CE. Adv Funct Mater. 2007; 17:1645. [PubMed: 19655035]

181. Lee JY, Bashur CA, Goldstein AS, Schmidt CE. Biomaterials. 2009; 30:4325. [PubMed: 19501901]

182. Richardson RT, Thompson B, Moulton S, Newbold C, Lum MG, Cameron A, Wallace G, Kapsa R, Clark G, O’Leary S. Biomaterials. 2007; 28:513. [PubMed: 17007922]

183. Wang XD, Gu XS, Yuan CW, Chen SJ, Zhang PY, Zhang TY, Yao J, Chen F, Chen G. J Biomed Mater Res A. 2004; 68A:411. [PubMed: 14762920]

184. Heywang G, Jonas F. Adv Mater. 1992; 4:116.

185. Kim D-H, Wiler JA, Anderson DJ, Kipke DR, Martin DC. Acta Biomater. 2010; 6:57. [PubMed: 19651250]

186. Luo S-C, Ali EM, Tansil NC, Yu H-H, Gao S, Kantchev EAB, Ying JY. Langmuir. 2008; 24:8071. [PubMed: 18588322]

187. Richardson-Burns SM, Hendricks JL, Foster B, Povlich LK, Kim D-H, Martin DC. Biomaterials. 2007; 28:1539. [PubMed: 17169420]

188. Herland A, Persson KM, Lundin V, Fahlman M, Berggren M, Jager EWH, Teixeira AI. Angew Chem Int Ed. 2011; 50:12529.

189. Svennersten K, Bolin MH, Jager EWH, Berggren M, Richter-Dahlfors A. Biomaterials. 2009; 30:6257. [PubMed: 19695696]

190. Wan AMD, Schur RM, Ober CK, Fischbach C, Gourdon D, Malliaras GG. Adv Mater. 2012; 24:2501. [PubMed: 22489011]

191. Collier JH, Camp JP, Hudson TW, Schmidt CE. J Biomed Mater Res. 2000; 50:574. [PubMed: 10756316]

192. Hodgson, AJ.; John, MJ.; Campbell, T.; Georgevich, A.; Woodhouse, S.; Aoki, T.; Ogata, N.; Wallace, GG. Smart Materials Technologies and Biomimetics - Smart Structures and Materials. Crowson, A., editor. Vol. 2716. 1996. p. 164

193. Kim D-H, Richardson-Burns SM, Hendricks JL, Sequera C, Martin DC. Adv Funct Mater. 2007; 17:79.

194. Finkenstadt VL. Appl Microbiol Biotechnol. 2005; 67:735. [PubMed: 15724215]

195. Jager EWH, Smela E, Inganas O. Science. 2000; 290:1540. [PubMed: 11090345]

196. Evans AJ, Thompson BC, Wallace GG, Millard R, O’Leary SJ, Clark GM, Shepherd RK, Richardson RT. J Biomed Mater Res A. 2009; 91A:241. [PubMed: 18814235]

197. Gandhi MR, Murray P, Spinks GM, Wallace GG. Synth Met. 1995; 73:247.

198. Lu W, Fadeev AG, Qi BH, Smela E, Mattes BR, Ding J, Spinks GM, Mazurkiewicz J, Zhou DZ, Wallace GG, MacFarlane DR, Forsyth SA, Forsyth M. Science. 2002; 297:983. [PubMed: 12098704]

199. Pei QB, Inganas O. Adv Mater. 1992; 4:277.

200. Spinks GM, Xi BB, Zhou DZ, Truong VT, Wallace GG. Synth Met. 2004; 140:273.

201. Wallace, GG.; Teasdale, PR.; Spinks, GM.; Kane-Maquire, LA. Conductive Electroactivepolymers: Intelligent Materials Systems. CRC Press; Boca Raton, FL, USA: 1997. 
202. Smela E. Adv Mater. 2003; 15:481.

203. Smela E, Inganas O, Lundstrom I. Science. 1995; 268:1735. [PubMed: 17834992]

204. Otero TF, Cortes MT. Adv Mater. 2003; 15:279.

205. Spinks GM, Mottaghitalab V, Bahrami-Saniani M, Whitten PG, Wallace GG. Adv Mater. 2006; 18:637.

206. Jager EWH, Inganas O, Lundstrom I. Science. 2000; 288:2335. [PubMed: 10875911]

207. Immerstrand C, Holmgren-Peterson K, Magnusson KE, Jager E, Krogh M, Skoglund M, Selbing A, Inganas O. MRS Bull. 2002; 27:461.

208. Delille R, Urdaneta MG, Moseley SJ, Smela E. J Microelectromech Syst. 2006; 15:1108.

209. Tsai H-KA, Moschou EA, Daunert S, Madou M, Kulinsky L. Adv Mater. 2009; 21:656.

210. Luo XL, Cui XT. Electrochem Commun. 2009; 11:402.

211. Simon DT, Kurup S, Larsson KC, Hori R, Tybrandt K, Goiny M, Jager EW, Berggren M, Canlon B, Richter-Dahlfors A. Nat Mater. 2009; 8:742. [PubMed: 19578335]

212. Luo X, Cui XT. Electrochem Commun. 2009; 11:1956. [PubMed: 20160915]

213. Thompson BC, Moulton SE, Ding J, Richardson R, Cameron A, O'Leary S, Wallace GG, Clark GM. J Controlled Release. 2006; 116:285.

214. Kovacs, GTA. Enabling Technologies for Cultured Neural Networks. Stenger, DA.; McKenna, T., editors. Academic; New York: 1990. p. 121

215. Schmidt, EM.; Humphrey, DR. Neurophysiological Techniques: Applications to Neural Systems. Boulton, AA.; Baker, GB.; Vanderwolf, CH., editors. Humana Press; Clifton, NJ, USA: 1990. p. 1

216. Paik SJ, Park Y, Cho DI. J Micromech Microeng. 2003; 13:373.

217. Cogan SF. Annu Rev Biomed Eng. 2008; 10:275. [PubMed: 18429704]

218. Drake KL, Wise KD, Farraye J, Anderson DJ, Bement SL. IEEE Trans Biomed Eng. 1988; 35:719. [PubMed: 3169824]

219. Robinson DA. Proc IEEE. 1968; 56:1065.

220. Edell DJ, Toi VV, McNeil VM, Clark LD. IEEE Trans Biomed Eng. 1992; 39:635. [PubMed: 1601445]

221. Cogan, SF.; Plante, TD.; Ehrlich, J. Proc. 26th Annu. Int. Conf. IEEE Engineering in Medicine and Biology Society; IEEE; 2004. p. 4153

222. Johnson MD, Otto KJ, Kipke DR. IEEE Trans Neural Syst Rehabil Eng. 2005; 13:160. [PubMed: 16003894]

223. Bobacka J, Lewenstam A, Ivaska A. J Electroanal Chem. 2000; 489:17.

224. Chang TY, Yadav VG, De Leo S, Mohedas A, Rajalingam B, Chen C-L, Selvarasah S, Dokmeci MR, Khademhosseini A. Langmuir. 2007; 23:11718. [PubMed: 17915896]

225. Thaning EM, Asplund MLM, Nyberg TA, Inganas OW, von Hoist H. J Biomed Mater Res B. 2010; 93B:407.

226. Iijima S. Nature. 1991; 354:56.

227. Baughman RH, Zakhidov AA, de Heer WA. Science. 2002; 297:787. [PubMed: 12161643]

228. Iijima S, Ichihashi T. Nature. 1993; 363:603.

229. Novoselov KS, Geim AK, Morozov SV, Jiang D, Zhang Y, Dubonos SV, Grigorieva IV, Firsov AA. Science. 2004; 306:666. [PubMed: 15499015]

230. Gao GH, Cagin T, Goddard WA. Nanotechnology. 1998; 9:184.

231. Kim P, Shi L, Majumdar A, McEuen PL. Phys Rev Lett. 2001; 87

232. Liang WJ, Bockrath M, Bozovic D, Hafner JH, Tinkham M, Park H. Nature. 2001; 411:665. [PubMed: 11395762]

233. Baughman RH, Cui CX, Zakhidov AA, Iqbal Z, Barisci JN, Spinks GM, Wallace GG, Mazzoldi A, De Rossi D, Rinzler AG, Jaschinski O, Roth S, Kertesz M. Science. 1999; 284:1340. [PubMed: 10334985]

234. Cai H, Cao XN, Jiang Y, He PG, Fang YZ. Anal Bioanal Chem. 2003; 375:287. [PubMed: 12560975] 
235. Williams KA, Veenhuizen PTM, de la Torre BG, Eritja R, Dekker C. Nature. 2002; 420:761. [PubMed: 12490938]

236. Chhowalla M, Unalan HE, Wang YB, Iqbal Z, Park K, Sesti F. Nanotechnology. 2005; 16:2982.

237. Mitchell DT, Lee SB, Trofin L, Li NC, Nevanen TK, Soderlund H, Martin CR. J Am Chem Soc. 2002; 124:11864. [PubMed: 12358526]

238. Harrison BS, Atala A. Biomaterials. 2007; 28:344. [PubMed: 16934866]

239. Gheith MK, Pappas TC, Liopo AV, Sinani VA, Shim BS, Motamedi M, Wicksted JR, Kotov NA. Adv Mater. 2006; 18:2975.

240. Hu H, Ni YC, Montana V, Haddon RC, Parpura V. Nano Lett. 2004; 4:507. [PubMed: 21394241]

241. Jan E, Kotov NA. Nano Lett. 2007; 7:1123. [PubMed: 17451277]

242. Bianco A, Kostarelos K, Partidos CD, Prato M. Chem Commun. 2005; 571

243. Schipper ML, Nakayama-Ratchford N, Davis CR, Kam NWS, Chu P, Liu Z, Sun XM, Dai HJ, Gambhir SS. Nat Nanotechnol. 2008; 3:216. [PubMed: 18654506]

244. Yang WR, Thordarson P, Gooding JJ, Ringer SP, Braet F. Nanotechnology. 2007; 18

245. Angelini G, Boncompagni S, De Maria P, De Nardi M, Fontana A, Gasbarri C, Menna E. Carbon. 2007; 45:2479.

246. Sun YP, Fu KF, Lin Y, Huang WJ. Acc Chem Res. 2002; 35:1096. [PubMed: 12484798]

247. Shim M, Kam NWS, Chen RJ, Li YM, Dai HJ. Nano Lett. 2002; 2:285.

248. Bianco A, Kostarelos K, Prato M. Chem Commun. 2011; 47:10182.

249. Jan E, Hendricks JL, Husaini V, Richardson-Burns SM, Sereno A, Martin DC, Kotov NA. Nano Lett. 2009; 9:4012. [PubMed: 19785391]

250. Wang K, Fishman HA, Dai HJ, Harris JS. Nano Lett. 2006; 6:2043. [PubMed: 16968023]

251. Kam NWS, Liu ZA, Dai HJ. Angew Chem Int Ed. 2006; 45:577.

252. Schipper ML, Nakayama-Ratchford N, Davis CR, Kam NWS, Chu P, Liu Z, Sun X, Dai H, Gambhir SS. Nat Nanotechnol. 2008; 3:216. [PubMed: 18654506]

253. Malarkey EB, Fisher KA, Bekyarova E, Liu W, Haddon RC, Parpura V. Nano Lett. 2009; 9:264. [PubMed: 19143503]

254. Gheith MK, Sinani VA, Wicksted JP, Matts RL, Kotov NA. Adv Mater. 2005; 17:2663.

255. Donaldson K, Aitken R, Tran L, Stone V, Duffin R, Forrest G, Alexander A. Toxicol Sci. 2006; 92:5. [PubMed: 16484287]

256. Pacurari M, Castranova V, Vallyathan V. J Toxicol Environ Health, Part A. 2010; 73:378. [PubMed: 20155580]

257. Kam NWS, Jan E, Kotov NA. Nano Lett. 2009; 9:273. [PubMed: 19105649]

258. Ni YC, Hu H, Malarkey EB, Zhao B, Montana V, Haddon RC, Parpura V. J Nanosci Nanotechnol. 2005; 5:1707. [PubMed: 16245532]

259. Wick P, Manser P, Limbach LK, Dettlaff-Weglikowska U, Krumeich F, Roth S, Stark WJ, Bruinink A. Toxicol Lett. 2007; 168:121. [PubMed: 17169512]

260. Monteiro-Riviere NA, Nemanich RJ, Inman AO, Wang YYY, Riviere JE. Toxicol Lett. 2005; 155:377. [PubMed: 15649621]

261. Raja PMV, Connolley J, Ganesan GP, Ci LJ, Ajayan PM, Nalamasu O, Thompson DM. Toxicol Lett. 2007; 169:51. [PubMed: 17275220]

262. Tian FR, Cui DX, Schwarz H, Estrada GG, Kobayashi H. Toxicol in Vitro. 2006; 20:1202. [PubMed: 16697548]

263. Nimmagadda A, Thurston K, Nollert MU, McFetridge PSF. J Biomed Mater Res A. 2006; 76A: 614. [PubMed: 16315191]

264. Belyanskaya L, Weigel S, Hirsch C, Tobler U, Krug HF, Wick P. Neurotoxicology. 2009; 30:702. [PubMed: 19465056]

265. Jia G, Wang HF, Yan L, Wang X, Pei RJ, Yan T, Zhao YL, Guo XB. Environ Sci Technol. 2005; 39:1378. [PubMed: 15787380]

266. Ding LH, Stilwell J, Zhang TT, Elboudwarej O, Jiang HJ, Selegue JP, Cooke PA, Gray JW, Chen FQF. Nano Lett. 2005; 5:2448. [PubMed: 16351195] 
267. Liopo AV, Stewart MP, Hudson J, Tour JM, Pappas TC. J Nanosci Nanotechnol. 2006; 6:1365. [PubMed: 16792366]

268. Bardi G, Tognini P, Ciofani G, Raffa V, Costa M, Pizzorusso T. Nanomed Nanotechnol. 2009; 5:96.

269. Malarkey EB, Reyes RC, Zhao B, Haddon RC, Parpura V. Nano Lett. 2008; 8:3538. [PubMed: 18759491]

270. Gaillard C, Cellot G, Li S, Toma FM, Dumortier H, Spalluto G, Cacciari B, Prato M, Ballerini L, Bianco A. Adv Mater. 2009; 21:2903.

271. Sayes CM, Liang F, Hudson JL, Mendez J, Guo WH, Beach JM, Moore VC, Doyle CD, West JL, Billups WE, Ausman KD, Colvin VL. Toxicol Lett. 2006; 161:135. [PubMed: 16229976]

272. Chao T-I, Xiang S, Chen C-S, Chin W-C, Nelson AJ, Wang C, Lu J. Biochem Biophys Res Commun. 2009; 384:426. [PubMed: 19426708]

273. Liu D, Yi C, Zhang D, Zhang J, Yang M. ACS Nano. 2010; 4:2185. [PubMed: 20218664]

274. Park SY, Park SY, Namgung S, Kim B, Im J, Kim Y, Sun K, Lee KB, Nam J-M, Park Y, Hong S. Adv Mater. 2007; 19:2530.

275. Saito N, Usui Y, Aoki K, Narita N, Shimizu M, Hara K, Ogiwara N, Nakamura K, Ishigaki N, Kato H, Taruta S, Endo M. Chem Soc Rev. 2009; 38:1897. [PubMed: 19551170]

276. Tay CY, Gu H, Leong WS, Yu H, Li HQ, Heng BC, Tantang H, Loo SCJ, Li LJ, Tan LP. Carbon. 2010; 48:1095.

277. Tay CY, Gu HG, Leong WS, Yu HY, Li HQ, Heng BC, Tantang H, Loo SCJ, Li LJ, Tan LP. Carbon. 2010; 48:1095.

278. Park SY, Park SY, Namgung S, Kim B, Im J, Kim Y, Sun K, Lee KB, Nam JM, Park Y, Hong S. Adv Mater. 2007; 19:2530.

279. Decher G. Science. 1997; 277:1232.

280. Lu Y, Li T, Zhao X, Li M, Cao Y, Yang H, Duan YY. Biomaterials. 2010; 31:5169. [PubMed: 20382421]

281. Nguyen-Vu TDB, Chen H, Cassell AM, Andrews R, Meyyappan M, Li J. Small. 2006; 2:89. [PubMed: 17193561]

282. Ansaldo A, Castagnola E, Maggiolini E, Fadiga L, Ricci D. ACS Nano. 2011; 5:2206. [PubMed: 21341752]

283. Baranauskas G, Maggiolini E, Castagnola E, Ansaldo A, Mazzoni A, Angotzi GN, Vato A, Ricci D, Panzeri S, Fadiga L. J Neural Eng. 2011; 8

284. Gabay T, Ben-David M, Kalifa I, Sorkin R, Abrams ZR, Ben-Jacob E, Hanein Y. Nanotechnology. 2007; 18

285. de Asis ED, Nguyen-Vu TDB, Arumugam PU, Chen H, Cassell AM, Andrews RJ, Yang CY, Li J. Biomed Microdevices. 2009; 11:801. [PubMed: 19291408]

286. Hsu HL, Teng IJ, Chen YC, Hsu WL, Lee YT, Yen SJ, Su HC, Yeh SR, Chen H, Yew TR. Adv Mater. 2010; 22:2177. [PubMed: 20358634]

287. Lin CM, Lee YT, Yeh SR, Fang WL. Biosens Bioelectron. 2009; 24:2791. [PubMed: 19272765]

288. Su HC, Lin CM, Yen SJ, Chen YC, Chen CH, Yeh SR, Fang W, Chen H, Yao DJ, Chang YC, Yew TR. Biosens Bioelectron. 2010; 26:220. [PubMed: 20685101]

289. Yu Z, McKnight TE, Ericson MN, Melechko AV, Simpson ML, Morrison B. Nano Lett. 2007; 7:2188. [PubMed: 17604402]

290. Mattson MP, Haddon RC, Rao AM. J Mol Neurosci. 2000; 14:175. [PubMed: 10984193]

291. Fuchsberger K, Le Goff A, Gambazzi L, Toma FM, Goldoni A, Giugliano M, Stelzle M, Prato M. Small. 2011; 7:524. [PubMed: 21246714]

292. Wilson BS, Finley CC, Lawson DT, Wolford RD, Eddington DK, Rabinowitz WM. Nature. 1991; 352:236. [PubMed: 1857418]

293. Humayun MS, Weiland JD, Fujii GY, Greenberg R, Williamson R, Little J, Mech B, Cimmarusti V, Van Boemel G, Dagnelie G, de Juan E. Vision Res. 2003; 43:2573. [PubMed: 13129543]

294. Zrenner E. Science. 2002; 295:1022. [PubMed: 11834821]

295. Bousse L, Bergveld P. Sens Actuators. 1984; 6:65. 
296. Cabruja E, Merlos A, Cane C, Lozano M, Bausells J, Esteve J. Surf Sci. 1991; 251:364.

297. Hess LH, Jansen M, Maybeck V, Hauf MV, Seifert M, Stutzmann M, Sharp ID, Offenhausser A, Garrido JA. Adv Mater. 2011; 23:5045. [PubMed: 21953832]

298. Chen CH, Lin CT, Hsu WL, Chang YC, Yeh SR, Li LJ, Yao DJ. Nanomed Nanotechnol. 2013; 9:600.

299. Chen, CH.; Lin, CT.; Chen, JJ.; Hsu, WL.; Chang, YC.; Yeh, SR.; Li, LJ.; Yao, DJ. 16th Int. IEEE Solid-State Sensors, Actuators and Microsystems Conf. (TRANSDUCERS); 2011. p. 1883

300. Ang PK, Chen W, Wee ATS, Loh KP. J Am Chem Soc. 2008; 130:14392. [PubMed: 18850701]

301. Dankerl M, Eick S, Hofmann B, Hauf M, Ingebrandt S, Offenhausser A, Stutzmann M, Garrido JA. Adv Funct Mater. 2009; 19:2915.

302. Steinhoff G, Baur B, Wrobel G, Ingebrandt S, Offenhausser A, Dadgar A, Krost A, Stutzmann M, Eickhoff M. Appl Phys Lett. 2005; 86

303. Heller I, Chatoor S, Mannik J, Zevenbergen MAG, Dekker C, Lemay SG. J Am Chem Soc. 2010; 132:17149. [PubMed: 21077655]

304. Sanchez VC, Jachak A, Hurt RH, Kane AB. Chem Res Toxicol. 2012; 25:15. [PubMed: 21954945]

305. Singh V, Joung D, Zhai L, Das S, Khondaker SI, Seal S. Prog Mater Sci. 2011; 56:1178.

306. Cohen-Karni T, Qing Q, Qiang L, Fang Y, Lieber CM. Abstr Pap Am Chem Soc. 2010; 240

307. Chen CH, Lin CT, Lee YH, Liu KK, Su CY, Zhang WJ, Li LJ. Small. 2012; 8:43. [PubMed: 22095939]

308. Nayak TR, Andersen H, Makam VS, Khaw C, Bae S, Xu XF, Ee PLR, Ahn JH, Hong BH, Pastorin G, Ozyilmaz B. ACS Nano. 2011; 5:4670. [PubMed: 21528849]

309. Stankovich S, Dikin DA, Dommett GHB, Kohlhaas KM, Zimney EJ, Stach EA, Piner RD, Nguyen ST, Ruoff RS. Nature. 2006; 442:282. [PubMed: 16855586]

310. Chiu CW, He XL, Liang H. Electrochimica Acta. 2013; 94:42.

311. Allen MJ, Tung VC, Kaner RB. Chem Rev. 2010; 110:132. [PubMed: 19610631]

312. Li F, Li JJ, Feng Y, Yang LM, Du ZF. Sens Actuators B. 2011; 157:110.

313. Zhu YW, Murali S, Cai WW, Li XS, Suk JW, Potts JR, Ruoff RS. Adv Mater. 2010; 22:5226.

314. Novoselov KS, Fal'ko VI, Colombo L, Gellert PR, Schwab MG, Kim K. Nature. 2012; 490:192. [PubMed: 23060189]

315. Shen H, Zhang LM, Liu M, Zhang ZJ. Theranostics. 2012; 2:283. [PubMed: 22448195]

316. Lee WC, Lim CHYX, Shi H, Tang LAL, Wang Y, Lim CT, Loh KP. ACS Nano. 2011; 5:7334. [PubMed: 21793541]

317. Sun XM, Liu Z, Welsher K, Robinson JT, Goodwin A, Zaric S, Dai HJ. Nano Res. 2008; 1:203. [PubMed: 20216934]

318. Zhang YB, Ali SF, Dervishi E, Xu Y, Li ZR, Casciano D, Biris AS. ACS Nano. 2010; 4:3181. [PubMed: 20481456]

319. Mao HY, Laurent S, Chen W, Akhavan O, Imani M, Ashkarran AA, Mahmoudi M. Chem Rev. 2013; 113:3407. [PubMed: 23452512]

320. Shao YY, Wang J, Wu H, Liu J, Aksay IA, Lin YH. Electroanalysis. 2010; 22:1027.

321. Tang LH, Wang Y, Li YM, Feng HB, Lu J, Li JH. Adv Funct Mater. 2009; 19:2782.

322. Bendali A, Hess LH, Seifert M, Forster V, Stephan A, Garrido JA, Picaud S. Adv Heathcare Mater. 2013; 2:929.

323. Li N, Zhang Q, Gao S, Song Q, Huang R, Wang L, Liu L, Dai J, Tang M, Cheng G. Sci Rep. 2013; 3

324. Li N, Zhang X, Song Q, Su R, Zhang Q, Kong T, Liu L, Jin G, Tang M, Cheng G. Biomaterials. 2011; 32:9374. [PubMed: 21903256]

325. Zhang Y, Ali SF, Dervishi E, Xu Y, Li Z, Casciano D, Biris AS. ACS Nano. 2010; 4:3181. [PubMed: 20481456]

326. Liu BF, Ma J, Xu QY, Cui FZ. Colloids Surf, B. 2006; 53:175.

327. Bruggemann D, Wolfrum B, Maybeck V, Mourzina Y, Jansen M, Offenhausser A.

Nanotechnology. 2011;22 
328. Stieglitz T, Beutel Hr, Schuettler M, Meyer JU. Biomed Microdevices. 2000; 2:283.

329. Heo C, Yoo J, Lee S, Jo A, Jung S, Yoo H, Lee YH, Suh M. Biomaterials. 2011; 32:19. [PubMed: 20880583]

330. Geim AK, Novoselov KS. Nat Mater. 2007; 6:183. [PubMed: 17330084]

331. Nair RR, Blake P, Grigorenko AN, Novoselov KS, Booth TJ, Stauber T, Peres NMR, Geim AK. Science. 2008; 320:1308. [PubMed: 18388259]

332. Jackowska K, Krysinski P. Anal Bioanal Chem. 2013; 405:3753. [PubMed: 23241816]

333. Anker JN, Hall WP, Lyandres O, Shah NC, Zhao J, Van Duyne RP. Nat Mater. 2008; 7:442. [PubMed: 18497851]

334. Wilson GS, Gifford R. Biosens Bioelectron. 2005; 20:2388. [PubMed: 15854814]

335. Grieshaber D, MacKenzie R, Voros J, Reimhult E. Sensors. 2008; 8:1400.

336. Liu Y, Dong X, Chen P. Chem Soc Rev. 2012; 41:2283. [PubMed: 22143223]

337. Liu Y, Yu D, Zeng C, Miao Z, Dai L. Langmuir. 2010; 26:6158. [PubMed: 20349968]

338. Pumera M, Ambrosi A, Bonanni A, Chng ELK, Poh HL. Trends Anal Chem. 2010; 29:954.

339. Shan C, Yang H, Han D, Zhang Q, Ivaska A, Niu L. Biosens Bioelectron. 2010; 25:1070. [PubMed: 19883999]

340. Shan C, Yang H, Song J, Han D, Ivaska A, Niu L. Anal Chem. 2009; 81:2378. [PubMed: 19227979]

341. Shao Y, Wang J, Wu H, Liu J, Aksay IA, Lin Y. Electroanalysis. 2010; 22:1027.

342. Yamacli S, Avci M. Expert Syst Appl. 2010; 37:8014.

343. Wightman RM, May LJ, Michael AC. Anal Chem. 1988; 60:A769.

344. Damier P, Hirsch EC, Agid Y, Graybiel AM. Brain. 1999; 122:1437. [PubMed: 10430830]

345. Viry L, Derre A, Poulin P, Kuhn A. Phys Chem Chem Phys. 2010; 12:9993. [PubMed: 20623074]

346. Zhu MF, Zeng CQ, Ye JS. Electroanal. 2011; 23:907.

347. Wang Y, Li YM, Tang LH, Lu J, Li JH. Electrochem Commun. 2009; 11:889.

348. Kim YR, Bong S, Kang YJ, Yang Y, Mahajan RK, Kim JS, Kim H. Biosens Bioelectron. 2010; 25:2366. [PubMed: 20307965]

349. Sheng ZH, Zheng XQ, Xu JY, Bao WJ, Wang FB, Xia XH. Biosens Bioelectron. 2012; 34:125. [PubMed: 22342696]

350. Chao MY, Ma XY, Li X. Int J Electrochem Soc. 2012; 7:2201.

351. Zhou M, Zhai Y, Dong S. Anal Chem. 2009; 81:5603. [PubMed: 19522529]

352. Wang Y, Li Y, Tang L, Lu J, Li J. Electrochem Commun. 2009; 11:889.

353. Duan XJ, Gao RX, Xie P, Cohen-Karni T, Qing Q, Choe HS, Tian BZ, Jiang XC, Lieber CM. Nat Nanotechnol. 2012; 7:174. [PubMed: 22179566]

354. Marom S, Shahaf G. Q Rev Biophys. 2002; 35:63. [PubMed: 11997981]

355. Fromherz P. ChemPhysChem. 2002; 3:276. [PubMed: 12503174]

356. Lambacher A, Jenkner M, Merz M, Eversmann B, Kaul RA, Hofmann F, Thewes R, Fromherz P. Appl Phys A: Mater Sci Process. 2004; 79:1607.

357. James CD, Spence AJH, Dowell-Mesfin NM, Hussain RJ, Smith KL, Craighead HG, Isaacson MS, Shain W, Turner JN. IEEE Trans Biomed Eng. 2004; 51:1640. [PubMed: 15376512]

358. Merz M, Fromherz P. Adv Funct Mater. 2005; 15:739.

359. Jimbo Y, Kasai N, Torimitsu K, Tateno T, Robinson HPC. IEEE Trans Biomed Eng. 2003; 50:241. [PubMed: 12665038]

360. Xie C, Cui Y. Proc Natl Acad Sci USA. 2010; 107:4489. [PubMed: 20194753]

361. Tsytsarev V, Taketani M, Schottler F, Tanaka S, Hara M. J Neural Eng. 2006; 3:293. [PubMed: 17124333]

362. Hutzler M, Lambacher A, Eversmann B, Jenkner M, Thewes R, Fromherz P. J Neurophysiol. 2006; 96:1638. [PubMed: 16687618]

363. Oviedo H, Reyes AD. J Neurosci. 2005; 25:4985. [PubMed: 15901779] 
364. Patolsky F, Timko BP, Yu GH, Fang Y, Greytak AB, Zheng GF, Lieber CM. Science. 2006; 313:1100. [PubMed: 16931757]

365. Rutten WLC. Annu Rev Biomed Eng. 2002; 4:407. [PubMed: 12117764]

366. Patolsky F, Zheng GF, Lieber CM. Anal Chem. 2006; 78:4260. [PubMed: 16856252]

367. Qing Q, Pal SK, Tian BZ, Duan XJ, Timko BP, Cohen-Karni T, Murthy VN, Lieber CM. Proc Natl Acad Sci USA. 2010; 107:1882. [PubMed: 20133836]

368. Llinas RR, Walton KD, Nakao M, Hunter I, Anquetil PA. J Nanopart Res. 2005; 7:111.

369. Watanabe H, Takahashi H, Nakao M, Walton K, Llinas RR. Electr Commun Jpn. 2009; 92:29.

370. Linsmeier CE, Prinz CN, Pettersson LME, Caroff P, Samuelson L, Schouenborg J, Montelius L, Danielsen N. Nano Lett. 2009; 9:4184. [PubMed: 19845389]

371. Cohen-Karni T, Timko BP, Weiss LE, Lieber CM. Proc Natl Acad Sci USA. 2009; 106:7309. [PubMed: 19365078]

372. Eschermann JF, Stockmann R, Hueske M, Vu XT, Ingebrandt S, Offenhausser A. Appl Phys Lett. 2009; 95

373. Nel A, Xia T, Madler L, Li N. Science. 2006; 311:622. [PubMed: 16456071]

374. Oberdorster G, Oberdorster E, Oberdorster J. Environ Health Perspect. 2005; 113:823. [PubMed: 16002369]

375. Hallstrom W, Martensson T, Prinz C, Gustavsson P, Montelius L, Samuelson L, Kanje M. Nano Lett. 2007; 7:2960. [PubMed: 17880143]

376. Roth S, Bugnicourt G, Bisbal M, Gory-Faure S, Brocard J, Villard C. Small. 2012; 8:671. [PubMed: 22228548]

377. Wise KD, Angell JB. IEEE Trans Biomed Eng. 1975; 22:212. [PubMed: 1116854]

378. Wise KD, Angell JB, Starr A. IEEE Trans Biomed Eng. 1970; Bm17:238. [PubMed: 5431636]

379. Kwiat M, Stein D, Patolsky F. Curr Opin Biotechnol. 2013; 24:654. [PubMed: 23419931]

380. Sniadecki N, Desai RA, Ruiz SA, Chen CS. Ann Biomed Eng. 2006; 34:59. [PubMed: 16525764]

381. Larkum ME, Zhu JJ. J Neurosci. 2002; 22:6991. [PubMed: 12177197]

382. Froemke RC, Poo MM, Dan Y. Nature. 2005; 434:221. [PubMed: 15759002]

383. Gulledge AT, Stuart GJ. J Neurosci. 2003; 23:11363. [PubMed: 14673000]

384. Tian B, Cohen-Karni T, Qing Q, Duan X, Xie P, Lieber CM. Science. 2010; 329:830. [PubMed: 20705858]

385. Duan X, Gao R, Xie P, Cohen-Karni T, Qing Q, Choe HS, Tian B, Jiang X, Lieber CM. Nat Nanotechnol. 2012; 7:174. [PubMed: 22179566]

386. He L, Lin D, Wang Y, Xiao Y, Che J. Colloids Surf, B. 2011; 87:273.

387. Kim DH, Abidian M, Martin DC. J Biomed Mater Res A. 2004; 71:577. [PubMed: 15514937]

388. Lu Y, Wang D, Li T, Zhao X, Cao Y, Yang H, Duan YY. Biomaterials. 2009; 30:4143. [PubMed: 19467702]

389. Luo X, Weaver CL, Tan S, Cui XT. J Mater Chem B. 2013; 1:1340.

390. Erik KAF, Malarkey B, Bekyarova Elena, Liu Wei, Haddon Robert C, Parpura Vladimir. Nano Lett. 2009; 9:264. [PubMed: 19143503]

391. Castagnola E, Ansaldo A, Maggiolini E, Angotzi GN, Skrap M, Ricci D, Fadiga L. ACS Nano. 2013; 7:3887. [PubMed: 23590691]

392. Lin CC, Metters AT. Adv Drug Delivery Rev. 2006; 58:1379.

393. Loh XJ, Peh P, Liao S, Sng C, Li J. J Controlled Release. 2010; 143:175.

394. Song BB, Song JS, Zhang SS, Anderson MA, Ao Y, Yang CY, Deming TJ, Sofroniew MV. Biomaterials. 2012; 33:9105. [PubMed: 22985994]

395. Lu Y, Li Y, Pan J, Wei P, Liu N, Wu B, Cheng J, Lu C, Wang L. Biomaterials. 2012; 33:378. [PubMed: 22018384]

396. Nyberg T, Inganäs O, Jerregård H. Biomed Microdevices. 2002; 4:43.

397. Lira LM, Córdoba de Torresi SI. Electrochem Commun. 2005; 7:717.

398. Lewitus DY, Landers J, Branch J, Smith KL, Callegari G, Kohn J, Neimark AV. Adv Funct Mater. 2011; 21:2624. [PubMed: 21887125] 
399. Agarwal S, Zhou X, Ye F, He Q, Chen GC, Soo J, Boey F, Zhang H, Chen P. Langmuir. 2010; 26:2244. [PubMed: 20099791]

400. Zu S-Z, Han B-H. J Phys Chem C. 2009; 113:13651.

401. Bai H, Li C, Wang X, Shi G. Chem Commun. 2010; 46:2376.

402. Hou C, Duan Y, Zhang Q, Wang H, Li Y. J Mater Chem. 2012; 22:14991.

403. Wang L, Zhang X, Xiong H, Wang S. Biosensors Bioelectron. 2010; $26: 991$.

404. Zhou H, Cheng X, Rao L, Li T, Duan YY. Acta Biomater. 2013; 9:6439. [PubMed: 23402765]

405. Chen S, Pei W, Gui Q, Tang R, Chen Y, Zhao S, Wang H, Chen H. Sens Actuators A. 2013; 193:141.

406. Chen H, Guo L, Ferhan AR, Kim D-H. J Phys Chem C. 2011; 115:5492.

407. Do Nascimento GM, Corio P, Novickis RW, Temperini ML, Dresselhaus MS. J Polym Sci, Part A: Polym Chem. 2005; 43:815.

408. Deng M, Yang X, Silke M, Qiu W, Xu M, Borghs G, Chen H. Sens Actuators B. 2011; 158:176.

409. Stankovich S, Dikin DA, Dommett GH, Kohlhaas KM, Zimney EJ, Stach EA, Piner RD, Nguyen ST, Ruoff RS. Nature. 2006; 442:282. [PubMed: 16855586]

410. Zhang LL, Zhao S, Tian XN, Zhao X. Langmuir. 2010; 26:17624. [PubMed: 20961127]

411. Liu A, Li C, Bai H, Shi G. J Phys Chem C. 2010; 114:22783.

412. Parker CB, Raut AS, Brown B, Stoner BR, Glass JT. J Mater Res. 2012; 27:1046.

413. Jackson A, Fetz EE. J Neurophysiol. 2007; 98:3109. [PubMed: 17855584]

414. Nicolelis MAL, Dimitrov D, Carmena JM, Crist R, Lehew G, Kralik JD, Wise SP. Proc Natl Acad Sci USA. 2003; 100:11041. [PubMed: 12960378]

415. Schmidt CE, Shastri VR, Vacanti JP, Langer R. Proc Natl Acad Sci USA. 1997; 94:8948. [PubMed: 9256415]

416. Kozai TDY, Langhals NB, Patel PR, Deng X, Zhang H, Smith KL, Lahann J, Kotov NA, Kipke DR. Nat Mater. 2012; 11:1065. [PubMed: 23142839]

417. Otto KJ, Johnson MD, Kipke DR. IEEE Trans Biomed Eng. 2006; 53:333. [PubMed: 16485763]

418. Harrison RR, Watkins PT, Kier RJ, Lovejoy RO, Black DJ, Greger B, Solzbacher F. IEEE J Solid-State Circuits. 2007; 42:123.

419. Wise KD, Anderson DJ, Hetke JF, Kipke DR, Najafi K. Proc IEEE. 2004; 92:76.

420. Kim YT, Hitchcock RW, Bridge MJ, Tresco PA. Biomaterials. 2004; 25:2229. [PubMed: 14741588]

421. Takeuchi S, Ziegler D, Yoshida Y, Mabuchi K, Suzuki T. Lab Chip. 2005; 5:519. [PubMed: 15856088]

422. Wester BA, Lee RH, LaPlaca MC. J Neural Eng. 2009; 6

423. Miller K, Chinzei K. J Biomech. 2002; 35:483. [PubMed: 11934417]

424. Peppas NA, Hilt JZ, Khademhosseini A, Langer R. Adv Mater. 2006; 18:1345.

425. Dalton PD, Flynn L, Shoichet MS. Biomaterials. 2002; 23:3843. [PubMed: 12164188]

426. Drury JL, Dennis RG, Mooney DJ. Biomaterials. 2004; 25:3187. [PubMed: 14980414]

427. Negi S, Bhandari R, Rieth L, Van Wagenen R, Solzbacher F. J Neurosci Methods. 2010; 186:8. [PubMed: 19878693]

428. Goryu A, Numano R, Ikedo A, Ishida M, Kawano T. Nanotechnology. 2012; 23

429. Stieglitz T. J Neural Eng. 2009; 6

430. Rodger DC, Fong AJ, Wen L, Ameri H, Ahuja AK, Gutierrez C, Lavrov I, Hui Z, Menon PR, Meng E, Burdick JW, Roy RR, Edgerton VR, Weiland JD, Humayun MS, Tai Y-C. Sens Actuators B. 2008; 132:449.

431. Kim DH, Viventi J, Amsden JJ, Xiao JL, Vigeland L, Kim YS, Blanco JA, Panilaitis B, Frechette ES, Contreras D, Kaplan DL, Omenetto FG, Huang YG, Hwang KC, Zakin MR, Litt B, Rogers JA. Nat Mater. 2010; 9:511. [PubMed: 20400953]

432. Lacour SP, Benmerah S, Tarte E, FitzGerald J, Serra J, McMahon S, Fawcett J, Graudejus O, Yu Z, Morrison B III. Med Biol Eng Comput. 2010; 48:945. [PubMed: 20535574]

433. Hassler C, Boretius T, Stieglitz T. J Polym Sci, Part B: Polym Phys. 2011; 49:18. 
434. Negredo P, Castro J, Lago N, Navarro X, Avendano C. Neuroscience. 2004; 128:605. [PubMed: 15381289]

435. Meacham KW, Giuly RJ, Guo L, Hochman S, DeWeerth SP. Biomed Microdevices. 2008; 10:259. [PubMed: 17914674]

436. MacDonald JD, Fisher KJ. Neurosurgery. 2011; 69:ons83. [PubMed: 21829146]

437. Gaillard C, Cellot G, Li SP, Toma FM, Dumortier H, Spalluto G, Cacciari B, Prato M, Ballerini L, Bianco A. Adv Mater. 2009; 21:2903.

438. Bendali A, Hess LH, Seifert M, Forster V, Stephan AF, Garrido JA, Picaud S. Adv Healthcare Mater. 2013; 2:929.

439. Li N, Zhang Q, Gao S, Song Q, Huang R, Wang L, Liu LW, Dai JW, Tang ML, Cheng GS. Sci Rep. 2013; 3

440. Zhou M, Zhai YM, Dong SJ. Anal Chem. 2009; 81:5603. [PubMed: 19522529]

441. Tian BZ, Cohen-Karni T, Qing Q, Duan XJ, Xie P, Lieber CM. Science. 2010; 329:830. [PubMed: 20705858]

442. Robinson JT, Jorgolli M, Shalek AK, Yoon MH, Gertner RS, Park H. Nat Nanotechnol. 2012; 7:180. [PubMed: 22231664]

443. Lewitus DY, Landers J, Branch JR, Smith KL, Callegari G, Kohn J, Neimark AV. Adv Funct Mater. 2011; 21:2624. [PubMed: 21887125]

444. Lu Y, Li T, Zhao XQ, Li M, Cao YL, Yang HX, Duan YWY. Biomaterials. 2010; 31:5169. [PubMed: 20382421]

445. Si P, Chen HL, Kannan P, Kim DH. Analyst. 2011; 136:5134. [PubMed: 22010122]

446. Deng M, Yang X, Silke M, Qiu WM, Xu MS, Borghs G, Chen HZ. Sens Actuators B. 2011; 158:176.

447. Salcman M, Bak MJ. IEEE Trans Biomed Eng. 1973; Bm20:253. [PubMed: 4708761]

448. Salcman M, Bak MJ. Fed Proc. 1974; 33:331.

449. Williams JC, Rennaker RL, Kipke DR. Brain Res Protoc. 1999; 4:303.

450. Liu XD, McCreery DB, Bullara LA, Agnew WF. IEEE Trans Neural Syst Rehabil Eng. 2006; 14:91. [PubMed: 16562636]

451. Hetke JF, Lund JL, Najafi K, Wise KD, Anderson DJ. IEEE Trans Biomed Eng. 1994; 41:314. [PubMed: 8063297]

452. Najafi K, Wise KD, Mochizuki T. IEEE Trans Electron Devices. 1985; 32:1206.

453. Ji J, Wise KD. IEEE J Solid-State Circuits. 1992; 27:433.

454. Najafi K, Wise KD. IEEE J Solid-State Circuits. 1986; 21:1035.

455. Hoogerwerf AC, Wise KD. IEEE Trans Biomed Eng. 1994; 41:1136. [PubMed: 7851915]

456. Yao, Y.; Gulari, AN.; Casey, B.; Wiler, JA.; Wise, KD. 3rd Int IEEE/EMBS Conf Neural Engineering; presented at 3rd Int. IEEE/EMBS Conf. Neural Engineering; Kohala Coast, HI, USA. May 2007; IEEE; 2007. p. 398

457. Wise KD, Sodagar AM, Yao Y, Gulari MN, Perlin GE, Najafi K. Proc IEEE. 2008; 96:1184.

458. Branner A, Stein RB, Fernandez E, Aoyagi Y, Normann RA. IEEE Trans Biomed Eng. 2004; 51:146. [PubMed: 14723504]

459. Kindlundh M, Norlin P, Hofmann UG. Sens Actuators B. 2004; 102:51.

460. Muthuswamy J, Okandan M, Jackson N. J Neurosci Methods. 2005; 142:45. [PubMed: 15652616]

461. Norlin P, Kindlundh M, Mouroux A, Yoshida K, Hofmann UG. J Micromech Microeng. 2002; 12:414.

462. Lee KK, He JP, Singh A, Massia S, Ehteshami G, Kim B, Raupp G. J Micromech Microeng. 2004; 14:32.

463. Cheung KC, Renaud P, Tanila H, Djupsund K. Biosens Bioelectron. 2007; 22:1783. [PubMed: 17027251]

464. Ismail YA, Martínez JG, Al Harrasi AS, Kim SJ, Otero TF. Sens Actuators B. 2011; 160:1180.

465. Chikar JA, Hendricks JL, Richardson-Burns SM, Raphael Y, Pfingst BE, Martin DC.

Biomaterials. 2012; 33:1982. [PubMed: 22182748] 
466. Guiseppi-Elie A. Biomaterials. 2010; 31:2701. [PubMed: 20060580]

467. Nadine Wong Shi Kam EJ, Kotov Nicholas A. Nano Lett. 2009; 9:273. [PubMed: 19105649]

\section{Biography}

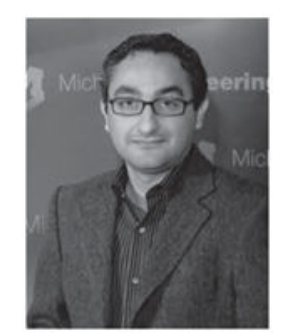

Mohammad Reza Abidian received his Ph.D. in Biomedical Engineering from University of Michigan in 2007. He completed postdoctoral training at the Center for Neural Communication Technology at the University of Michigan. Since 2010, he has been an Assistant Professor in the Departments of Biomedical Engineering, Materials Science \& Engineering, and Chemical Engineering. His current research interests include: multifunctional organic-inorganic hybrid nanobiomaterials for smart targeted drug delivery to brain tumors and conducting polymers for axonal regeneration and neurochemical detection. 


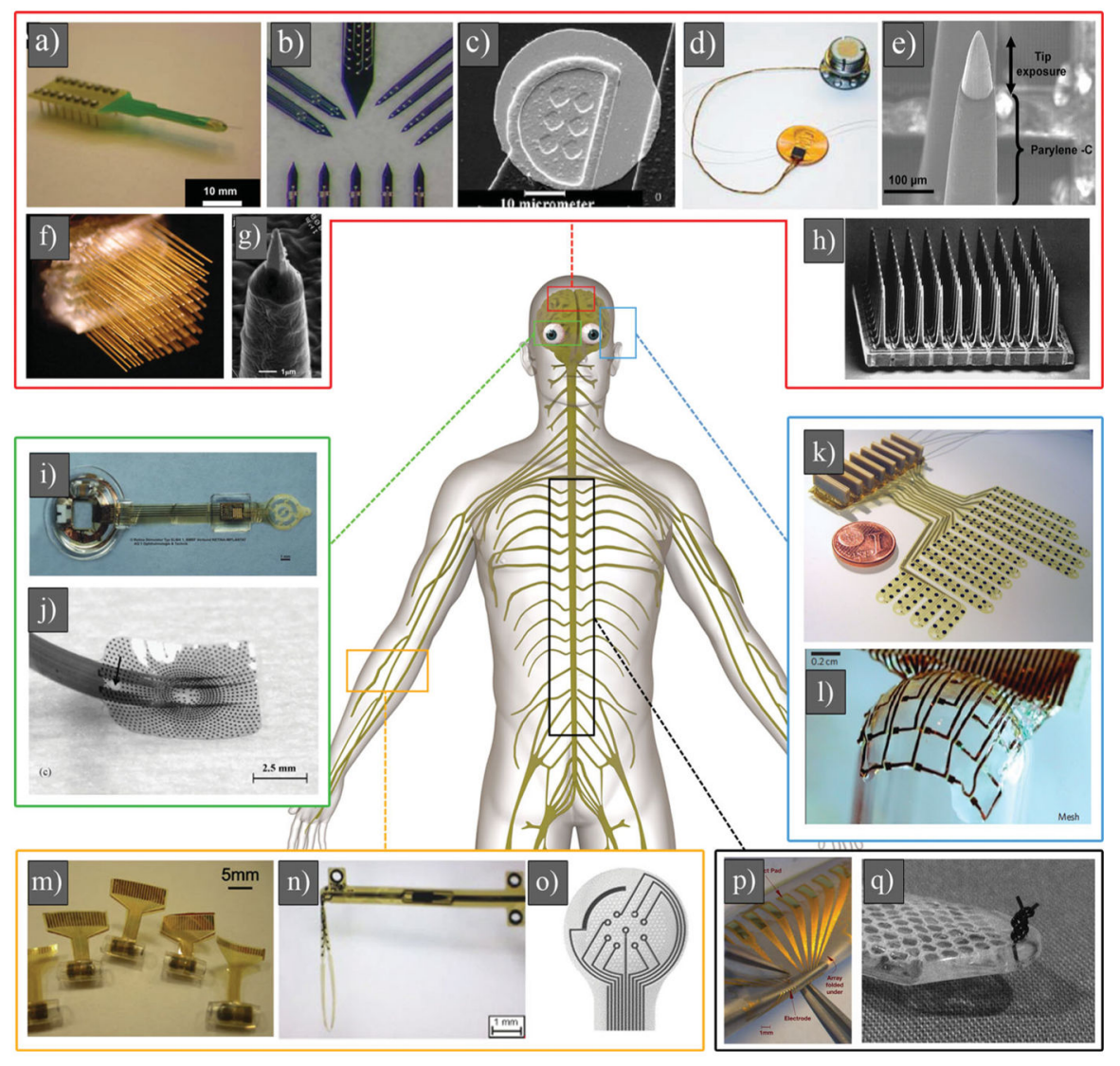

Figure 1.

a) Eight-channel silicon substrate acute Michigan electrode. Reproduced with permission. ${ }^{[174]}$ Copyright 2008, Elsevier. b) High-magnification photograph illustrating four different types of sites layouts for Michigan electrode (NeuroNexus Technologies). Reproduced with permission. ${ }^{[3]}$ Copyright 2008, Society for Neuroscience. c) SEM image of a single gold site of Michigan electrode. Reproduced with permission. ${ }^{[170]}$ Copyright 2003, Elsevier. d) BrainGate microelectrode array (i.e. Utah array) connected by a $13 \mathrm{~cm}$ ribbon cable to percutaneous Ti pedestal secured to skull. Reproduced with permission. [84] Copyright 2006, Nature Publishing Group. e) High-magnification image of an electrode of Utah array. Reproduced with permission. ${ }^{[427]}$ Copyright, 2010, Elsevier. f) Multiple boards stacked up to form arrays with up to 128 microwires. Reproduced with permission. [414] Copyright 2003, National Academy of Sciences. g) SEM image of a microwire, showing Au tip coated with parylene. Reproduced with permission. ${ }^{[428]}$ Copyright 2012, IOP Publishing. h) SEM image of 100 microelectrodes of Utah electrode array. Reproduced with permission. ${ }^{[84]}$ Copyright 2006, Nature Publishing Group. i) An epiretinal vision prosthesis, final implant with parylene $\mathrm{C}$ and silicone rubber encapsulation. Reproduced with permission. ${ }^{[429]}$ Copyright 2009, IOP Publishing.) Heat molded and annealed retinal electrode array with retained spherical curvature (arrow denotes retinal tack hole). Reproduced with permission. ${ }^{[430]}$ Copyright 2008, Elsevier. k) Fully assembled electrode array. The diameter of the coin is $16 \mathrm{~mm}$. Reproduced with permission. ${ }^{[110]}$ Copyright 2009 , IOP Publishing. 1) Optical image of silk-supported polyimide electrode arrays of a $25 \mu \mathrm{m}$ 
mesh wrapped onto a glass hemisphere. Reproduced with permission. ${ }^{[431]}$ Copyright 2010, Nature Publishing Group. m) Schematic cross-section of the channel pattern showing the structure neutral plane (strain \& $0 \%$ ) at the electrode layer. Reproduced with permission. ${ }^{[432]}$ Copyright, 2010 Springer. n) Transversal intrafascicular multichannel electrode. Reproduced with permission. ${ }^{[433]}$ Copyright 2011, Wiley. o) Enlarged view of the sieve portion of the regenerative electrodes, with nine ring electrodes around via holes and a larger counter electrode. Reproduced with permission. ${ }^{[434]}$ Copyright 2004, Elsevier. p) Fabricated PDMS-substrate MEA wrapped around a wire of similar diameter $(2 \mathrm{~mm})$ to that of the neonatal intact or hemisected juvenile in vitro rat spinal cord. Reproduced with permission. ${ }^{[435]}$ Copyright 2008, Springer. q) Distal aspect of paddle-style epidural electrode prepared with a 3-0 suture passed and knotted through the tip. The knot serves as a fixation point for wire snare. Reproduced with permission. ${ }^{[436]}$ Copyright 2011, Congress of Neurological Surgeons; published by Wolters Kluwer Health. 

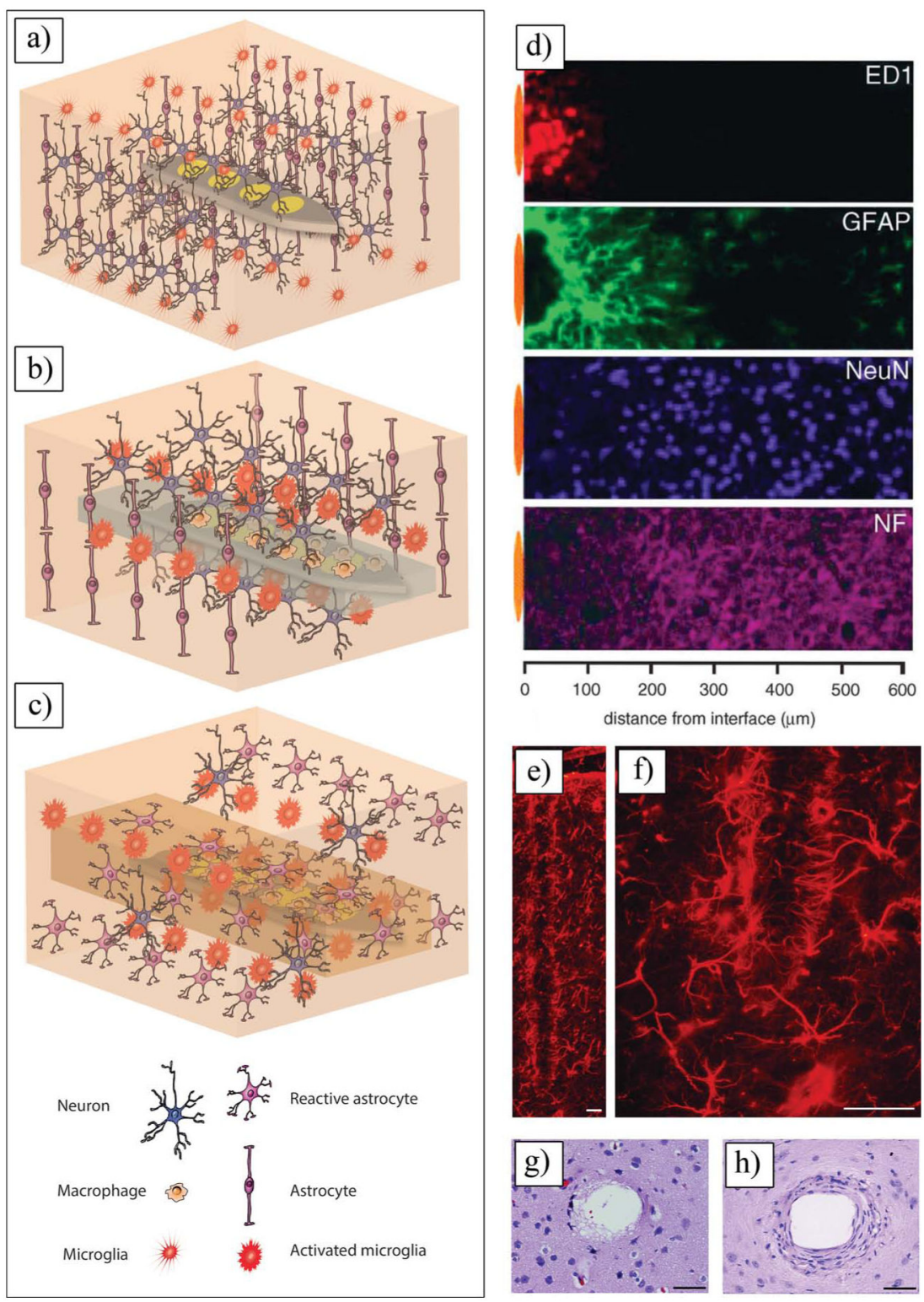

Figure 2.

a) Schematic of insertion of a neural electrode inside the brain. b) Schematic of acute response to an implanted electrode. c) Schematic of chronic response to an implanted electrode. d) Immunoreactivity images using cell-type-specific markers at microelectrode brain tissue interface. Representative image collected from adjacent section of an animal with 4-week microelectrode implant illustrates general appearance of foreign body response. Position of microelectrode illustrated by orange oval (drawn to scale) left to each image. d) Reproduced with permission. ${ }^{[53]}$ Copyright 2005, Elsevier. e,f) Reactive astrocytes labeled with GFAP staining encapsulate neural probes in a dense cellular sheath, Calibration bar = $50 \mu \mathrm{m} . \mathrm{g})$ Acute injury caused by inserting a microelectrode into brain cortex, showing activation and migration of astrocytes and microglial cells to injury site, Calibration bar $=50$ $\mu \mathrm{m}$. h) Chronic response forming dense sheath of fibroblasts, macrophages, and astrocytes 
around implant, Calibration bar $=50 \mu \mathrm{m}$. e-h) Reproduced with permission. ${ }^{[97]}$ Copyright 2010, C. Marin, E. Fernandez; published by Frontiers. 

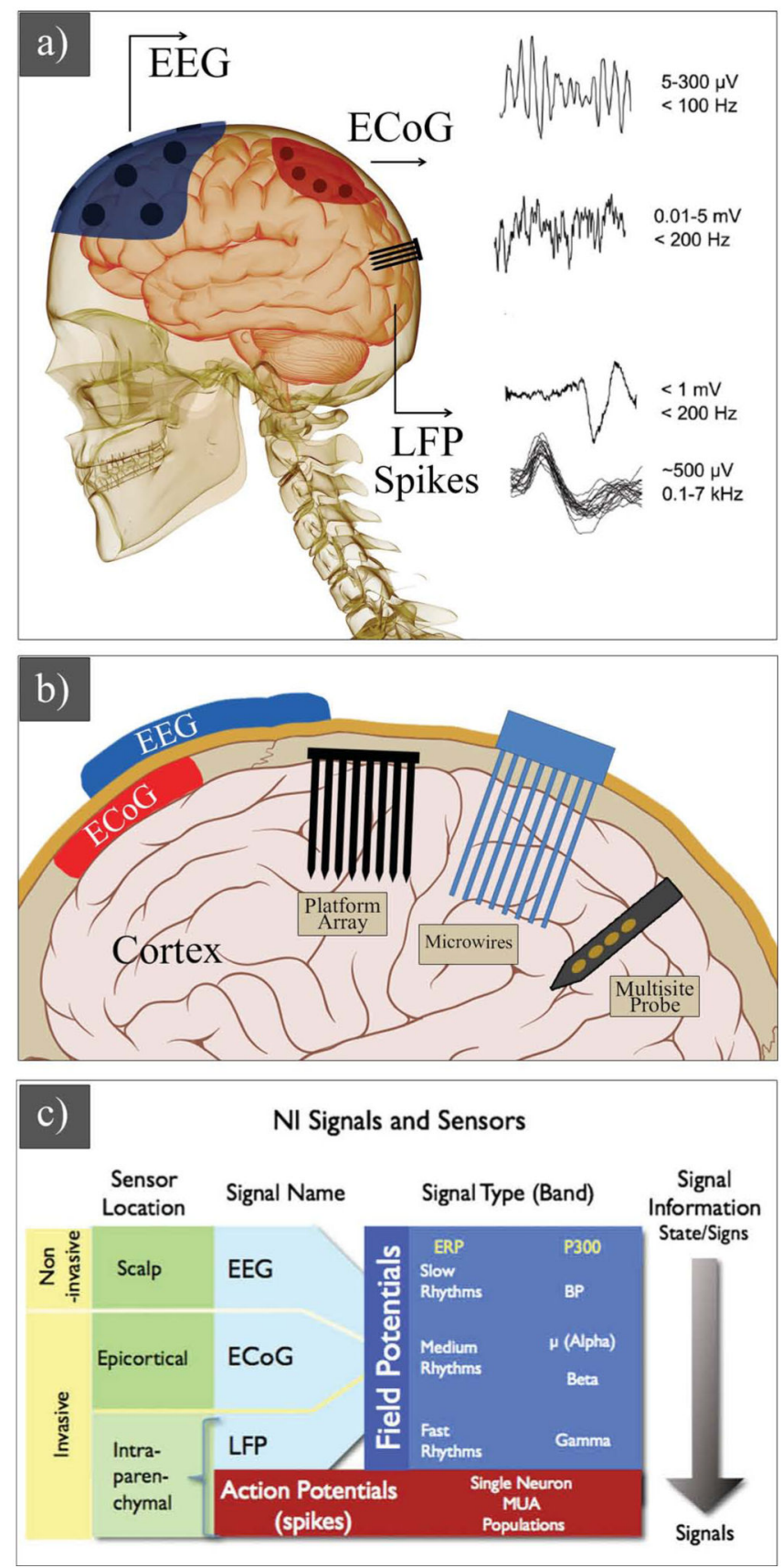

Figure 3.

Schematic of a) neural signals (EEGs, ECoGs, LFPs, and spikes) and their properties. b) EEG electrode on the skull, ECoG electrode on the surface of brain, and penetrating electrodes: three main types of intraparenchymal (intracortical) sensors now in use are illustrated: platform array, an array of electrodes emanating from a substrate that rests on the cortical surface; multisite probe, with contacts along a flattened shank; and microwire assemblies, consisting of fine wires. c) Signals and sensors for neural interface systems. c) Reproduced with permission. ${ }^{[88]}$ Copyright 2008, Elsevier. 


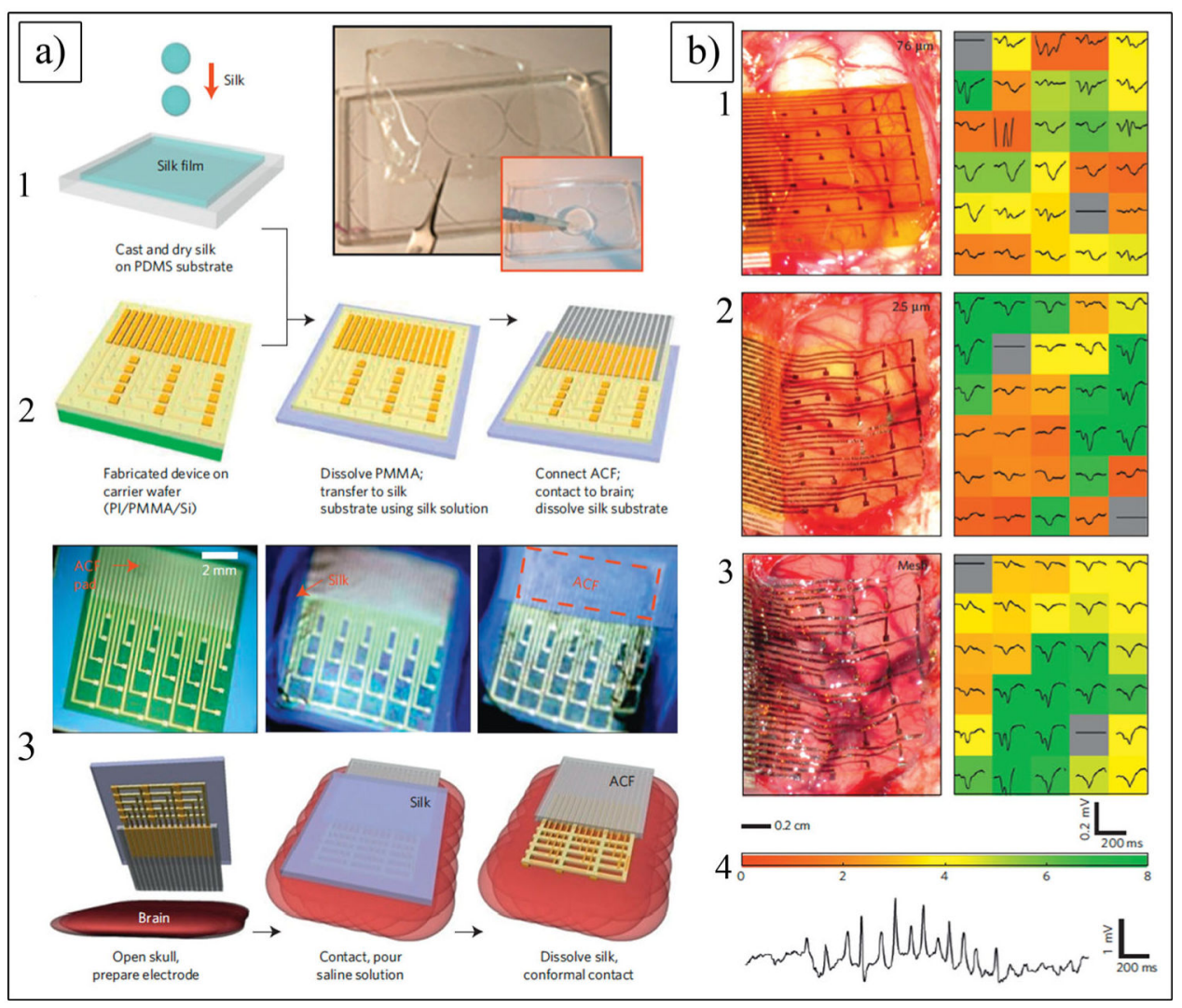

Figure 4.

a) Schematics and images showing fabricating steps for conformal silk-supported PI electrode arrays. a1) Casting and drying of silk fibroin solution on temporary PDMS substrate. a2) Fabricating steps for electrode arrays. a3) Schematics of clinical use of a representative device in ultrathin mesh geometry with dissolvable silk support. b) Photos and data from animal validation experiments. b1-b3) Images of electrode array on a feline brain (left) and average evoked response from each electrode (right) with color showing ratio of root mean square (rms) amplitude of each average electrode response in $200 \mathrm{~ms}$ window (plotted) immediately preceding the stimulus presentation for a $76 \mu \mathrm{m}$ (b1), $2.5 \mu \mathrm{m}$ (b2) and $2.5 \mu \mathrm{m}$ mesh (b3) electrode array. Color bar at bottom of (b3) provides scale used in right frames of b1-b3 to indicate rms amplitude ratios. b4) Representative voltage data from a single electrode in $2.5 \mu \mathrm{m}$ mesh electrode array showing a sleep spindle. $\mathrm{a}, \mathrm{b}$ ) Reproduced with permission. ${ }^{[431]}$ Copyright 2010, Nature Publishing Group. 

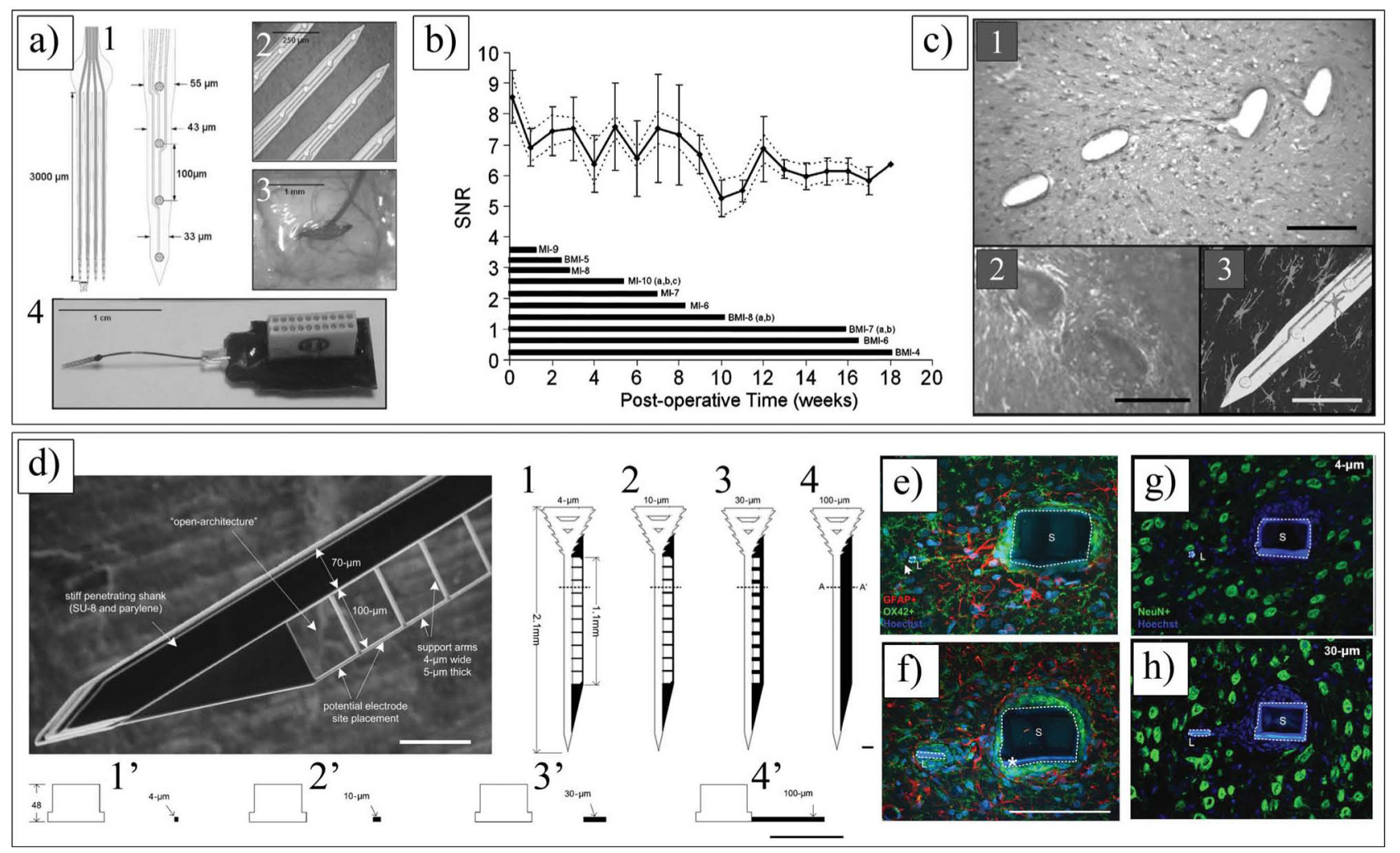

Figure 5.

a) Michigan 16-channel probe. a1) Schematic of four shanks. a2) Four shank, 16-channel probe with $20 \mu \mathrm{m}$ diameter-recording sites. a3) Implanted probe in auditory cortex. Thin layer of ALGEL covers implanted probe and surface of the brain. a4) Assembled probe. b) Average percent of active electrodes on implanted arrays. Time bars at bottom of figure represent each animal's contribution to mean results. c) c1) $20 \mu \mathrm{m} H \& \mathrm{E}$ stained section from a four-shank device implanted in animal for 127 days. c2) $50 \mu \mathrm{m}$ immunostained section (GFAP and laminin) showing a close-up of two shanks from four-shank device implanted in animal for 36 days. c3) $150 \mu \mathrm{m}$ section taken parallel to a probe with a single shank remaining intact within the section for 38 days. Calibration bar $=100 \mu \mathrm{m}$. a-c) Reproduced with permission. ${ }^{[17]}$ Copyright 2004, Institute of Electrical and Electronics Engineers. d) SEM image of a parylene-based open-architecture probe used for in vivo testing. d1-d4) CAD drawings of each probe design indicating overall length and width of three lattice platforms $(4,10,30 \mu \mathrm{m})$, and d4) one nonlattice platform (100 $\mu \mathrm{m}$ wide). d12-d42) Crosssectional view of line A-A2 shown in (d1-d4). All the probes have identical shank and outer dimensions. Calibration bar $=100 \mu \mathrm{m}$. e,f) Expression of astrocytes (dyed with red GFAP stain), microglia (dyed with green OX-42 protein stain), and cell nuclei (dyed with blue Hoechst 33342 stain) of parylene electrode implanted in the rat brain. Calibration bar = $100 \mu \mathrm{m} . \mathrm{g}, \mathrm{h}$ ) IHC images showing $\mathrm{NeuN}^{+}$reactivity (green) and Hoechst counterstain (blue) for each probe type. Shank marked with $\mathrm{S}$ and much smaller lateral edge marked with L. Calibration bar $=100 \mu \mathrm{m}$. d-h) Reproduced with permission. ${ }^{[113]}$ Copyright 2007, Elsevier. 

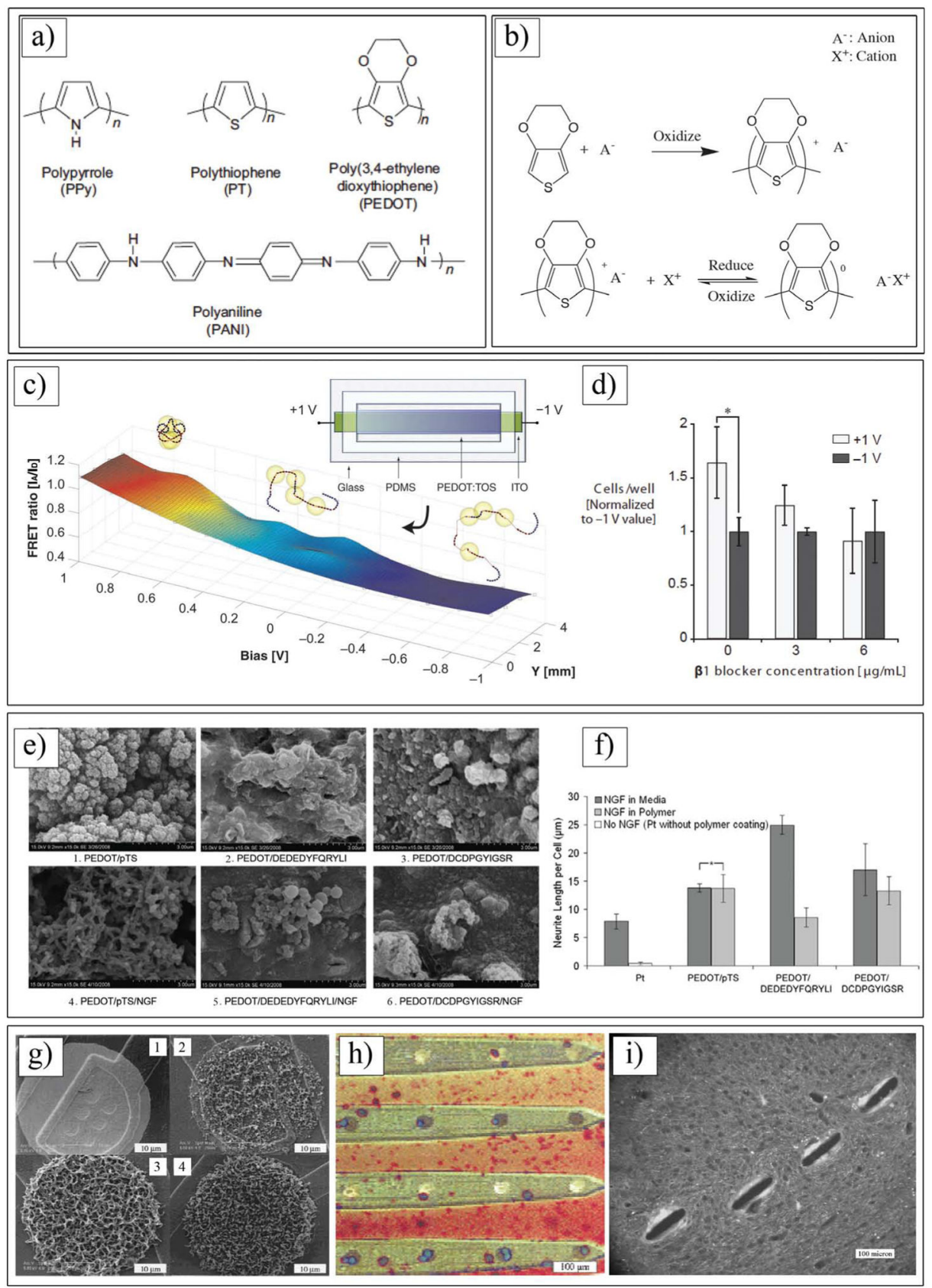

Figure 6.

a) Chemical structures of various conducting polymers. b) Electrochemical polymerization of PEDOT and redox behavior of PEDOT doped with motile anion A. c) FRET (Förster Resonance Energy Transfer) ratios on gradient devices as a function of applied bias and position. d) Relative number of adhered 3T3-L1 mouse fibroblasts on fully oxidized (+1 V) and reduced $(-1 \mathrm{~V})$ pixels, for varying doses of a $\beta 1$ function-blocking antibody. $c, d)$ Reproduced with permission. ${ }^{[190]}$ Copyright 2012, Wiley-VCH. e) SEM images at $15,000 \times$ magnification of NGF entrapped in PEDOT films compared with control films produced without NGF modification of the electrolyte. f) Neurite outgrowth of PC12 cells 
on laminin peptide-doped PEDOT with NGF incorporation at $96 \mathrm{~h}$ post-plating. Neurite outgrowth is represented as neurite length per adhered cell, calculated by normalizing total neurite length to cell density. Standard error of mean is given $(n=3)$. *No significant difference. e,f) Reproduced with permission. ${ }^{[36]}$ Copyright 2010, Elsevier. g) SEM images of Ppy/SLPF-coated electrode sites. From g1) to g4), deposition time increased, corresponding to a total charge passed of (g1) $0 \mu \mathrm{C}$, (g2) $1 \mu \mathrm{C}$, (g3) $4 \mu \mathrm{C}$ and (g4) $10 \mu \mathrm{C}$. Area of uncoated electrode site is $1250 \mu \mathrm{m}^{2}$. Reproduced with permission. ${ }^{[168]}$ Copyright 2001, Wiley. h) Ppy/SLPF coated 4-shank 16-channel neural probe cultured with rat glial cells. Dark black spots are coated electrode sites and bright ones are uncoated. i) Neurofilament immunostained tissue sections of guinea pig brain where 4-shank Ppy/ DCDPGYIGSR coated probes were implanted and pulled out after 3 weeks. h,i) Reproduced with permission. ${ }^{[35]}$ Copyright 2003, Elsevier. 

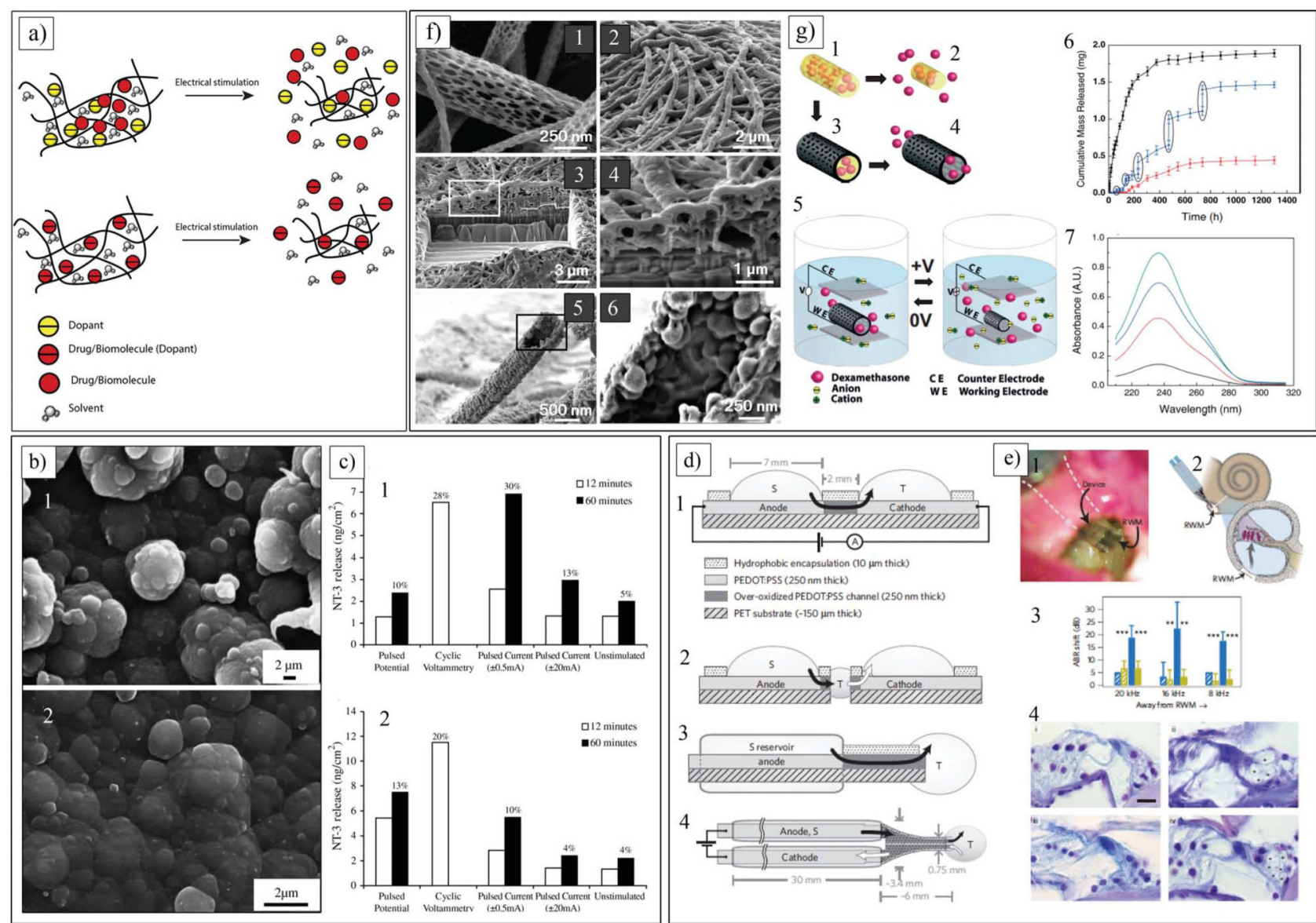

Figure 7.

a) Schematic of incorporation and controlled release of drugs and biomolecules as dopants or non-doping inclusion in CPs. b) SEM images of Ppy/pTS/NT-3 films (b1) before and (b2) after 60 min electrical stimulation in $0.9 \% \mathrm{NaCl}$ solution. c) Mass of NT-3 released from a (c1) thin $(3.6 \mu \mathrm{m})$ and $(\mathrm{c} 2)$ thick $(26 \mu \mathrm{m})$ Ppy/pTS/NT-3 polymer films in $1 \mathrm{~mL}$ of $0.9 \%$ $\mathrm{NaCl}$ by various electrochemical release methods. b,c) Reproduced with permission. ${ }^{\text {[213] }}$ Copyright 2006, Elsevier. d) Planar and encapsulated geometries of delivery device. d1) Side view of planar device used in initial Glu, Asp and GABA transport studies. Black arrow indicates flow of charged neurotransmitters from source electrolyte, S, through anode, then through over-oxidized channel and finally out into target electrolyte, $\mathrm{T}$, through cathode. d2) Side view showing developmental progression from planar device (d1), d3) Side-view scheme of encapsulated device. d4) Top view of encapsulated device with electrolyte reservoir tubes $2 \mathrm{~mm}$ in outer diameter. e) In vivo application of ion pump. e1) Photograph of device mounted on RWM, with two ion channels visible as dark blue strips on transparent substrate. e2) Experimental scheme. e3) Mean ABR shift (re:pre-treatment thresholds) as a function of recording frequency after $15 \mathrm{~min}$ (hatched bars) and $60 \mathrm{~min}$ (filled bars) of Glu (blue) and HC (yellow) delivery. Frequencies are illustrated in relation to their increasing distance from RWM. Error bars indicate standard deviation. e4) Histological sections of cochlea with inner hair cells on right and outer hair cells on left showing (i) effect of HC delivery (as control) and (ii) effect of Glu delivery (excitotoxic-induced 
damage to auditory dendrites indicated with asterisks) in lower basal region (turn 1), and similar (iii) HC and (iv) Glu effect in upper basal region (turn 2). Calibration bar $=20 \mu \mathrm{m}$. d,e) Reproduced with permission. ${ }^{[166]}$ Copyright 2009, Nature Publishing Group. f) SEM images of PLGA nanofibers and PEDOT nanotubes. f1) Diameters of the PLGA fibers range 40-500 nm. f2) Electropolymerized PEDOT nanotubes on electrode site of an acute neural probe tip after removing the PLGA core fibers. f3) A section of f2) cut with a FIB showing silicon substrate layer and PEDOT nanofiber coating. f4) Higher-magnification image of f3) showing PEDOT nanotubes crossing each other. f5) PEDOT nanotube. f6) Highermagnification image of PEDOT nanotube. g) Schematics of controlled release of dexamethasone: g1) dexamethasone-loaded electrospun PLGA, g2) hydrolytic degradation of PLGA fibers leading to release of drug, and g3) electrochemical deposition of PEDOT around dexamethasone loaded electrospun PLGA fiber slows down release of dexamethasone. g4) PEDOT nanotubes in a neutral electrical condition. g5) External electrical stimulation controls the release of dexamethasone from the PEDOT nanotubes due to contraction or expansion of the PEDOT. g6) Cumulative mass release of dexamethasone from: PLGA nanofibers (black squares), PEDOT-coated PLGA nanofibers (red circles) without electrical stimulation, and PEDOT-coated PLGA nanofibers with electrical stimulation of $1 \mathrm{~V}$ applied at five specific times indicated by circled data points (blue triangles). g7) UV absorption of dexamethasone-loaded PEDOT nanotubes. f,g) Reproduced with permission. ${ }^{[173]}$ Copyright 2006, Wiley-VCH. 

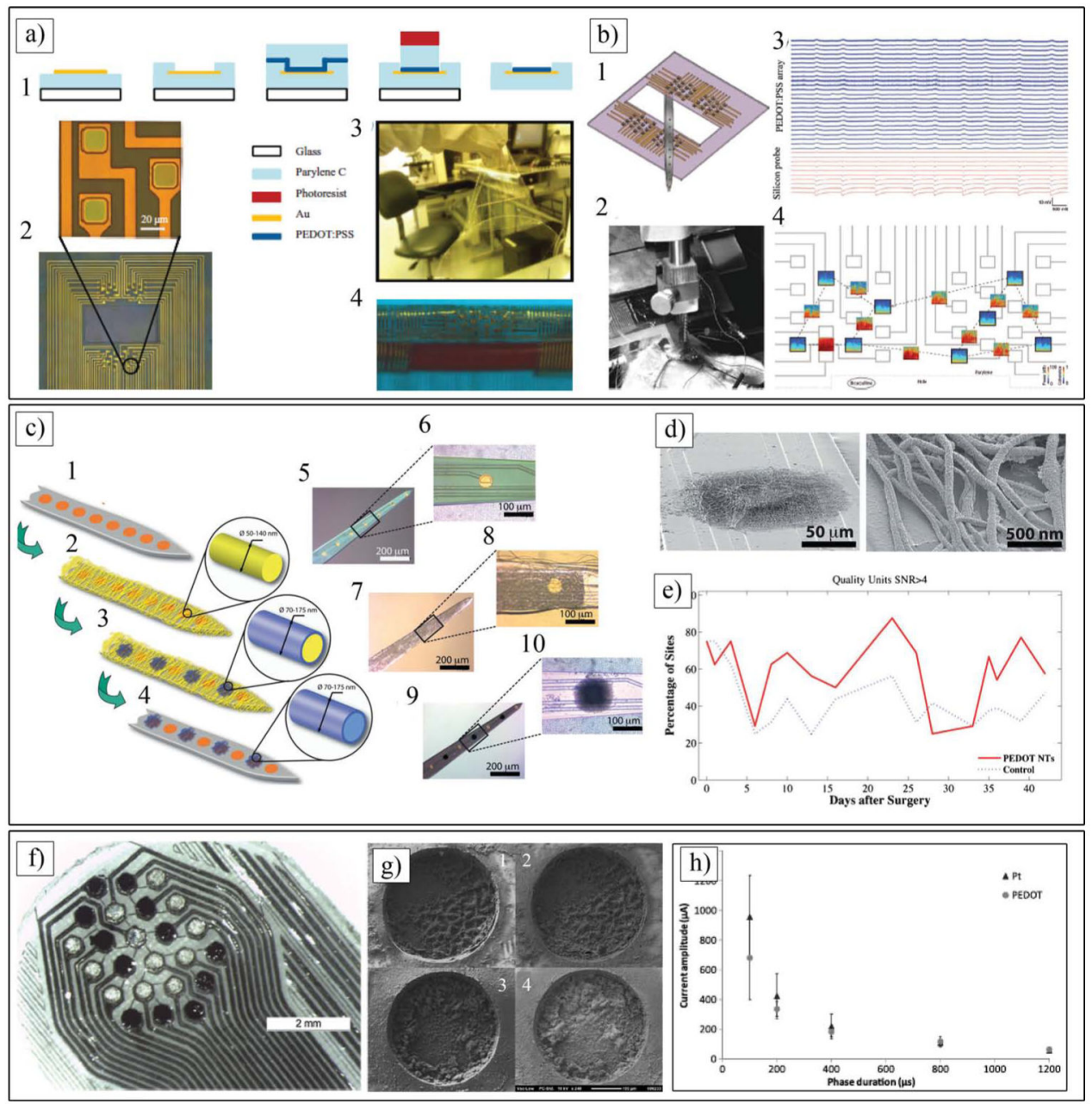

Figure 8.

a) a1) Schematic representation of the fabrication process indicating the cross-section of an electrode (not to scale). a2) Microscopy images of the array and a detailed view of three electrodes. a3) The electrode array is shown to support the weight of a quartz wafer a4) to conform to a cylinder with a radius of $2.2 \mathrm{~mm}$. b) b1) Schematic of the experiment used for the validation of the PEDOT:PSS array with a silicon probe viewed from inside the brain. b2) photograph showing the implantation. b3) Recordings from 25 electrodes in the PEDOT:PSS array, and from 10 electrodes in the silicon probe, ordered from superficial to deeper in the cortex. b4) Time-frequency (TF) analysis of the signals recorded by a few electrodes (black frames, X-axis: time, $10 \mathrm{~min}$; y-axis: frequency, 0.1-50 Hz; color coding: power, $\mathrm{dB}$ ) and their cross-spectrum coherences (open boxes, same axes as TF plots, color coding: coherence). a,b) Reproduced with permission. ${ }^{[95]}$ Copyright 2011, Wiley-VCH. c) Schematic illustration of PEDOT nanotube fabrication on neural microelectrodes: c1, c2) Electrospinning of biodegradable PLLA template fibers. c3) Electrochemical deposition of PEDOT. c4) dissolving the electrospun core fibers to create conducting polymer nanotubes. c5-c10) Optical microscopy images of the entire microelectrode (c5) and single electrode site (c6) before surface modification. (c7) and single electrode site (c8) after electrospinning of PLLA nanofibers. (c9) and single electrode site (c10) after electrochemical deposition of 
PEDOT and removing the PLLA core fibers. d) PEDOT nanotubes on the surface of a single microelectrode site. Right image is a higher magnification of left image. e) Percentage of sites recording low-and high-quality units. PEDOT nanotube sites demonstrated a significant improvement in percentage of sites recording high-quality units on a day-to-day basis. f) 24electrode array in hexagonal (hex) configuration used for in vivo studies with 12 bare $\mathrm{Pt}$ (light electrode sites) and 12 PEDOT/pTS-coated electrodes (dark electrodes). g) SEM images of g1) active PEDOT (prior to stimulation), g2) active PEDOT (after stimulation), g3) passive PEDOT (prior to stimulation) and g4) passive PEDOT (after stimulation). c-g) Reproduced with permission. ${ }^{[32]}$ Copyright 2009, Wiley-VCH. h) Strength vs duration curve, demonstrating the relationship between average current required to reach threshold and duration of phases for biphasic current driven stimulation of tissue using suprachoroidal electrodes $(n=5)$. h,j) Reproduced with permission. ${ }^{[156]}$ Copyright 2013, IOP Publishing. 

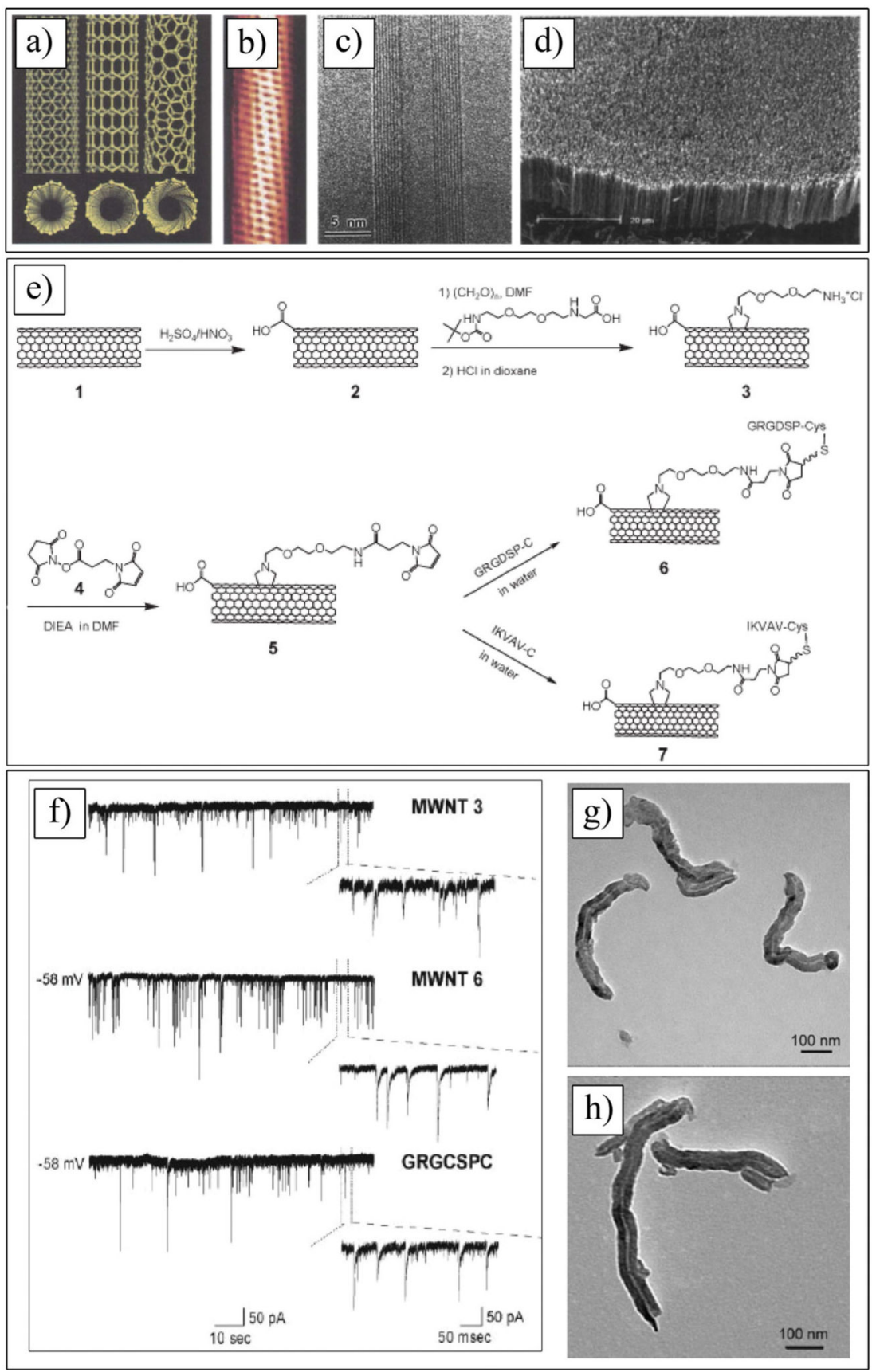

Figure 9.

a) Schematic illustrations of the structures of armchair, zigzag, and chiral SWCNTs.

Projections normal to the tube axis and perspective views along the tube axis are on the top and bottom, respectively. b) Tunneling electron microscope image showing the helical structure of a 1.3-nm-diameter chiral SWCNT. c) TEM image of a MWCNT containing a concentrically nested array of nine SWCNTs. d) SEM image of an array of MWCNTs

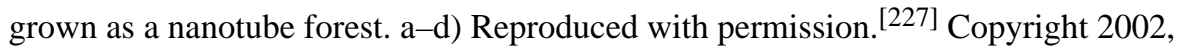
American Association for the Advancement of Science. e) Synthesis of MWNT-peptide conjugates. f) MWCNTs 3, 6, and peptide GRGDSPC (Pep 1) alone do not affect neuronal 
survival and activity. Tracings represent spontaneous synaptic activity recorded from neurons ( 8 days in vitro) after MWCNTs 3, 6, and GRGDSPC incubation at $24 \mathrm{~h}$ washout. Below each recording, on the right, the magnifications show the presence of heterogeneous events (inward currents), representing the activation of mixed synapses impinging on the recorded neurons. g,h) TEM images of MWCNTs 2, and 7. e-h) Reproduced with permission. ${ }^{[437]}$ Copyright 2009, Wiley-VCH. 

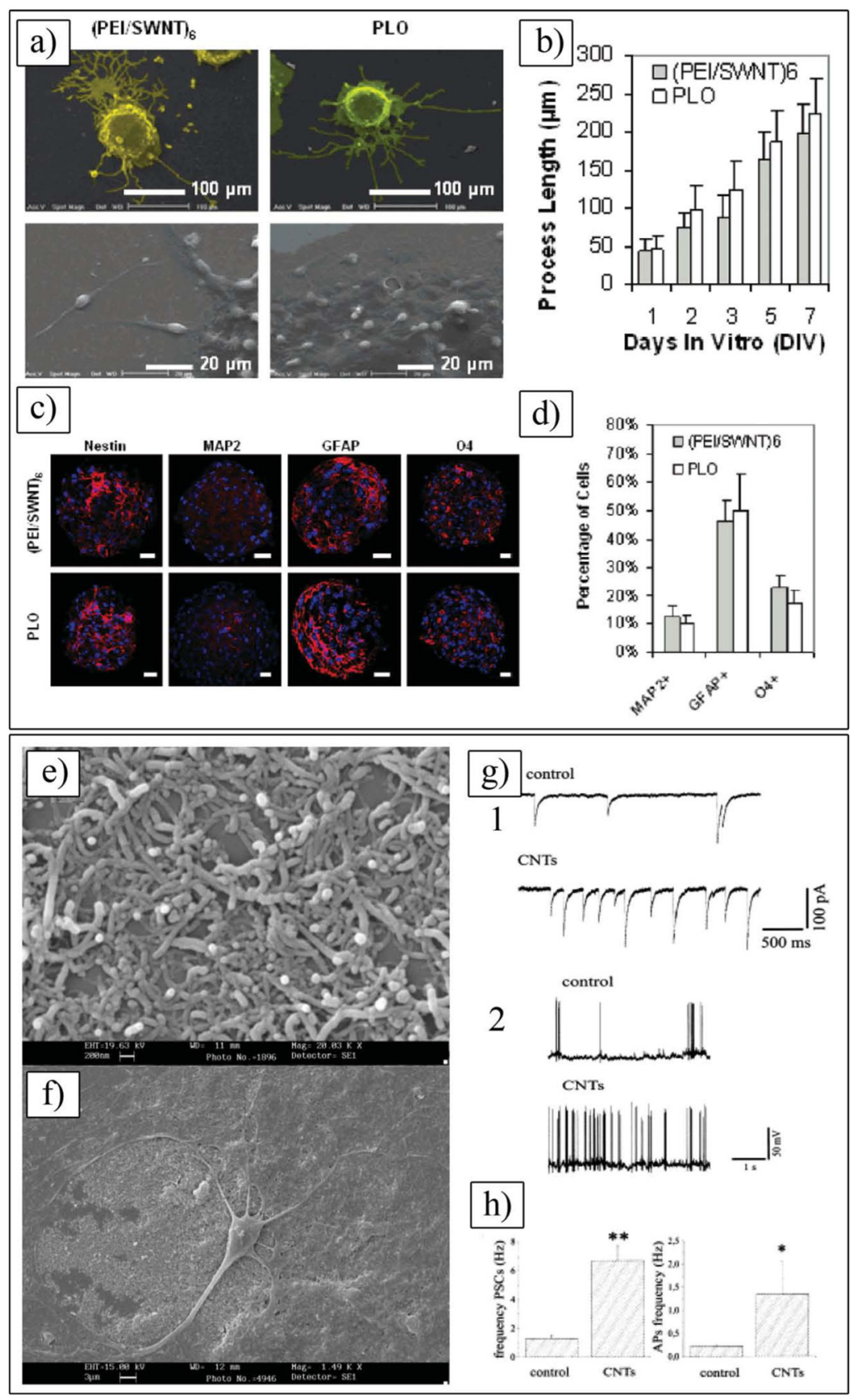

Figure 10.

a) Color-enhanced SEM images highlighting neurite outgrowth of differentiated neurospheres on day 7 (first row). SEM images at higher magnification showing migrating NSCs around neurospheres (second row). b) Evaluation of the lengths of processes extending from the differentiated neurospheres for the 7 day culture period. c) Confocal microscopy images differentiated neurospheres on day 7. Neurospheres were stained for markers of NSCs (nestin), neurons (MAP2), astrocytes (GFAP), and oligodendrocytes (O4). Neural markers are shown in red, while the cell nuclei, counterstained with DAPI, are shown in blue. Images represent scans near the center of the neurospheres. Calibration bar $=20 \mu \mathrm{m}$. 
d) Average percentages of differentiated cell phenotypes after 7 days in culture. a-d) Reproduced with permission. ${ }^{[241]}$ Copyright 2007, ACS Publications. e) SEM image showing the retention on glass of MWCNT films after an 8-day test in culturing conditions. f) Neonatal hippocampal neuron growing on dispersed MWCNT after 8 days in culture. The surface structure, composed of films of MWCNT and peptide-free glass, allows neuron adhesion. Dendrites and axons extend across MWCNT, glial cells, and glass. g) CNT substrate increases hippocampal neurons spontaneous synaptic activity and firing. g1) Spontaneous synaptic currents (PSCs) are shown in both control (top tracings) and in cultures grown on CNT substrate (bottom tracings). g2) Current clamp recordings from cultured hippocampal neurons in control (top tracings) and CNT growth conditions (bottom tracings). Spontaneous firing activity is greatly boosted in the presence of CNT substrates. h) Histogram plots of PSCs-(left) and APs-(right) frequency in control and CNT cells; note the significant increase in the occurrence of both events when measured in CNT cultures. $* * P<0.0001$ and $* P<0.05$. e-h) Reproduced with permission. ${ }^{[127]}$ Copyright 2005, ACS Publications. 

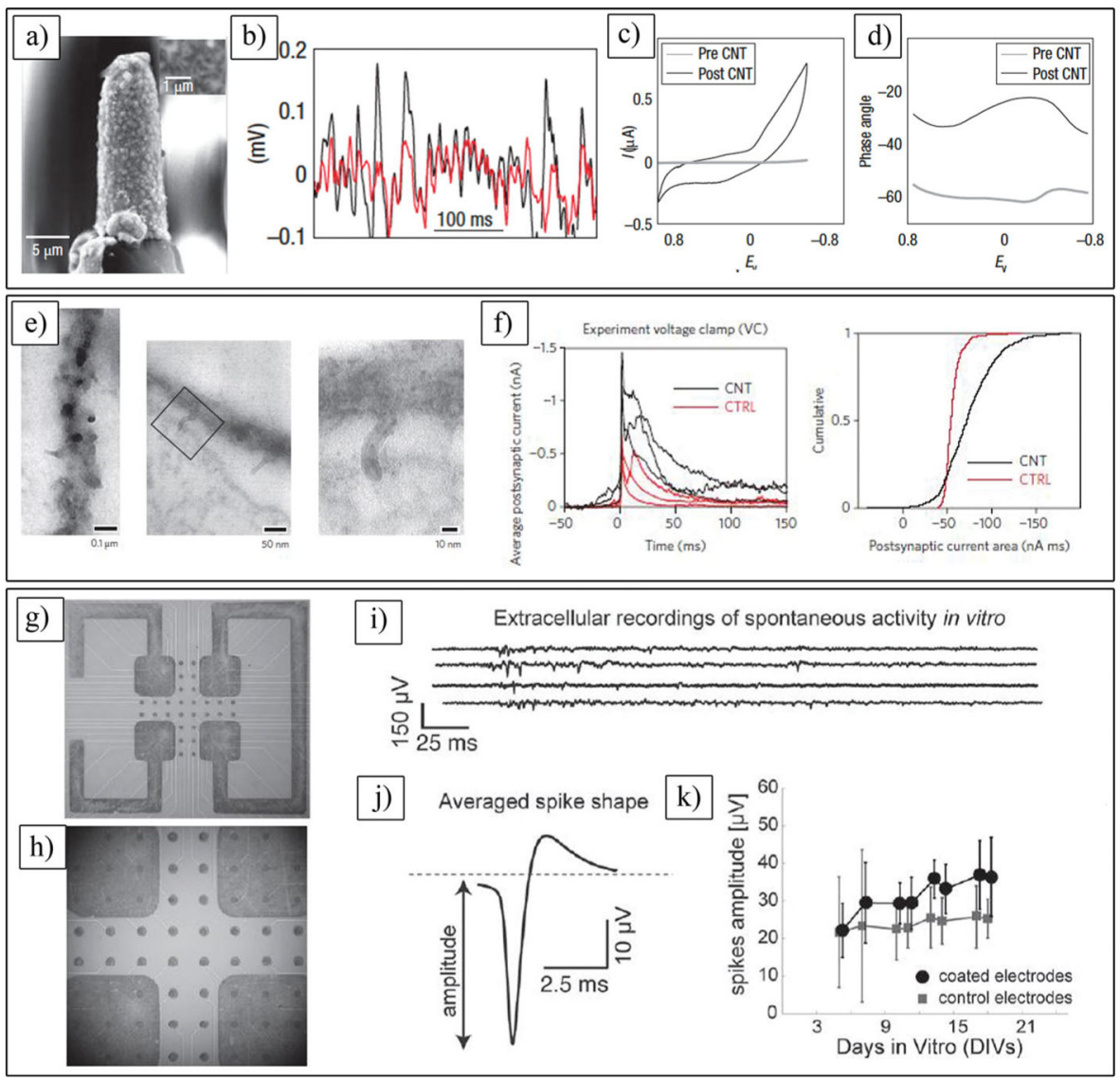

Figure 11.

a) CNTs covalently attached to a sharp tungsten electrode. b) Local field potential traces from bare controls (red trace) and CNT-coated (black trace) electrodes show correlated activity but larger amplitude responses from CNT-coated electrodes. c,d) Covalent coating of CNTs increased the charge transfer (c) and decreased the phase angle (d). a-d) Reproduced with permission. ${ }^{[28]}$ Copyright 2008, Nature Publishing Group. e) 1) Morphology of nanotubes. 2,3) High-magnification micrographs from a section consecutive. The rectangular area in 2 is magnified in 3. f) average spontaneous postsynaptic currents waveforms in six neurons were computed to provide a measure of the probability of presynaptic event clustering (that is, a burst of spikes), within a window of 50-150 ms around its peak. Significant differences in the postsynaptic currents duration are apparent from the shift in the empirical cumulative distributions of their areas. e,f) Reproduced with permission. ${ }^{[29]}$ Copyright 2009, Nature Publishing Group. g,h) Optical microscopy images of titanium nitride (TiN) microelectrode arrays printed by functionalized COOH-MWCNTs. Stamps of arbitrary shape were designed in this case to cover single electrodes and connect them together. i) Extracellular raw voltage waveforms as detected by four MEA electrodes in long-term neuronal culturing experiments. Each recording channel independently captures extracellular action potentials or $\mathrm{j}$ ) "spikes", spontaneously fired by neurons growing in proximity of the microelectrode. k) Comparing the average amplitude of the extracellular spikes detected across several days by MEA electrodes coated by CNTs to those detected by uncoated electrodes reveals, on average, much higher signal amplitudes, which are attributed 
to the improved electrical properties at the electrode-electrolyte interface and the resulting signal-to-noise ratio. g-k) Reproduced with permission. ${ }^{[291]}$ Copyright 2011, Wiley-VCH. 

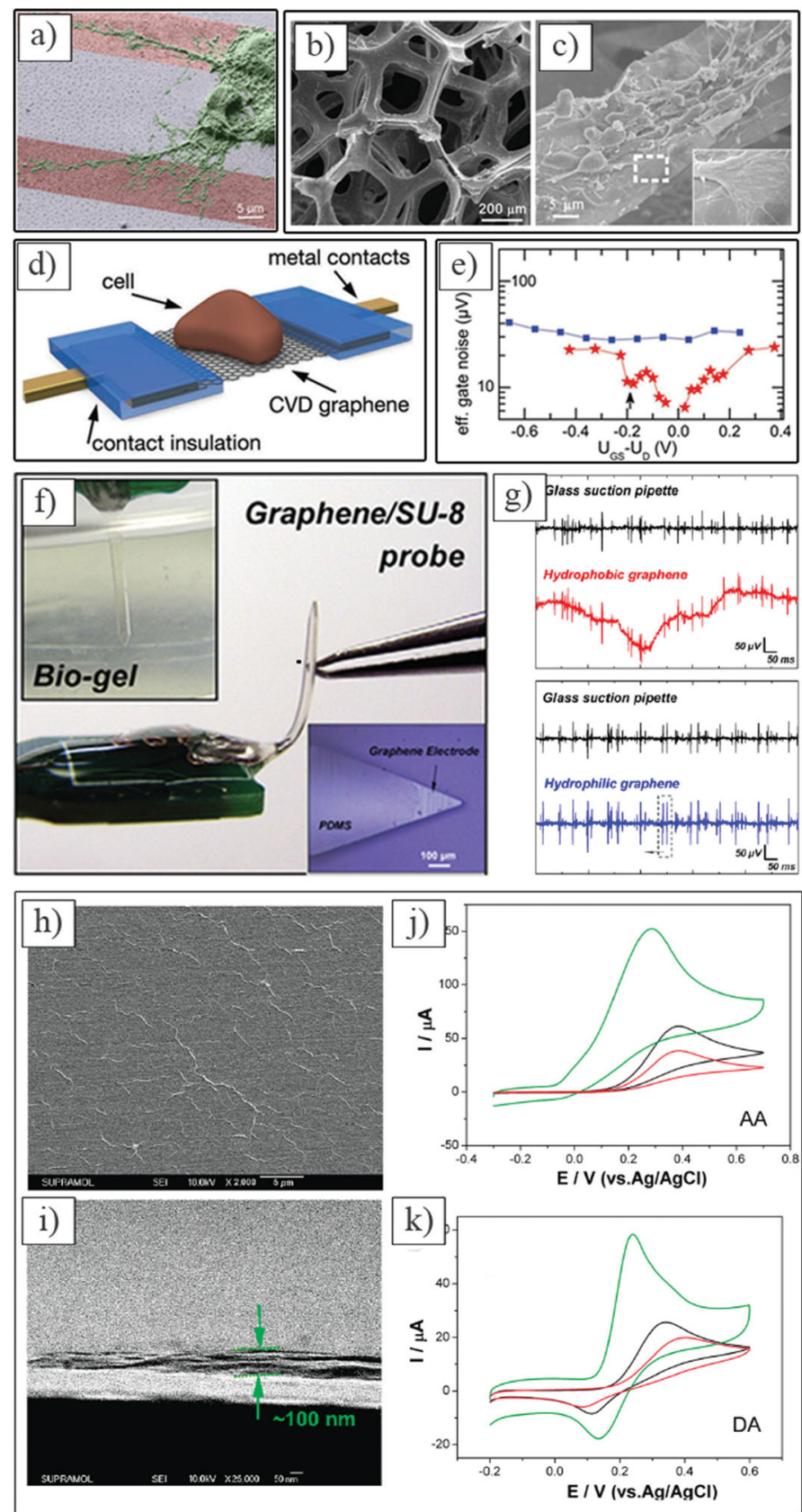

Figure 12.

a) SEM image with graphene regions colored in red, corresponds to the region of the 3-cell aggregate marked in green. Reproduced with permission. ${ }^{[438]}$ Copyright 2013, Wiley-VCH. b) SEM micrographs of 3D-Graphenes (GFs). c) High magnified SEM images of NSCs cultured on 3D-GFs under the proliferation medium. The inset illustrates the interaction between the cell filopodia and 3D-GF surface. b,c) Reproduced with permission. [439] Copyright 2013, Nature Publishing Group. d) Schematic of a G-SGFET with a cell on the gate area. The graphene is shown between the drain and source metal contracts, which are protected by a chemically resistant layer. e) Effective gate noise of a graphene (red stars) 
and a silicon SGFET (blue squares). $\mathrm{U}_{\mathrm{D}}$ refers to the $\mathrm{U}_{\mathrm{GS}}$ (gate voltage) at which the minimum of the current is observed. The arrow marks the point of maximum transductance. d,e) Reproduced with permission. ${ }^{[297]}$ Copyright 2011, Wiley-VCH. f) Optical micrograph of a flexible microprobe bent through 90 degree configurations and penetrating an agar gel. Inset shows graphene electrode upon the SU-8 substrate. g) Extracellular signals with a larger SNR were recorded with a graphene electrode after steam plasma treatment. $\mathrm{f}, \mathrm{g}$ ) Reproduced with permission. ${ }^{[298]}$ Copyright 2013, Elsevier. h,i) SEM images of the CRGO/GC electrode (h and i). j,k) CVs for $3 \mathrm{mM} \mathrm{AA} \mathrm{(j)} \mathrm{and} \mathrm{DA} \mathrm{(k)} \mathrm{at} \mathrm{CR-GO/GC} \mathrm{(green),}$ graphite/GC (red), and GC electrodes (black). Electrolyte: $0.1 \mathrm{M} \mathrm{pH} 7.0$ PBS. Scan rate: 50 $\mathrm{mV} \mathrm{s}^{-1}$. h-k) Reproduced with permission. ${ }^{[440]}$ Copyright 2009, ACS Publications. 

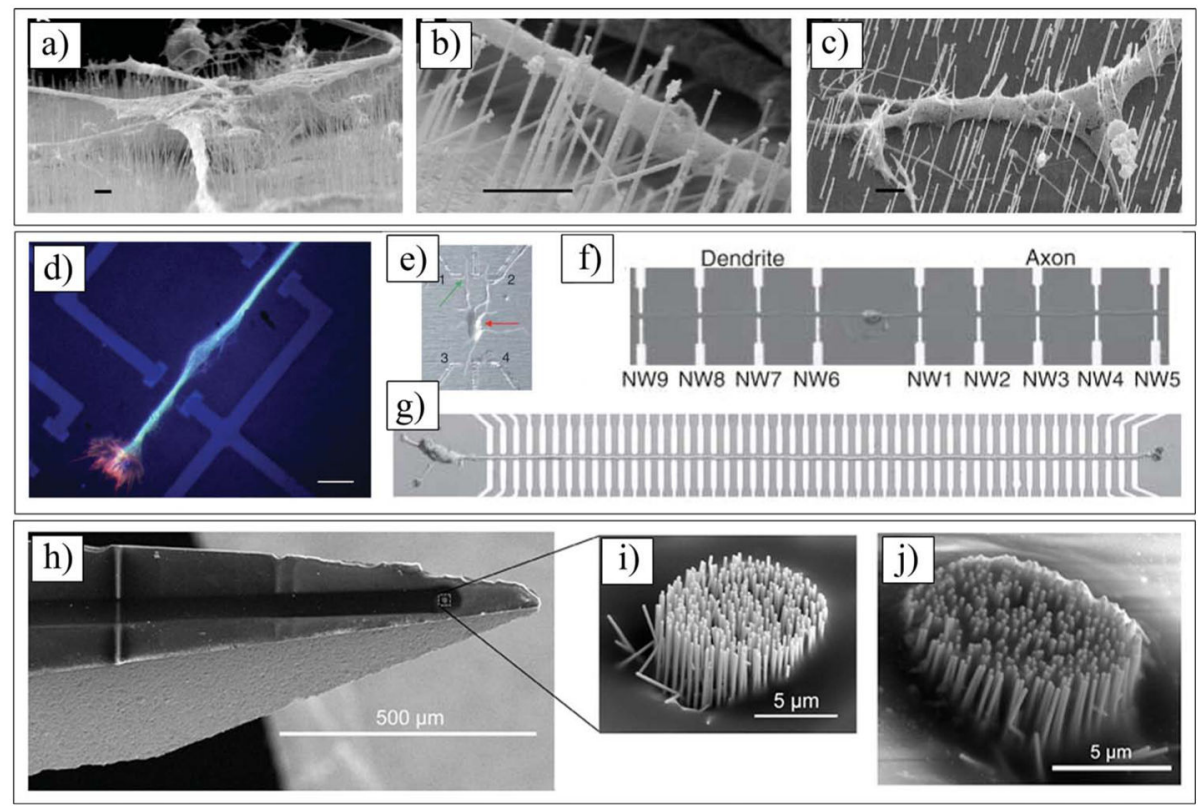

Figure 13.

Images a-c demonstrate three different types of process growth. a) Processes growing on top of wires, attached to their tips. b) Axon growing in space between substrate and wire tips, adhering to sides of wires. c) Process spreading over bulk substrate, apparently engulfing nanowires encountered along its path. Scale bars $1 \mu \mathrm{m}$. a-c) Reproduced with permission. ${ }^{[375]}$ Copyright 2007, ACS Publications. d) Neuritic guidance on SiNW-FETs. Microtubules staining (anti-tyrosinated tubulin, green) reveals neurite shaft and F-actin labeling (phalloidin, red) shows growth cone at neurite tip. Calibration bar $=5 \mu \mathrm{m}$. Reproduced with permission. ${ }^{[376]}$ Copyright 2012, Wiley-VCH. e) Optical image of a cortex neuron connected to three of four functional NW devices in array. f) Optical image of a cortex neuron with axon and dendrite aligned in opposite directions. g) Optical image of aligned axon crossing an array of $50 \mathrm{NW}$ devices with a $10-\mu \mathrm{m}$ interdevice spacing. e-g) Reproduced with permission. ${ }^{[364]}$ Copyright 2006, American Association for the Advancement of Science. h) SEM image of the nanowire-based electrode tip. i) SEM image of nanowire-based sensing region made with an array of freestanding vertical gallium phosphide nanowires covered with hafnium oxide and metal film. j) SEM image of sensing site presented after multiple implantations into rat cortex. $\mathrm{h}-\mathrm{j}$ ) Reproduced with permission. ${ }^{[31]}$ Copyright 2013, Suyatin et al.; published by PLOS ONE. 

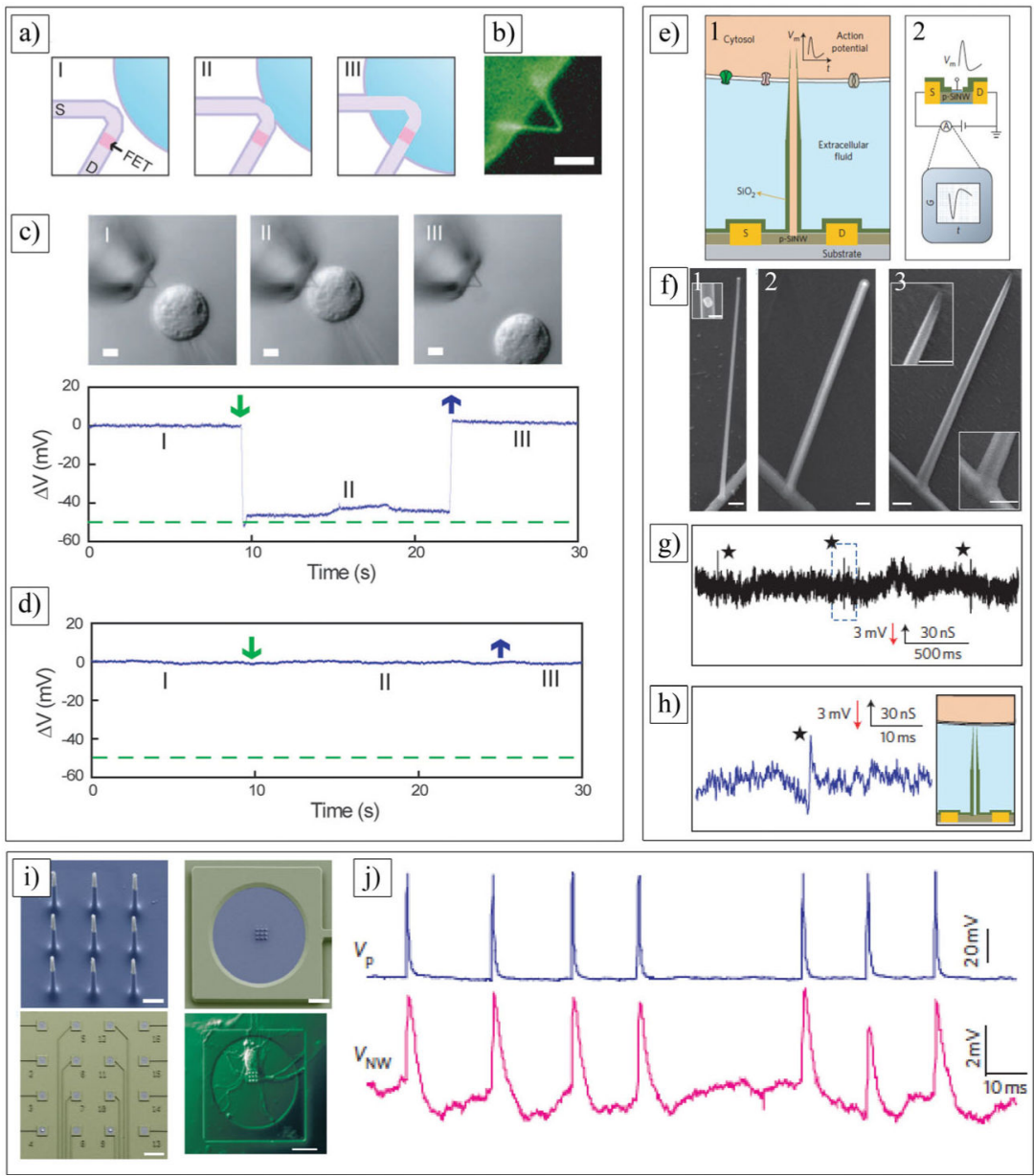

Figure 14.

Surface modification and cellular entry. a) Schematics of nanowire probe entrance into a cell. Dark purple, light purple, pink, and blue colors denote phospholipid bilayers, heavily doped nanowire segments, active sensor segment, and cytosol, respectively. b) False-color fluorescence image of a lipidcoated nanowire probe. c) Differential interference contrast microscopy images (top) and electrical recording (bottom) of an HL- 1 cell and $60^{\circ}$ kinked nanowire probe as cell approaches (I), contacts and internalizes (II), and is retracted from (III) nanoprobe. A pulled-glass micropipette (inner tip diameter $\approx 5 \mu \mathrm{m}$ ) was used to manipulate and voltage clamp HL-1 cell. Dashed green line corresponds to micropipette potential. Calibration bar $=5 \mu \mathrm{m}$. d) Electrical recording with a $60^{\circ}$ kinked nanowire probe without phospholipids surface modification. Green and blue arrows in (c) and (d) mark beginnings of cell penetration and withdrawal, respectively. a-d) Reproduced with permission. ${ }^{[441]}$ Copyright 2010, American Association for the Advancement of Science. e) Schematic diagrams showing (left) a cell coupled to a BIT-FET and variation in device conductance $\mathrm{G}$ (right) with time t during an action potential Vm. S and D indicate source and drain electrodes. f1) SEM image of a germanium nanowire branch on a silicon nanowire oriented close to surface normal. Inset: gold nanodot on a silicon nanowire before growth of germanium nanowire. f2) SEM image of a germanium/silicon heterostructure coated with $\mathrm{ALD} \mathrm{SiO}_{2}$. f3) SEM image of a final nanotube on a silicon nanowire. Insets: magnified 
images of top and bottom of nanotube. Calibration bar $=100 \mathrm{~nm}$ (inset of b), $200 \mathrm{~nm}$ (all other images). g) Magnified view of Representative trace (conductance versus time) reflecting transition from extracellular to intracellular recording. h) Magnified view of trace inside blue dashed rectangle in (g). Stars in (g) and (h) mark position of extracellular spikes. e-h) Reproduced with permission. ${ }^{[353]}$ Copyright 2012, Nature Publishing Group. i1) SEM image of nine silicon nanowires that constitute active region of a VNEA. Calibration bar $=1$ $\mu \mathrm{m}$. i2) SEM image of a VNEA pad. False coloring indicates additional insulation from $\mathrm{Al}_{2} \mathrm{O}_{3}$ (green). Calibration bar $=10 \mu \mathrm{m}$. i3) SEM image of a device consisting of 16 stimulation/recording pads for parallel multi-site interrogation of neuronal circuits. Calibration bar $=120 \mu \mathrm{m}$. i4) Representative DIC micrograph of a rat cortical neuron cultured on a VNEA pad (6 DIV). Calibration bar $=20 \mu \mathrm{m}$. j) Action potentials were stimulated using a patch pipette (blue) and recorded by the VNEA pad in Faradaic mode (magenta). i,j) Reproduced with permission. ${ }^{[442]}$ Copyright 2012, Nature Publishing Group. 

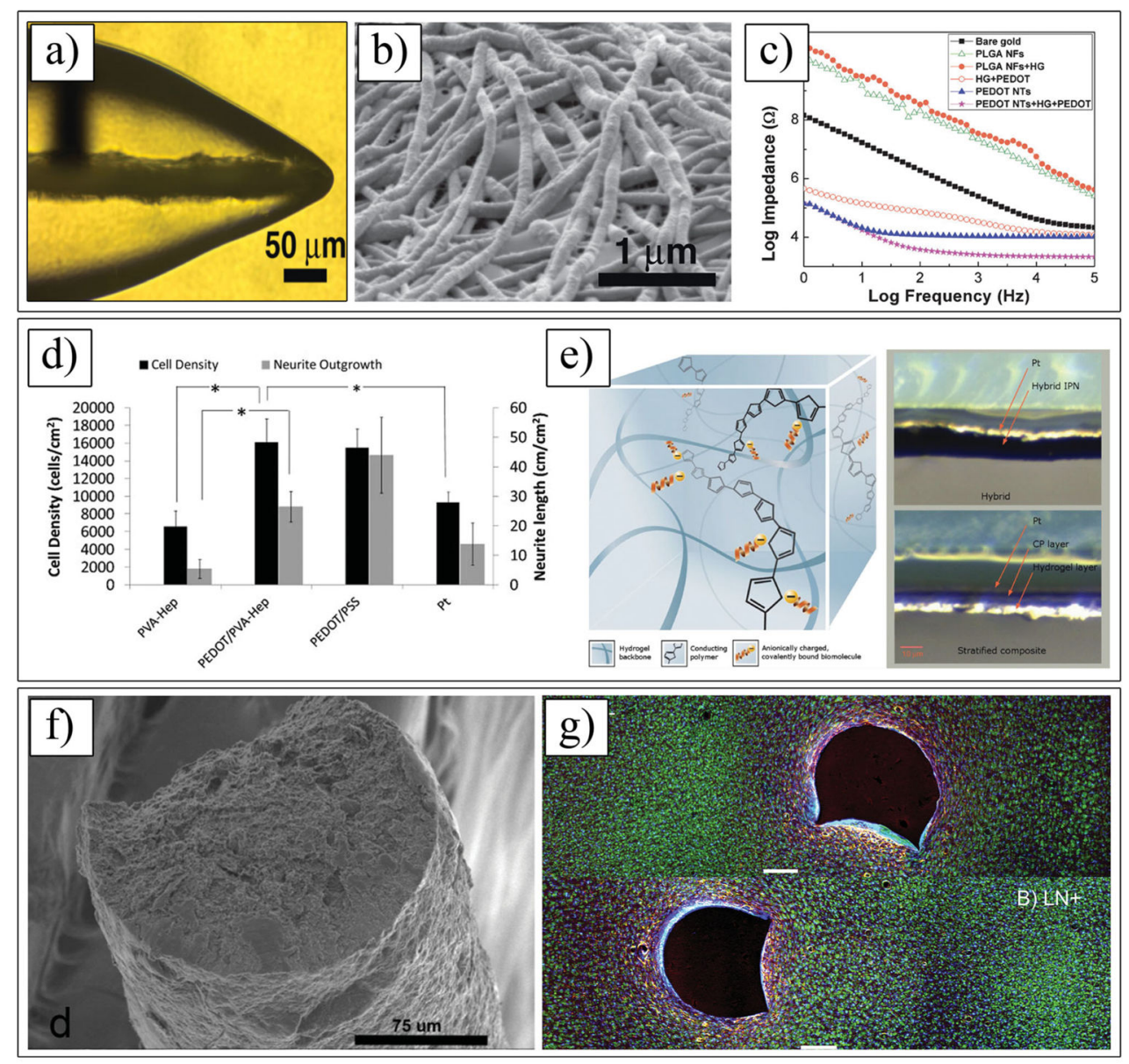

Figure 15.

a) Side view of optical micrograph of deposited PEDOT on electrode site showing vertical growth of PEDOT from an electrode site and through the alginate hydrogel scaffold (black color). b) SEM image of electrode site after dissolving the alginate coating and electrospun nanofibers. This image reveals that PEDOT was grown around the electrospun nanofibers to form PEDOT nanotubes. c) EIS of bare gold (black squares), PLGA NFs (green hollow triangles), PLGA NFs+HG (orange circles), HG+PEDOT (red hollow circles), PEDOT NTs (blue triangles), and PEDOT NTs+HG+PEDOT (pink stars), with the applied deposition charge density was $2.88 \mathrm{C} \mathrm{cm}^{-2}$. a-c) Reproduced with permission. ${ }^{[38]}$ Copyright 2009 , Wiley-VCH. d) PC12 cell density and neurite outgrowth are shown with standard deviation $(N=3$, * $p<0.05)$. e) Schematic of ideal hybrid configuration (left) and photo comparison of hybrid material created from using a bound dopant, compared to stratified composite produced from using a free dopant (right). Both material samples are hydrated. d,e) Reproduced with permission. ${ }^{[39]}$ Copyright 2012, Wiley-VCH. f) Cross section of CNT/ Agarose fiber. g) Representative immunohistochemical images of fibers inserted into rat cortex. top) non-laminin functionalized fiber, down) laminin functionalized fiber, yellow astrocytes (GFAP). blue - microglia (Iba-1). green - neurons (Nissl). Calibration bar $=100$ $\mu \mathrm{m} . \mathrm{f}, \mathrm{g})$ Reproduced with permission. ${ }^{[443]}$ Copyright 2011, Wiley-VCH. 

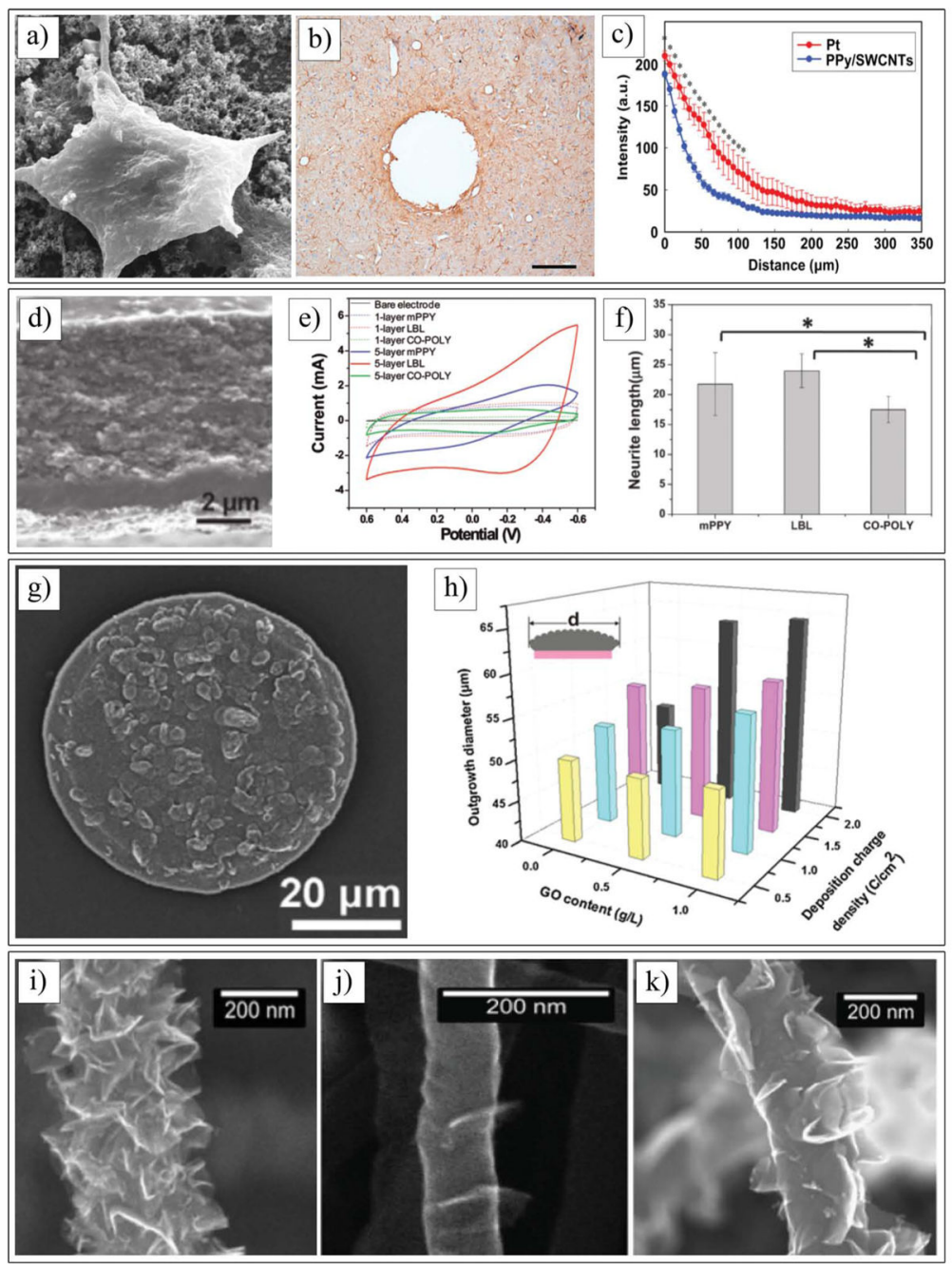

Figure 16.

a) SEM image of PC12 cells cultured on Ppy/SWCNT deposited ITO substrate in the presence of $50 \mathrm{mg} \mathrm{mL}^{-1} \mathrm{NGF}$ at day 7. Calibration bar $=5 \mu \mathrm{m}$. b) Astrocyte response was evaluated using GFAP immunostaining for PPy/SWCNT deposited Pt implant after 6 weeks post-implantation. c) Quantitative comparison of GFAP immunoreactivity between the control and deposited implants was made via GFAP intensity profiles as a function of distance from the implant interface. a-c) Reproduced with permission. ${ }^{[444]}$ Copyright 2010 , Elsevier. d) SEM image of cross-sectional view of multilayered Ppy/MWCNT, the thickness is $7.53 \pm 0.21 \mu \mathrm{m}$. e) CV measurement of multilayered Ppy, LBL, and CO-POLY. $\mathrm{f}$ ) Average neurite length per cell in PC12 cells treated with NGF for three days (n $\geq 3)$. d-f) Reproduced with permission. ${ }^{[45]}$ Copyright 2011, RSC Publishing. g) FESEM image of electrochemically deposited Ppy/GO (Prepared with $1.0 \mathrm{~g} \mathrm{~L}^{-1} \mathrm{GO}$ in aqueous solution) coating on Pt electrode site with fixed deposition charge density of $1.5 \mathrm{C} \mathrm{cm}^{-2} . \mathrm{h}$ ) Chart of outgrowth diameters of different PPy/GO coatings as a function of GO content and deposition charge density. g,h) Reproduced with permission. ${ }^{[46]}$ Copyright 2011, Elsevier. $\mathrm{i}-\mathrm{k}$ ) SEM images of graphenated carbon nanotubes (g-CNTs). Low-density graphene foliates on a CNT (i). Medium-density graphene foliates on a CNT (j). High-density 
graphene foliates on a CNT (k). Structures were reproducible and observed over several square centimeters after microwave plasma chemical vapor deposition growth. i-k) Reproduced with permission. ${ }^{[412]}$ Copyright 2012, Materials Research Society/Cambridge University Press. 


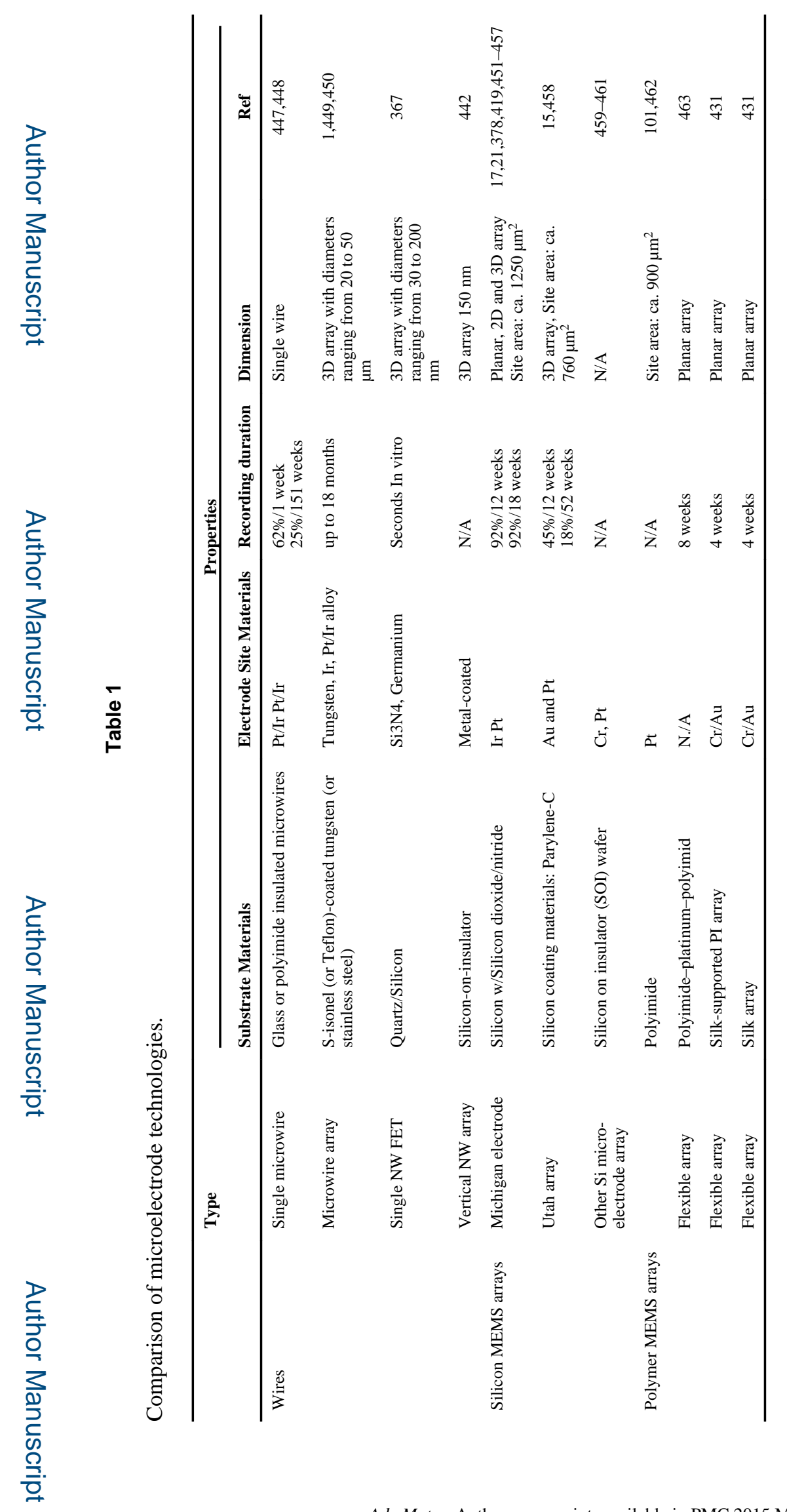

Adv Mater. Author manuscript; available in PMC 2015 March 25. 
Fattahi et al.

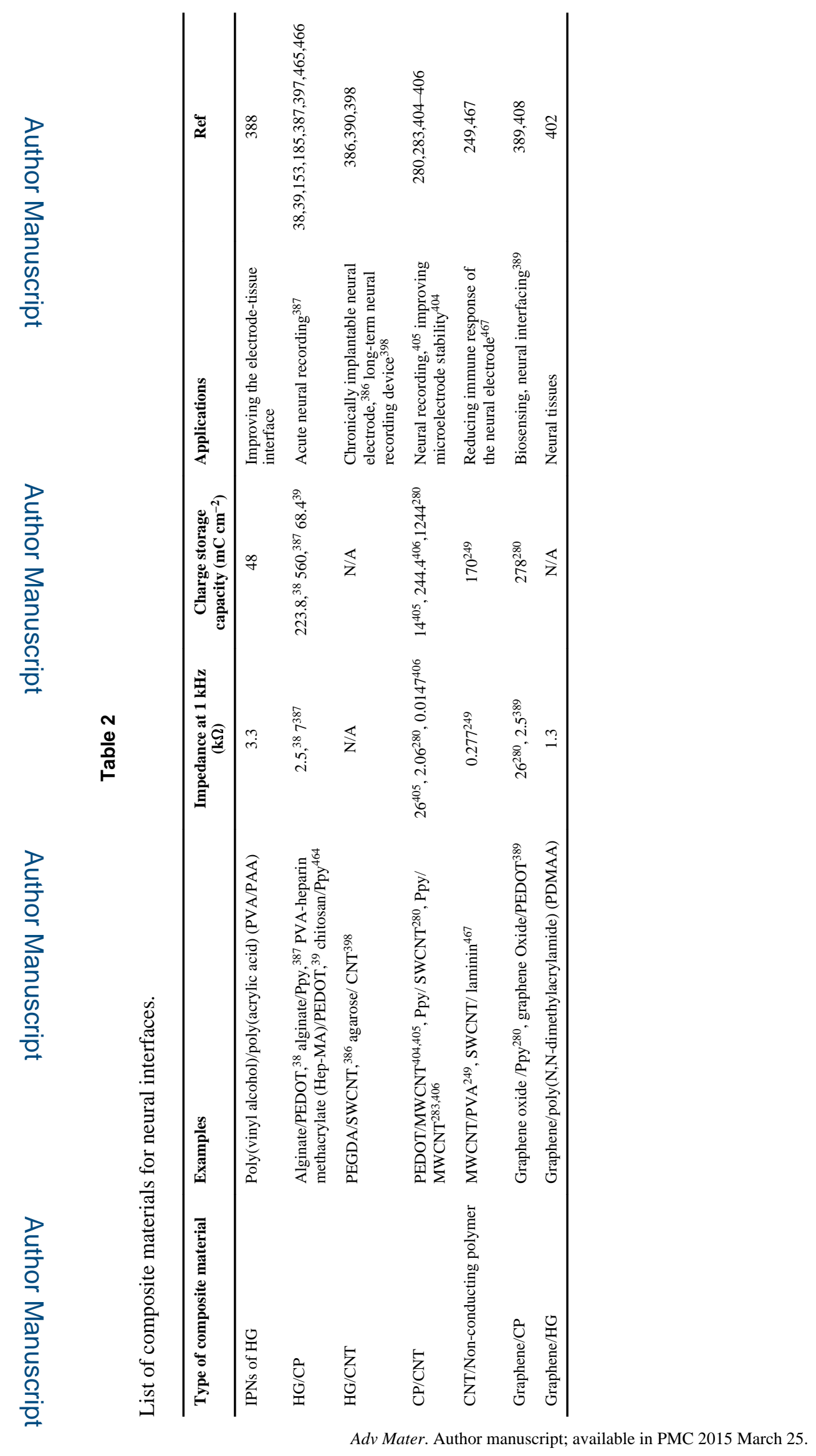

